\title{
ELEMENTARY
}

\section{PHYSICS AND CHEMISTRY}

\section{GREGORY AND SIMLiNONS}

\section{THIRD STAGE}

HIST

QC

23

MB2

1900

$\mathrm{BK}, 3$

C. 3

EL

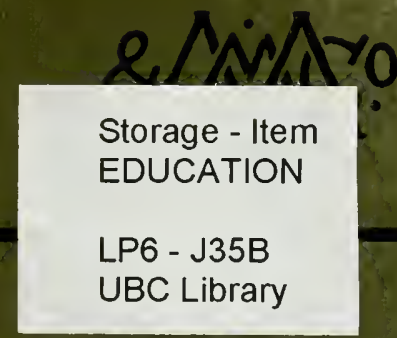


Digitized by the Internet Archive in 2010 with funding from University of British Columbia Library 

ELEMENTARY PHYSICS AND

CHEMISTRY 


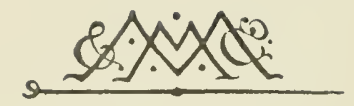

\section{MACMILLAN AND CO., LIMITED \\ LONDON - BOMBAY - CALCUTTA MELBOURNE}

THE MACMILLAN COMPANY

NEW YORK - BOSTON - CHICAGO

ATLANTA - SAN FRANCISCO

THE MACMILLAN CO. OF CANADA, LTD. TORONTO 


\section{ELEMENTARY}

\section{PHYSICS AND CHEMISTRY}

\section{THIRD STAGE}

BY

R. A. GREGORY, F.R.A.S.

PROFESSOR OF ASTRONOMY, QUEEN'S COLLEGE, LONDUN

AND

A. T. SIMMONS, B.Sc.(Lond.)

ASSOCIATE OF THE ROYAL COLLEGE UF SCIENCF, I.ONDON

MACMILLAN AND CO., LIMITED ST. MARTIN'S STREET, LONDON 
First Edition 1900.

Reprinted 1901, 1904, 1905, 1906, 1908 (twice).

GLASGOW : PIRTED AT THF INIVERSTT PRESS BY RORERT MACLFHOSE AND (O), LTD. 


\section{PREFACE.}

THIS book is the last of three little volumes containing a course of elementary Physics and Chemistry based upon a syllabus of work approved several years ago by the Board of Education as suitable for the upper standards of elementary schools. The object of the instruction prescribed is not so much to convey information as to develop a scientific habit of thinking in the pupils, and it is in sympathy with this spirit that the books have been prepared.

Wherever the study of science is being commenced, it should be through the consideration of the properties of familiar things; for this is the best way to encourage an intelligent interest in scientific reasons and results. The course of work here followed is thus as suitable for the lower forms of secondary schools as for schools of other grades. A knowledge of the scientific meaning of such facts of ordinary experience as are described and examined in this and the two companion volumes should, indeed, be possessed by everyone.

The value of practical exercises in all scientific instruction, however elementary, is now so widely recognised that it is almost unnecessary to advise that the experiments described in each lesson should be actually performed. Unfortunately, it is not often possible to provide accommodation and apparatus sufficient to enable individual pupils to experiment. This 
difficulty has been borne in mind in designing the form of the following lessons, each of which is divided into two parts -the first consisting of instructions for the performance of simple experiments, the second of explanations of the principles taught by the practical work.

When circumstances permit, every pupil should perform the experiments, and when this is impossible he should see them done by someone else. The descriptive text, which is complete in itself, and independent of the experimental work, though covering the same ground, provides suitable lessons to be studied at home.

Every effort has been made to arrange a practicable and instructive first course of science based upon sound educational principles. No difficult point has been passed without attempting to present it in the simplest way, and in such relation with everyday phenomena as to encourage pupils to use their observant and reasoning faculties.

Several of the illustrations have been specially engraved for the book by Mr. O. L Lacour, and all of them have been inserted with the object of simplifying the text, or impressing some fact upon the mind of the pupil.

For the help readily given us by $\mathrm{M}_{1}$. J. A. Humphris, Science Demonstrator for the Bristol School Board, we gladly take this opportunity of recording our thanks.

R. A. G.

A. T. S.

LoNDON, July, 1900 . 


\section{CONTENTS.}

Summary of First and Second Stages, - . . . I

30 I. Characteristic Properties of Water, - - I7

II. Action Between Water and Iron, - - * 2 I

III. The Composition of Water, - - - 25

IV. Action of Zinc upon Acids, - - $\quad$ - 30

V. Properties of Hydrogen, - $\quad$ - $\quad$ - 34

VI. The Burning of Hydrogen, - - - 40

ilu ViI. The Action of Hydrogen on Metal Rusts, - 46

ViII. Natural Waters, - - - - - - 50

IX. Chalk and the Action of Heat upon it, - 54

M $\mathcal{X}$ X. Chalk and Lime Compared, - - - 58

XI. Further Study of the Action of Heat on

Chalk, - - - - - - - - 63

XII. Action of Acids on Chalk, - . - - 67

128 xili. Study of the Gas Obtained from Chalk, - 70

Xiv. Further Study of the Action of Acids on

Metals and Carbonates, - - - $\quad$ - 76 vii 
LESSON

XV. Burning And Breathing, - - + - . 79

XVI. Carbon Dioxide in the Air, - - . . 86

XVII. HARD and Soft Waters, - - . - 90

XVIII. LIMESTONES, - $\quad$ - $\quad$ - $\quad$ - $\quad$ - 95

XIX. Natural Changes in which Chalk and CaRboN Dioxine TAKE PART, - - . - IOO XX. MORTAR, = - . - . - IOS 


\section{ELEMENTARY PHYSICS AND CHEMISTRY.}

\section{SUMMARY OF FIRST AND SECOND STAGES.}

To comnect this volume with the two previous books, a summary of the subjccts already dealt with is given before commencing the new work. This will not only scrve to refresh the memory of the pupil who has been through the courses of work described in the earlier volumes, but will also enable students who have used other books to follow intelligently the experiments and descriptions in this one. The Third Stuge commences on $p$. 17.

\section{PROPERTIES OF COMMON STUFFS.}

The study of science.-Facts about things are found out by means of the five senses - seeing, feeling, hearing, smelling, and tasting. There is no difference between science and ordinary knowledge learnt by the senses, for organised common knowledge, or common sense, is science.

To all those things which are studied by means of the senses the name matter, or things, or stuffs, is given. There are many kinds of things, but they can be arranged into classes according to their properties. Substances differ in hardness, shape, size, colour, and other properties, and a study of these properties enables different things to be arranged in classes.

Solids, liquids, and gases.-All things can be arranged by such a study of their properties into three classesim-solids, liquids, and gases. Solids, liquids, and gases are not alike as 
regards size and shape. Solids have a size and shape of their own, which differ for each solid, but remain the same for one particular solid. Liquids have a size of their own, but no particular shape, and when they are not held by any vessel they at once flow; they also form drops. Gases have no definite size or shape; and they fill any vessel in which they are confined. However small a quantity of gas may be taken, it always spreads out until something prevents it from taking up more space.

Properties of common stuffs.-Things differ from one another in many other ways, and their different properties are given certain names. Thus, glass can be seen through, or is transparent; it is also easily broken, or is brittle. Opaque things cannot be seen through. Lead is heavy in comparison with the same bulk of many other substances, or is dense; it is malleable, or can be beaten into thin sheets; it is also pliable, or can be bent or twisted into different shapes. India-rubber is elastic, or returns to the original shape after its shape has been changed. Flexible things also return to their original shape after being bent. Sponge is porous, or contains numerous sinall holes or pores. All things are more or less porous. Things through which water will not pass are impervious. Salt and sugar are crystalline, or are made up of little crystals, each having a certain regular shape; they are soluble in water, that is, they disappear when put in water. Particles of soot and flour have no regular shape, or are amorphous. Things which burn are combustible, and things which will not burn are incombustible.

Every substance has many properties, but it usually differs from all other substances in one property or another. By making use of this fact it is possible to distinguish one thing from another.

\section{MEASUREMENT OF SIZE AND MASS.}

Measurement of length.--Whenever you measure a length, you use a rule or tape measure having certain divisions marked upon it. An inch, or a foot, or a yard, always means a definite length, and in order that everyone shall use the same inches, feet, and yards, a standard length has been agreed upon. The British standard of length is the distance between two 
lines upon a bronze bar deposited with the Board of Trade, and is called a yard. The length of one third of a yard is called a foot, while one-twelfth the length of a foot is called an inch. The table known as "Long Measure" shows how British standards of length are related to one another.

In France, and most other countries, the metric system of measurement is used. The metric standard of length is the metre. It is divided into tenths or decimetres, hundredths or centimetres, and thousandths or millimetres. Similarly, a length which contains exactly ten metres is called a dekametre; one which just contains a hundred metres is called a hektometre; and one which is exactly a thousand times as long as a metre is called a kilometre. The length of a metre in British units is roughly 3 feet $3: 3^{1}$ inches.

Measurement of area.-Area is found by measuring length in two directions. A foot square is a square which has each side I foot in length. Square Measure is derived from Long Measure; it tells the standards which must be used in measuring areas.

Some of the units of area, and the way they are related to the units of length in the British syster, are shown in the following table :

$144(=12 \times 12)$ square inches make I square foot.

$9(=3 \times 3) \quad$, feet , I " yard.

$30 \frac{1}{4}\left(=5 \frac{1}{2} \times 5 \frac{1}{2}\right) \quad$, yards $, \quad 1 \quad, \quad$ pole.

The measures of area or surface in the metric system can be shown in a similar way:

$$
\begin{aligned}
& 100(=10 \times 10) \text { square millimetres make I square centimetre. } \\
& \mathrm{IOO}(=\mathrm{IO} \times \mathrm{IO}) \text {, centimetres, } 1 \text {, decimetre. } \\
& 100(=10 \times 10) \quad, \quad \text { decimetres , I ", metre. }
\end{aligned}
$$

Measurement of volume.-The amount of room a solid takes up, or the space it fills, or its cubical content, is called its volume. Length, breadth, and thickness have to be measured in determining volume. Cubic Measure is derived from Long Measure in the way the following table makes clear:

$1728(=12 \times 12 \times 12)$ cubic inches make 1 cubic foot.

$$
27(=3 \times 3 \times 3) \quad, \text { feet } \quad, \quad \text { I }, \text { yard. }
$$

The litre.-If a hollow cube is made 1 decimetre long, I decimetre broad, and I decinetre deep, it will hold 1000 cubic centimetres of liquid. This capacity is called a litre. 
The chief measures of capacity in the metric system are connected with one another as follows:

Io centilitres make I decilitre.

Io decilitres $\quad$ I litre (I000 cubic centimetres).

ro litres

ro dekalitres ",

Io hektolitres ", I dekalitre.

I hektolitre.

I kilolitre or I cubic metre.

Measurement of mass. - Mass is the amount of substance in a thing, and its weight is the force with which the thing is pulled down by the earth. In this country the standard of mass is the amount of matter in a lump of platinum which is deposited with the standard yard at the Board of Trade. The lump of platinum is called the imperial standard pound avoirdupois. The divisions, etc., of the imperial pound you have already learnt in your arithmetic lessons, under the name of "Avoirdupois Weight."

The standard of mass which is adopted in the metric system is called the kilogram. This standard is bigger than the British pound, being equal to about two and one-fifth of our pounds. The mass of one-thousandth of a kilogram is called a gram, and is the unit generally used in scientific work. A gram is the mass of one cubic centimetre of water at a temperature of $4^{\circ} \mathrm{C}$.

The fractions and multiples of a gram are connected as follows :

Io milligrams $=$ I centigram.

Io centigrams $=$ I decigram. Io decigrams $=$ I gram.
Io grams= = d dekagram.

Io dekagrams = I hektogram. Io hektograms = I kilogram.

The balance is used to compare masses. The principle upon which it depends is that, when two masses placed at the same distance on opposite sides of the turning point balance one another, they are equal.

\section{DENSITY AND RELATIVE WVIGHT.}

Meaning of density.-It is found that equal volumes of different substances may have different masses; and that equal masses of different substances may have different volumes. It is usual to speak of these facts by saying that things have different densities. Density is shown by the proportion which the mass of a thing bears to its volume. The mass of a cubic 
centimetre of water at a temperature of $4^{\circ} \mathrm{C}$. is I gram, and the density of water at this temperature is consequently taken as the standard density. The mass in grams of a cubic centimetre of any substance at a temperature of $4^{\circ} \mathrm{C}$. is the density of the substance. It is easy to see that this gives the number of times the substance is heavier or lighter than an equal volume of water.

Some things sink, others float in water.-When an object sinks in a liquid the volume of liquid displaced by the object is equal to its own volume. This fact provides a means of determining the volume of an irregular solid, for if it is insoluble in water, when it is immersed in water, the volume of water displaced can be observed, and tells the volume of the solid.

When an object floats in a liquid, the volume of liquid displaced is equal to the volume of the immersed portion of the object; but the mass of the liquid displaced is equal to the whole mass of the object. An object which floats in water sinks deeper into a liquid which is less dense than water, and not so deep into one which is denser than water. The lactometer is an instrument which depends for it use upon these facts.

The density of solids. - When an object is immersed in water it loses weight equal to the weight of the water displaced by the object. This fact is known as the Principle of Archimedes. By means of this principle the density of a solid compared with that of water can be readily determined. The object is first weighed in air, and then while hanging in water. The density of the object compared with that of water can be found by dividing the weight in air by the loss of weight in water.

Relative density of an object $=\frac{\text { Weight of the object in air }}{\text { Loss of weight in water }}$.

\section{BAROMETERS AND THERMOMETERS.}

The air around us.-Air has mass, and its mass can be found by weighing a tightly-stoppered bottle first full of air and then with the air sucked out. Because of its mass, the air has weight and exerts pressure upon objects on the earth's surface, as is shown by the use of a sucker as well as in other ways. IVhen air is removed by suction from the inside of a tube dipping into a liquid, the pressure of the air outside forces the liquid up the tube. This explains the action of a squirt and of a common? 
pump. The pressure of the air is best measured by means of a barometer.

Barometers. - A barometer is an instrument for measuring the pressure exerted by the atmosphere. The principle of a barometer is that a colımn of mercury in a tube containing no air is balanced by the pressure of the atmosphere outside the tube. The length of the column of mercury supported by the pressure of the atmosphere is, on the average, jo inches at sealevel. The height of the top of the mercury column changes slightly from day to day on account of alterations in the pressure of the atmosphere. The pressure of the atmosphere at sea-level is, on the average, equal to the weight of 15 lbs. on every square inch. The higher we rise above sea-level the less is the pressure. At a height of $3 \frac{1}{2}$ miles the mercury column in a barometer stands at 15 inches instead of 30 inches. At such a height, the pressure is, therefore, equal to the weight of $7 \frac{1}{2}$ lbs. on every square inch instead of the weight of 15 lbs. per square inch. Mercury is generally used for barometers, because it is a very dense liquid, does not leave a mark upon the tube, and can easily be seen.

Thermometers. - If a thing is made hotter and hotter, several changes in it may be noticed. These changes are the effects of heat, and they may thus be stated: (I) Change of size, shown by the expansion and contraction of solids, liquids, and gases when heated and cooled. (2) Change of state, as when ice is converted into water, and water into vapour, or steam, by heat. (3) Change of temperature, which means the condition of bodies as regards heat, a hot body being at a higher temperature than a cold one.

Thermometers are instruments used for accurately measuring changes of temperature. The sense of touch cannot be trusted for this purpose, because our feeling does not tell us accurately how hot or cold a substance is. A thermometer usually consists of a sealed glass tube having a bulb at one end. The bulb and part of the stem contain a liquid, mercury or alcohol being the liquid generally used.

The liquid in a thermometer should ( 1 ) expand a great deal for a small increase of temperature, (2) not easily change into the solid or gaseous state, (3) be in a tube of equal bore having a comparatively large bulb at one end.

In order to mark the divisions upon a thermometer, that is, 
to graduate the thermometer, advantage is taken of two temperatures which have been found to be constant. These temperatures are $(1)$ the temperature at which ice melts or pure water freezes; (2) the temperature of the steam issuing from boiling water when the barometer stands at 30 inches. The difference of temperature between these two fixed points is divided into degrees.

Two common kinds of thermometers are the Centigrade and the Fahrenheit thermometers. The degrees of temperature indicated upon these instruments when they are placed first in boiling water and then in ice are as follows:

Boiling point, Freezing point,
Centigrade.

$100^{\circ}$

$0^{\circ}$
Fahrenheit.

$212^{\circ}$

$32^{\circ}$

\section{SOLUTIONS AND CRYSTALS.}

Soluble and insoluble solids.-Solution is the process by which some substances, when placed in water or other liquicls, disappear, and their particles spread through the entire mass of the liquid. A substance is said to be soluble in a liquid, or to dissolve in it, when it disappears in the liquid and forms a solution. Sugar, salt, and soda are soluble in water.

A substance is said to be insoluble in a liquid when it will not dissolve in the liquid. Sand, gravel, camphor, sulphur are insoluble in water. Substances which will not dissolve in water will often dissolve in other liquids. Camphor and shellac are soluble in spirits of wine; sulphur is soluble in carbon bisulphide. Small particles of insoluble substances are held in suspension in the liquid in which they do not dissolve, and they can be got rid of by filtering, or by letting the liquid stand undisturbed for a short time.

Soluble liquids and gases.--Some liquids mix or dissolve other liquids. Alcohol (whisky or brandy) dissolves in water; so does vinegar. Some liquids do not mix, or are insoluble, in one another. For instance, oil, water, and mercury do not mix. Some gases dissolve in liquids. The gas in soda-water, and ammonia gas in the so-called liquid ammonia, are examples of gases dissolved in liquids. The air dissolved in water is necessary for the life of water animals and plants. 
There is no loss during simple solution.-Matter is not lost when a substance is simply dissolved. A solid and liquid when separate have the same mass as when the solid is dissolved in the liquid.

\section{Mass of Solid + Mass of Solvent $=$ Mass of Solution.}

When chemical action accompanies solution, changes in mass do occur, but there is no loss of matter. For example, if a piece of copper is dissolved in moderately strong nitric acid and the blue solution which is formed after all the brown fumes have been given off is evaporated to dryness, the blue residue left behind weighs more than the copper. But the total mass of the new substances obtained when a chemical change takes place is the same as that of those originally taken. Thus, if the masses of the copper and nitric acid be added together, the same result is obtained as by adding the masses of the blue residue, the gas evolved, and the steam given off during evaporation.

Saturated solutions.-A solution is saturated with a substance when it contains as much of that substance as it will hold at the temperature of the solution. The effect of an increase of temperature on saturation is usually to increase the amount of a substance which can be held in solution. The solubility of a substance usually decreases as the temperature is lowered. Water dissolves most substances, but in different degrees. Salt is more soluble in water than sugar, and sugar is more soluble than chalk.

The solubility of a substance in water can be found by shaking up the substance with a certain quantity of water until no more will dissolve, and then evaporating the water. The amount dissolved in this volume of water can afterwards be determined by weighing, and the amount which would dissolve in Ioo cubic centimetres of water can be calculated.

Solubility of things in acids.-Certain metals dissolve in acids, and their solution is accompanied by the formation of new substances with new properties. Such solution is therefore an example of a chemical change. In this way copper dissolves in nitric acid, and zinc in dilute sulphuric acid.

Other substances besides metals will dissolve in acids. The solution of marble in weak hydrochloric acid is an example. This is also an instance of a chemical change.

Crystals.-Crystals are naturally-formed lumps of certain substances having a regular shape, which is always the same 
for the same kind of thing. Rock-salt and some other sub. stances form crystals which are perfect cubes. Diamond crystals have the shape, of the octahedron.

Soda crystals can be obtained from carbonate of soda by making a saturated solution of the powder and allowing it to cool.

Water of crystallisation is the water contained in some crystals. It has something to do with their shape and sometimes with their colour.

Efflorescent crystals easily give up their water of crystallisation to the air. Deliquescent crystals readily take up moisture and become wet.

Two examples of waterless crystals are common salt and sulphur. Sulphur crystals can be obtained by melting sulphur in an evaporating basin and pouring out the liquid sulphur from the interior after a crust has been formed.

\section{THE MOISTURE IN THE AIR.}

Evaporation.-The process by which water, or any other liquid, is changed into an invisible substance which spreads throughout the air in its neighbourhood, is called evaporation. Evaporation takes place at all temperatures, and is more rapid when the air above the liquid is in motion. Some liquids evaporate more rapidly than others at the same temperature. But, in all circunistances, when water and other liquids are converted into vapour, they must take up heat from somewhere, and consequently evaporation causes cooling.

Quiet evaporation and boiling are not the same. In quiet evaporation, vapour is only formed at the surface of the liquid; in boiling, on the other hand, vapour is formed everywhere throughout the liquid, as well as at the surface.

Condensation.-Condensation is an exactly opposite process to evaporation; it may be spoken of as the process by which vapours, such as steam, are reconverted into liquids by cooling. Common instances of condensation are found ( $\mathrm{I}$ ) in the moisture which collects on the inside of the window panes of a warm room when the air outside is very cold, and (2) the cloud formed when we breathe in the open air on a frosty day.

Distillation.-Distillation is a process, used by chemists and 
others, in which a liquid is first converted into a vapour by heating it, and so causing evaporation ; and then the vapour is reconverted into a liquid by cooling it to bring about condensation. This is the way in which pure water is obtained from water having dissolved impurities in it, such as sea-water. The pure water got by these means is called distilled water. It differs from ordinary water in containing no solids dissolved in it. Rain water is really distilled water.

There is always water in the air.-The amount of water vapour in the air varies greatly from day to day. Whenever the water vapour gets condensed it becomes visible, forming fog, cloud, rain, snow, hail, hoar-frost, or dew. Damp air is not alsvays air which contains a great deal of water vapour, but that which contains nearly as much water vapour as it is able to hold at the time. Similarly, dry air is capable of holding a much larger quantity of water vapour than it actually contains.

The amount of water vapour in the air.-Some substances, like calcium chloride and sulphuric acid, are able to take up or absorb moisture from the air. By finding the mass of some calcium chloride or sulphuric acid before and after exposing it to the air, it is possible to ascertain how much water vapour has been taken out of the air. If care is taken to arrange the experiment so that all the water vapour is removed in this way from a given amount of air, the actual amount of moisture in the air is determined. The apparatus by which this is done is called a chemical hygrometer.

Another, more common form of hygrometer is the wet and dry-bulb thermometer, which consists of two exactly similar thermometers. The bulb of one is covered with a muslin bag from which hang threads that dip into water. The muslin thus becomes wet; and the evaporation from it lowers the reading of the thermometer. The difference in the readings of the thermometers is great when the air is dry, and small when the air has much moisture in it.

\section{CHANGES IN VOLUME AND DENSITY OF IVATER.}

Changes in volume of water.- The first effect of cooling water is to make it contract. This goes on steadily until the temperature of four degrees centigrade $\left(4^{\circ} \mathrm{C}\right.$. $)$ is reached. From this 
point, though the cooling is continued, the water no longer contracts, but begins to expand. This expansion continues until the temperature $0^{\circ} \mathrm{C}$. is reached, when the water begins to change into solid ice, which is one-tenth larger than the water from which it is formed.

If, instead of making warm water cooler, some ice-cold water is allowed to get warmer, it steadily gets smaller in volume until the temperature of $4^{\circ} \mathrm{C}$. is reached, but after this temperature it gets larger as it becomes warmer. Thus, unlike most other liquids, water at a temperature of $4^{\circ} \mathrm{C}$. expands not only if it is heated, but also if it is cooled.

Maximum density of water.-Any mass of water has a smaller volume at $4^{\circ} \mathrm{C}$. than at any other temperature. But when the volume is least the density is greatest, therefore the temperature of $4^{\circ} \mathrm{C}$. is the temperature at which water has its maximum density.

It may be remembered that in the First Stage of this book the mass of $\mathbf{r}$ cubic centimetre of water was said to be one gram. This, however, is only exactly true when the temperature of the water is $4^{\circ} \mathrm{C}$. At any other temperature the mass of a cubic centimetre of water is less than I gram. A cubic foot of water also weighs more at $4^{\circ} \mathrm{C}$. than at any other temperature.

Density of ice.- When water is changed into ice it increases in volume. Ice is consequently lighter than water and floats upon it. If this were not so, a pond would begin to freeze at the bottom, and would, during a long frost, become frozen right through. The density of ice is $0^{\circ} 9$. A cubic foot of water weighs 62 lbs.; a cubic foot of ice only weighs 57 lbs.

\section{HEAT AND TEMPERATURE.}

Temperature may be compared with water level.-Temperature is a condition of hotness or coldness; it can be compared with the level of a liquid. Bodies are at different temperatures when heat tends to pass from one to the other. Liquids at high and low levels, in vessels of the same diameter, come to a level midway between the two original levels if the liquids are free to move. Similarly, when equal masses of water at high and low temperatures are mixed, the temperature of the mixture is midway between the two original temperatures. 
When unequal masses of water at different temperatures are allowed to mix, the smaller mass undergoes the greater change of temperature. But, in every case,

$$
\begin{aligned}
& \text { Rise of temperature } \\
& \times \text { mass of cold water }
\end{aligned}=\begin{aligned}
& \text { Fall of temperature } \\
& \times \text { mass of hot water. }
\end{aligned}
$$

Quantity of heat.-The quantity of heat in any given amount of water depends both upon the mass of the water and its temperature. The unit quantity of heat is the amount of heat required to raise the temperature of one gram of water $\mathrm{I}^{\circ} \mathrm{C}$., or that which is given out by one gram of water when its temperature falls through $1^{\circ} \mathrm{C}$. The unit quantity of heat is called a calorie or a therm.

The number of units of heat taken up, or given out, by water, when its temperature rises or falls, is determined by multiplying the mass of the water in grams by the number of degrees through which its temperature rises or falls.

Capacity for heat.-Just as the same amount of liquid rises to different levels in similar vessels of different capacities, so, the same amount of heat produces different temperature effects when added to equal masses of substances of different capacities for heat.

The temperature of a substance can be compared with the level of a liquid in a vessel, and the capacity for heat corresponds to the fluid capacity of the vessel. The capacity of water for heat is greater than that of any other substance, and consequently water takes longer to get hot, and longer to become cold, than an equal mass of any other substance.

Equal masses of different substances often contain different quantities of heat, though their temperatures may be the same. The amounts of heat absorbed (or given out) by equal masses of different materials when heated (or cooled) through the same number of degrees of temperature are generally different. Any mass of water at a given high temperature has a greater heating effect than an equal mass of any other substance at the same high temperature.

Specific heat.-By the specific heat of a substance is meant the fraction which represents the comparison of the number of units of heat absorbed (or given out) by the substance in undergoing a given change of temperature and the number of units of leat absorbed (or given out) by an equal mass of water in experiencing the same change of temperature. Specific heat 
may also be regarded as the number of units of heat required to change the temperature of unit mass of the substance $I^{\circ} \mathrm{C}$.

The quantity of heat in a substance depends upon: (I) the mass, (2) the temperature, (3) the specific heat, of the substance.

\section{HEAT ABSORBED IN THE FUSION OF ICE.}

Latent heat of fusion. - When a solid is heated sufficiently it melts. The temperature at which the melting takes place is called the melting point. So long as there is any of the solid unmelted, the temperature does not rise above the melting point. The number of heat units necessary to change a gram of a solid into a liquid, without raising its temperature, is spoken of as latent heat of fusion.

The latent heat of water is the number of heat units required to change one gram of ice into one gram of water at $0^{\circ} \mathrm{C}$. ; and its value is 80 . This number is determined by mixing known masses of warm water and ice and recording the temperature of the mixture at the instant the last piece of ice disappears.

As a natural consequence of the latent heat of water, ponds require many frosty nights to freeze them over; and a thaw takes many days to become complete.

\section{HEAT ABSORBED IN THE CONVERSION OF WATER INTO STEAM.}

Convection.-Convection is the process by which liquids and gases become heated by the actual movement of their particles. When liquids and gases are heated, upward warm currents and downward cold currents are caused. These currents are called convection currents. Heating buildings by hot water is a practical way of making use of convection currents. Ventilation, too, is possible because of the convection currents set up in rooms as the air in them becomes heated.

The latent heat of steam means the number of heat-units required to change a gram of water at $100^{\circ} \mathrm{C}$. into a gram of steam at the same temperature. The latent heat of steam is 536. Or, it requires as much heat to change a gram of water at $100^{\circ} \mathrm{C}$. into a gram of steam at the same temperature as 
would be necessary to raise the temperature of 536 grams of water through $\mathrm{I}^{\circ} \mathrm{C}$.

Some familiar instances of the heat absorbed when a liquid is changed into a vapour are, the cooling of the hand when it is waved about after sprinkling some ether or alcohol on it, and the cooling of the air after roads have been watered in the summer. It is because of the latent heat of steam that a scald from the steam of boiling water is worse than a scald from the boiling water itself.

\section{RUSTING AND BURNING.}

The rusting of iron.--Iron in rusting gains in mass, taking some material from the air, and this material is the part of the air which causes substances to burn in it. Substances, like copper, which tarnish when heated in the air, similarly increase in mass. Metals, like magnesium, which burn when heated in the air, also increase in mass. In all these cases the increase in mass is due to the part of the air they have taken up. This part, which is taken from the air in this way, is that concerned in burning, and is called the active part of air. The part of the air which is left will not allow things to burn in it and is called the inactive part of air. There are, then, two kinds of gases in the air: one used up when iron rusts, and another in which a light is extinguished.

When iron rusts in an enclosed amount of air it always takes up one-fifth of the volume of air, and leaves four-fifths behind. Air is thus made up of one part by volume of the active part and four parts by volume of the inactive part.

The active part of the air is oxygen, the inactive part is nitrogen.

The burning of phosphorus.-Great care is necessary in working with phosphorus, as it easily catches on fire. The waxy form of phosphorus is always kept under water. Phosphorus readily burns in the air ; in doing so it takes out the active part of the air, the oxygen, and combines with it to form a white snow-like powder. This is done very rapidly if the phosphorus is first lighted; but, like iron, phosphorus can slowly take out the active part of the air without being lighted. When phosphorus burns in an encloserl volume of air, one-fifth of the air in the vessel is used up and four-fifths of it remain behind. 
Phosphorus increases in mass in combining with the active part of the air, and forms a white powder. This powder dissolves in water with a hissing noise, forming an acid solution, so called because it turns a blue litmus paper red.

The burning of a candle.-When a candle burns in air, two substances are formed, namely, (1) water and (2) a gas which turns lime-water milky. The material of the candle combines with the active part of the air. It can be shown by burning a candle in an enclosed quantity of air over water that one-fifth of the enclosed air is used up. Nothing is lost when a candle burns-a fact which is proved by collecting the substances formed as the candle burns, and then weighing them. They are found to have a greater mass than the part of the candle which has disappeared.

The burning of oil and coal-gas.-The burning of familiar combustible bodies, such as oil and coal-gas, is similar to that of a candle. The same substances are formed, and they are recognised in the same way. There is no loss in any of these cases of burning. All substances in burning use up the active part of the air.

\section{OXYGEN-THE ACTIVE PART OF AIR.}

Search for the active part of air.-In searching for the active part of air, the "rusts" which metals form when heated in the air are strongly heated. "Rusts" which are formed with difficulty are split up most easily when heated. Thus, red lead when heated gives off some of the active part of the air and is changed into litharge. But red lead is made from litharge with difficulty; litharge combines with more of the active part of air but slowly, even if heated very strongly. The red oxide of mercury is also made with difficulty by heating mercury in the air. And the red oxide of mercury is easily split up when heated into mercury and the active part of air.

The active part of the air, or oxygen, is at once recognised by its power of re-kindling a glowing splinter of wood.

Preparations of oxygen.-Oxygen is generally prepared from substances different from the compounds formed by heating metals in air. When potassium chlorate is heated it crackles, melts, and gives off bubbles of oxygen. If manganese dioxide, 
or sand, is mixed with the potassium chlorate the oxygen is given off more readily and at a lower temperature. Such a mixture is called oxygen mixture. Oxygen is generally obtained in small quantities by heating oxygen mixture in a suitable vessel, and collecting the gas over water.

Properties of oxygen.-Oxygen is a gas with no colour, no taste, and no smell. It is a little heavier than an equal volume of air. Carbon, sulphur, phosphorus, etc., at the ordinary temperature of the air do not ignite when placed into oxygen.

Carbon, if red hot, combines with oxygen when placed in the gas, burning brightly and forming an invisible, odourless gas, which turns lime-water milky. The solution of this gas in water turns blue litmus red, and is therefore acid.

lgnited sulphur burns much more brightly in oxygen than in air. In burning, it forms a gas which has a suffocating smell. The gas is soluble in water, and the solution turns a blue litmus paper a brilliant red colour, thus proving it to be acid.

Ignited phosphorus burns with a dazzling flame in oxygen, forming a snow-white powder which easily dissolves in water with a hissing noise. The solution thus obtained turns a blue litmus paper red.

Iron under suitable conditions will burn in oxygen. 


\section{LESSON I.}

\section{CHARACTERISTIC PROPERTIES OF WATER.}

\section{PRACTICAL WORK.}

Things required.-Flask. Thermometer marked in centigrade degrees to over $150^{\circ}$. Laboratory burner. Tripod and gauze. Ice and salt, or sodium sulphate and hydrochloric acid. Evaporating basin. Test-tubes. 4-oz. flask. Balance and weights. Salt, sugar. Paraffin wax. Methylated and pure spirits of wine.

\section{REVISION EXPERIMENTS.}

\section{What to do.}

Boiling point.-Boil some water in a flask and determine the boiling point with a mercury thermometer, divided into centigrade degrees, held in the steam (Fig. 1).

Freezing point.-Freeze some vater contained in a testtube, by plunging the tube into a freezing mixture (either salt or ice, or sodium sulphate and hydrochloric acid). Allow the ice formed to partially melt and measure the temperature of the mixture of ice and water.

Try to freeze some methylated spirit in the same way.

Melting point of wax:-Carefully melt some paraffin wax in a small test-tube, and when it begins to turn solid, take the temperature. A nore accurate method than this was described on page 77 of the Second Stage.

Solution and evaporation.-Make solutions of common salt, sugar, etc., in water. Ubserve that warm water dissolves more sugar than cold water. Evaporate the solutions so obtained and observe that the solid remains behind as a residue. 
Whater is not combustible.-If some spirits of wine (not methylated) is obtainable, compare its appearance with water.

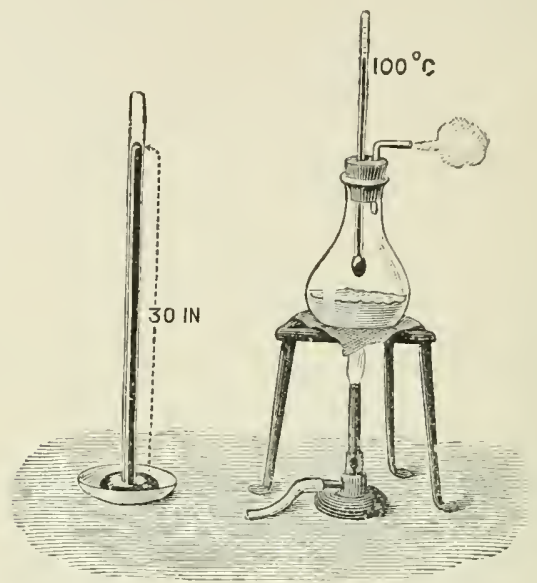

FIG. I.-Water boils at a temperature of $100^{\circ} \mathrm{C}$. when the mercury in a barometer stands at jo inches.

Put a little into the bottom of a porcelain dish, or upon a plate, and set fire to it with a lighted match. Try to perform the same experiment with water.

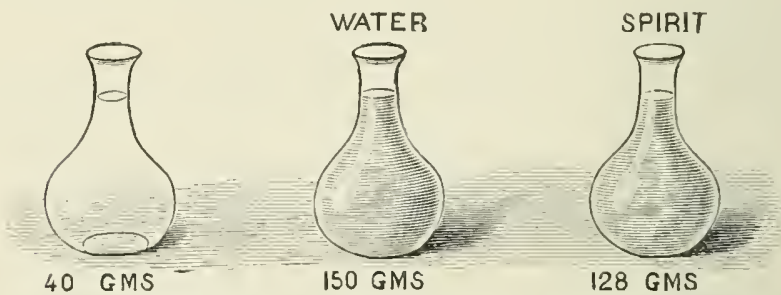

FIG. 2.-The empty flask weighs 40 gms, ; when filled with water up to a certain mark it weighs 150 gms.; and with spirit, $128 \mathrm{gms}$. Compare the densities of water and spirit.

Density.-Half-way up the neck of a 4 -cz. flask, stick a strip of gummed paper or make a mark with a file (Fig. 2). Counterpoise the flask on a balance. Fill the flask to the 
lower edge of the strip with the spirit and weigh it. Empty the flask and perform a similar experiment with water. Compare the densities of these liquids.

\section{REASONS AND RESULTS.}

Air and water.-You have already learnt many valuable facts about the composition of the air which surrounds the earth. By a series of experiments you have discovered that it is chiefly made up of two gases possessing very different properties. One of these, called oxygen, is a very active gas in which many substances burn with great brilliancy; while the other, of which there is four times as much as the oxygen, is called nitrogen, and is an extremely inactive gas, combining with but few substances, and only doing so with difficulty. The nitrogen in the air counteracts the great activity of the oxygen.

You must now turn your attention to the study of another very common and abundant substance, namely water, and learn as much as you can about it. Following the previous plan, it will be best to consider first what has already been found out about this useful liquid. Most of the physical properties of water have been studied in previous lessons, and it will be well to call then to mind before dealing with the chemical properties.

Chief physical properties of water.- IVater is a clear liquid which appears colourless when seen in thin layers, but when deep clear water (such as that of mountain lakes) is looked at, a beautiful blue-green tint is well seen. This blue-green colour can be shown by passing a beam of white light through a long tube closed at the ends with glass plates, and filled with pure water. Other liquids resemble water in colour, but the following properties are possessed by water alone : they are the characteristics or peculiarities of water, and serve to distinguish it from everything else.

Water boils at a temperature of $100^{\circ} \mathrm{C}$., when the pressure of the atmosphere upon its surface is equal to the weight of a column of mercury 30 inches high ; water is then converted into a rapour which is called steam. At $\mathrm{o}^{\circ} \mathrm{C}$. water freezes or is converted into a clear glassy' solicl, called ice.

The quantity of heat needed to melt one gram of ice is so calories, and the quantity reyuired to change one gram of boiling water into steam is 536 calories. 
The density of water, which as you know is the mass of one cubic centimetre of it measured in grams, is, at $4^{\circ} \mathrm{C}$., equal to $\mathrm{I}$. This density is taken as the standard with which the densities of other substances are compared.

Water as a solvent.-It has been learnt that water dissolves more substances than any other liquid. By the disappearance of a solid in water in this way, a solution is obtained. The amount of a solid which water can dissolve depends upon the temperature of the water. As a rule, the warmer the water the more of the solid will it dissolve. When warm water, which has dissolved as much of any soluble solid as it can, is allowed to cool, part of the solid separates out again as crystals. But if a solution of a substance in water is gently heated for some time, the liquid slowly passes off in the form of steam and the dissolved material is left behind in the form of a residue. If the steam which escapes is again condensed into water it is found to contain no solids dissolved in it.

Chemical properties of water.-But none of the facts which have been mentioned tell you anything about the composition of water, that is, of what it is made. The water present in each of the cases described undergoes no change in composition. It is always the same substance in one of the three states: gas, liquid, or solid. To ascertain what the water is made of, or what new substances can be obtained from it, it is necessary to proceed in a similar way to that employed when air was the material under examination. In the next lesson such questions as: Have metals any action on water? and is it possible to obtain new substances from water? will be considered, and when answers have been obtained to them you will be on the way to knowing something of the chemical properties of water.

\section{TO BE ReMEMBERED.}

The air is chiefly made up of two gases. oxygen, which forms onefifth of the whole, is a very active gas, in which many sulsstances burn very brilliantly. Nitrogen, which forms nearly four-fifths, is a very inactive gas which only combines with few substances.

The physical properties of water are:

It is a clear liquid, which, when seen in large quantities, has a bluegreen colour.

It boils at $100^{\circ} \mathrm{C}$, , and at this temperature is converted into steam.

If cooled to $\mathrm{O}^{\circ} \mathrm{C}$. it is converted into ice. 
The mass of 1 cubic centimetre at a temperature of $4^{\circ} \mathrm{C}$. is $1 \mathrm{gram}$.

The latent heat of fusion of ice is So; and of vaporisation of water is 536 .

The density of all other substances is compared with that of water at $4^{\circ} \mathrm{C}$.

Water dissolves many substances and generally dissolves more when hot than cold. The dissolved solids may be recovered by driving off the water as steam, when the solids are left behind.

\section{EXERCISE I.}

1. If a liquid was given you which looked much like water, describe several ways by which you could determine whether it was water or not.

2. "Sea-water is not pure water." If some were given you, how would you show this statement to be correct?

3. What do you understand by the "chemical" and what by the "physical" properties of water?

4. Describe any way you know of by which distilled water may be prepared.

5. Mention as many characteristics of water as you can remember.

\section{LESSON II.}

\section{ACTION BETWEEN WATER AND IRON.}

\section{PRACTICAL WORK.}

Things required.-Two or three laboratory burners. Indiarubber stoppers. Piece of combustion tubing about 12 inches iong, for experiment described in the lesson. Flask. Glass dish or trough. Iron filings or tacks. Clean iron. Stands as shown in Fig. 3 .

\section{What to do.}

Iron becomes misty in water containing dissolved air.Leave a piece of clean iron in water for several hours. Notice that rust forms upon it.

Iron in boiled water does not rust.-Boil some water in a flask or clean saucepan for some time so as to 
drive out the dissolved air. Place a piece of clean iron 1 in a bcttle and quickly fill up the bottle with the boiled water. Insert a tightly-fitting india-rubber stopper, being careful to cnclose no air between the stopper and the top of the water. Place on one side and examine the iron after several hours. No rust will be seen.

Inflammable gus obtained from watcr.-Place some clean dry iron filings or iron tacks in a hard glass tube like $C$ (Fig. 3). Fit an india-rubber stopper, through which a delivery tube $A$ passes into one end of the hard glass tube as

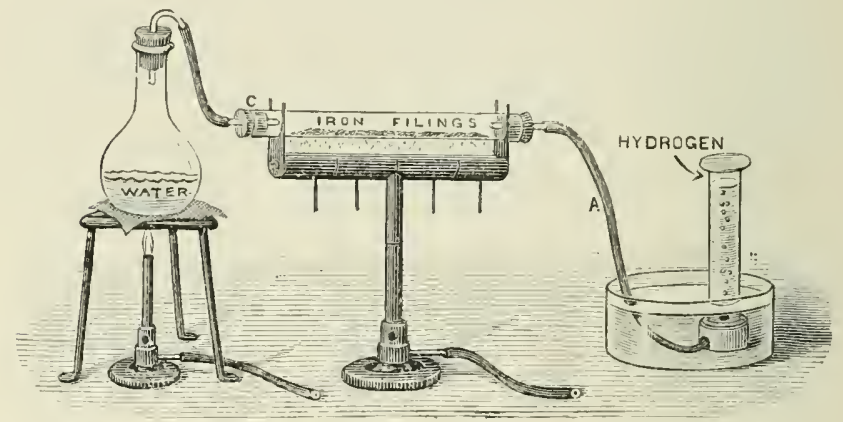

FIc. 3. - When steam is driven over red-hot iron filings, the lilings become rusty, and an inflammable gas is produced.

shown in the accompanying illustration. To the end $C$ fit another stopper through which passes a short piece of glass tube. The free end of this tube is comnected by india-rubiber tubing with a glass tube passing through a cork in the neck of the flask containing water, which has boiled for some time. The delivery tube is arranged so that one end dips into water in a trough as shown. A cylinder full of water is inverted in the trough and kept ready for usc later.

Strongly heat the iron filings and boil the water in the flask so that steam passes over the heated iron and then into the water in the trough, where it condenses. Now placc over the end of the tube in the trough the inverted cylinder of water. Notice the steam is not completely condensed, but

$1 \mathrm{~A}$ wire nail which has been well washed in soap and water to remove oil, and then dried, will do well. 
that small bubbles ascend to the top of the cylinder. In this way collect a cylinder, full of the gas. When the cylinder is full of gas, disconnect the india-rubber tubing on the glass tube in the stopper at $C$ and remove the burner from underneath the flask of water. While the cylinder still dips under the water in the trough, cover its open end with a piece of ground glass, and holding a lighted match to the mouth with your left hand, open the cylinder. Observe that the gas takes fire with a slight pop and burns.

Now examine the iron filings in the tube $C$, and observe that a quantity of rust has been formed.

\section{REASONS AND RESULTS.}

Action of cold iron upon water. - Just as in studying the composition of air the effect of iron upon it was examined, so in investigating the chemical properties of water, we may begin by finding out what changes, if any, take place when iron and water are placed together. Whenever iron is left in water for some time, a considerable quantity of reddish rust is formed. You have, however, already learnt that water always contains air dissolved in it, and also that iron can combine with the oxygen in the air. This suggests, therefore, that iron which rusts when left in water, does so by combining with the oxygen of the air which the water has previously dissolved.

When water is boiled for some time, the air which it has dissolved is driven out. If a piece of bright clean iron is sealed up in a tube, from which all the air has been driven, with some of this boiled water and left for some time, it is found that either the iron does not rust at all or that it does so to a very small extent only. Evidently, then, little can be found out about the composition of water by putting cold iron into it. But when heated iron is used a different result is obtained.

Action of heated iron upon water in the form of steam.--To make as large a surface of heated iron as possible come into contact with the water, it is best to use iron filings in studying the action of steam upon hot iron. The filings are contained in a hard glass tube which will not melt when strongly heaterl. A piece of iron gas-tubing or a tube made of porcelain could be used, though glass is the best, because it can be seen through. The hard glass tube is fitted at each end with india-rubber 
stoppers, through each of which a hole is made to take a glass tube. One of these tubes is connected with a flask, or other vessel, containing boiling water. The other tube is bent to make a delivery tube, which dips into a trough of water.

The iron filings in the hard glass tube are made red hot by strongly heating the tube. The tube is then connected with the flask containing boiling water, and the stopper with the delivery tube is inserted at its other end. At first, air escapes through the water in the trough; and, after that, bubbles of steam pass from the end of the delivery tube and are condensed by the water in the trough. When this occurs, a tube full of water is inverted over the end of the delivery tube, and as it is watched it is noticed that small bubbles of gas pass up into the tube and collect there. When a lighted match is brought in contact with the gas which collects in the cylinder, it is found to burn. Moreover, an examination of the iron filings shows they have been partly changed into red rust.

What happens when steam passes over red-hot iron.--Since the gas which collects in the cylinder burns, it is clearly not uncondensed steam, for when a lighted match is put into steam it goes out. Nor is it air from the flask, or from the water, because air will not burn. It must be a new substance which has been obtained from the water, and you can now be quite sure that the water contains a gas which will burn. This gas used to be called infiammable air, that is, air which will burn. It is now called hydrogen.

But why should the iron have gone rusty? You must bear in mind what you have already learnt about the rusting of iron in air. You know that iron, when it rusts in air, takes out the active part, that is the oxygen, and combines with it. You will be quite justified in saying, therefore, that the iron filings have combined with oxygen or they would not have gone rusty. Where did the oxygen come from? Certainly not from air, because that was driven out before the change took place. The result indicates that the oxygen comes from the steam, and that steam is made up of this oxygen and the gas which burns, that is, hydrogen. It is, however, necessary to study the question more fully before you can be convinced that this conclusion is correct. 
TO BE REMEMBERED.

Iron and water at ordinary temperatures have no action on one another. - If bright iron is left in water it becomes rusty, but if all the air is driven out, and air is not allowed to come in contact with the water, the iron does not rust.

When steam is passed over heated iron filings or tacks, in an iron or glass tube, the iron turns rusty, and an inflammable gas known as Hydrogen is collected.

Since iron rust consists of iron and oxygen, it looks as though the latter must have been obtained from the water by the iron. The hydrogen also comes from the steam which apparently consists of hydrogen and oxygen.

\section{EXERCISE II.}

1. How would you show that cold water has no action on bright iron?

2. Describe, with a sketch, how the chemical composition of water may be determined.

3. Write down all you have observed in this lesson about "inflammable air."

4. How do you know that the gas which comes from the delivery tube in Fig. 3, and collects in the test-tube, is neither air nor steam?

5. Why does iron become rusty when left in water? Can iron ever be left in water without becoming rusty?

6. Describe a means of obtaining inflammable air by the action of steam upon heated iron.

7. Why is it usual to paint the iron fence round a garden?

\section{LESSON III.}

\section{THE COMPOSITION OF WATER.}

\section{I'RACTICAL WORK.}

Things required.-Sodium, knife and forceps, glass tumbler, piece of lead or "compo" tubing about 2 ins. long, or a roll of wire gauze. test-tube, thin beaker, filter papers.

Caution! Sodium must never be touched with bure fingers, for it takes fure when in contact with wet or moist things. II hen placed in water the fuce should not be near it, for after a little while the piece of sodium bursts, and small pieces are thrown out in all directions. 


\section{What to do.}

Appearance of sodium.-Examine a piece of sodium. With a knife, or a pair of forceps, remove one of the lumps from the naphtha in which it is kept and place it on a piece of dry glass or a dry plate. Cut it in two and notice the clear shining surfaces so formed. Notice that these bright surfaces soon tarnish, and if exposed to the air for a short time they become covered with a white powder.

Effect of putting sodium in water.-Cut off a piece of sodium about the size of a pea. By means of the forceps, place it upon the surface of some water in a glass tumbler and quickly put a large glass beaker or shade over the tumbler. Notice that the sodium floats, takes the form of a ball, and runs about over the surface, and finally bursts with a slight explosion.

Bring a lighted taper near a piece of floating sodium. A golden yellow flame appears, and it looks as if the sodium is burning.

Sodium used to set free the inflammable gas in watcr.-

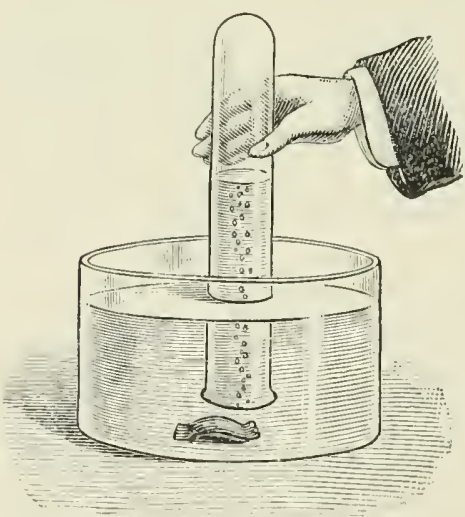

Fir. 4.-1 picte of sodium is inside the metal gauze or tube, and bubbles of an inflammable gas are being collected.

Make a short roll of wire gauze, or obtain a short piece of "compo" tubing. Close one end, and put a pebble or a small piece of lead into the roll or tube. Cut oft a piece of dry sodium about the size of a pea. Put it into the roll or tube and then nearly close the open end of the roll. Have an inverted test-tube full of water ready in a trough or a basin and drop the gauze or tube, with the sodium in it, into the water. Notice the bubbles of gas which rise from the sodium, and collect them in the test-tube. (Hold the tube in a clamp of a retort stand.)

Examine the gas in the test-tube as described in the last lesson and notice that it burns. 
The hydrogen furned out of water by sodium sometimes burns without applying a light.-Fold a filter paper in the usual way. Select a small thin beaker such that the filter paper will not go right into it. Put water into the beaker so that it will rise just above the point of the filter paper. Put a small piece of sodium into the $d r y$ filter paper, and quickly put the paper with the point in the water. A flame appears, though no light is brought near the sodiun. When the sodium is made to burn in one place in this way, the inflammable

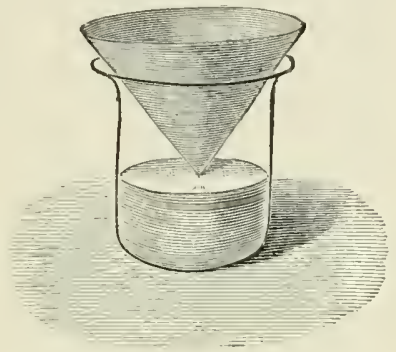

FIG. 5.-Arrangement for obtaining a flane from sodium on water. gas is kindled by the heat produced, and the particles of sodium mixed with it give the flame a yellow colour.

There is something dissolied in the water on which sodium has actal. - Dip your finger into some of the water on which sodium has acted, and rub this water between finger and thumb. Notice the soapy feel of the water; this is produced by the new substance formed in the water. Wash your fingers afterwards under the tap. Add a little red litmus solution to the water; it is turned blue.

\section{REASONS AND RESULTS.}

Other metals besides iron will turn hydrogen out of water.You have learnt that before iron can set free from water a gas which burns it must be red hot. Some other metals will do the same thing without being heited. It has been found that a metal called sodium will turn the hydrogen out of water even when it is cold.

Sodium.-The metal known as sodium is quite unlike all the common metals which you come across in everyday life. In the first place it is very soft. It can be eut with a knife quite easily. It has so strong a liking for oxygen that it immediately takes it out of the air when exposed to it, combining with it to form a white powder which is the rust of sodiun. Similarly, when sodium comes in contact with water it at once takes something, which we shall eventually see is oxygen, out of it, and sets free 
a quantity of a gas which burns. Because of these two facts sodium is always kept immersed in a liquid such as naphtha or petroleum, which contains no oxygen. Moreover, as sodium so readily unites with something out of water it must never be handled with the fingers. The hand is generally more or less moist, and, if sodium is touched, its combination with part of this moisture is accompanied by so great a raising of the temperature that a serious burn results.

The action of sodium on water.-Though sodium is heavier than naphtha it is lighter than water. Consequently when a piece of sodium is put upon water it floats. As soon as it touches the water, however irregular its shape, the piece of sodium soon becomes quite round and darts about from one place to another, spinning round the whole time. All the while it gets smaller and smaller, and just before its disappearance there is often a little explosion and small pieces of sodium are scattered in every direction. The greatest care must be taken that none of these tiny fragments hit the face.

If, as the little ball of sodium is careering about the surface of the water, a lighted taper is brought near it, it seems to catch on fire and burn with a golden yellow flame. It is, however, not really the sodium which is burning, iut the inflammable gas which it sets free from the water as it travels from place to place. If the sodium is kept in one place on the surface of the water, as shown in Fig. 5, not so much heat is lost to the water, and the sodiun reaches a temperature high enough to set fire to the gas which it drives out of the water. The golden yellow colour of the flame is due to particles of sodium mixed with the gas. The gas itself burns with an almost colourless flame. Can we collect this gas which sodium turns out of the water and examine it?

How to collect the gas which sodium turns out of water.-If a piece of sodium is put into a small length of lead piping, and the ends of the piping be nearly closed by hammering, then when the piece of lead is dropped in the water the sodium, too, will go to the bottom. Instead of the piece of lead piping, a weighted roll of wire gauze may be used. As soon as the sodium enters the water, bubbles of gas begin to appear. These can easily be collected by holding an inverted test-tube full of water over the piece of lead piping. In this way tubes can be filled with the gas which sodium turns out of the water. 
The gas which sodium turns out of water will burn.-. When one of the tubes which has been filled with the gas which sodium turns out of the' water is treated in the way already described, that is, is covered with the thumb of the left hand before it is lifted out of the water, and while still held mouth downward a lighted taper, held in the right hand, is brought near to its mouth the gas burns with an almost colourless flame on removing the thumb. It seems to be the same sort of gas as was got from steam by the action of heated iron; it really is so.

The water into which the sodium is put undergoes a change.When a piece of reddened litmus paper is put into pure water it undergoes no change in colour. If, however, it is put into the water upon which sodium has acted it is soon changed to a blue colour. If some of the white powder, which sodium forms by combining with the oxygen of the air, is dissolved in water, a reddened litmus paper is turned blue in exactly the same way.

The two effects are the same, and as in one case it is produced by a substance formed by sodium and oxygen, it is reasonable to suppose that in the other case the same or a similar compound is the cause. If this is true, then when sodium sets hydrogen free from water, it unites at the same time with oxygen. Evidently, therefore, water must contain both hydrogen and oxygen. The change which occurs may be written down thus:

$$
\begin{array}{c|c}
\text { Before Action. } & \text { After Action. } \\
\text { Sodum and Water. } & \text { Hydrogen. Sodium United } \\
\text { Writh Oxygen. }
\end{array}
$$

As neither hydrogen nor oxygen were taken to begin with, they must come from the water.

\section{TO BE REMEMBERED.}

Sodium is a soft, silvery-looking metal which readily removes oxygen from the atmosphere or from water. It forms with the oxygen a white powder - the rust of sodium. To prerent the formation of this rust, sodium is usually kept in naphtha.

Sodium will float on water; the floating piece darts about and quickly becomes spherical. It drives out of water an inflammable gas 
known as hydrogen, which by a suitable arrangement may be collected in a tube and tested.

If a piece of reddened litmus is dipped into the water on which solium has floated, the paper is turned blue, showing that a change has taken place in the water.

\section{EXERCISE III.}

I. After carefully examining a piece of sodium, write all you can about it.

2. What is the action of sodium on water? Describe this fully.

3. By experiments with sodium and water, what can be learnt about the composition of the liquid?

4. How would you show that the gas which iron turns out of water is the same as that which sodium turns out of it?

5. Give reasons for believing that water sontains both hydrogen and oxygen.

\section{LESSON IV.}

\section{ACTION OF ZINC UPON ACIDS.}

\section{PRACTICAL WORK.}

Things required.-Apparatus for preparing hydrogen, as shown in Fig. 6. Granulated zinc. Common sulphuric acid. Test-tubes. Pneumatic trough.

What to do.

Production of infammable gus by the action of zinc upon acid.-Select a Hask, or wide-mouthed bottle, and fit it up as is shown in Fig. 6. He very careful that both the stopper and the tubes fit very closely. Into the flask put enough granulated zinc to cover the bottom. Pour some water upon the zinc. Arrange the delivery tube in the trough as shown.

Pour a little sulphuric acid down the thistle-headed acid funnel, and be quite sure that the end of the funnel dips beneath the licpuid in the flask. Do not collect bottles of the gas until you are sure pure hydrogen is being given off, which you can find out in the following way: 
Fill a test-tube with water and invert it over the end of the delivery tube. When it is full of gas, still holding it upside down, take it to a flame, which should not be near the flask you are using. Notice that there is a slight explosion. Continue this until the hydrogen burns quietly down the test-tube.

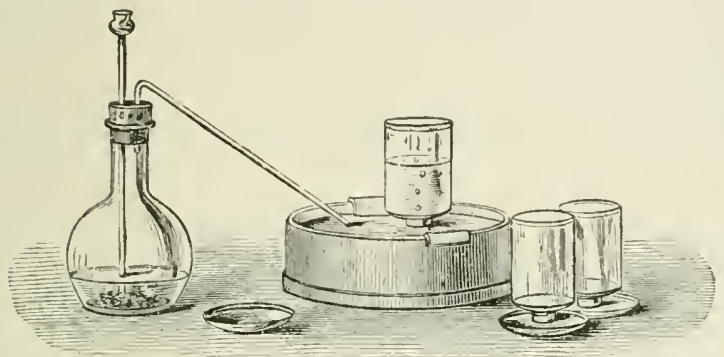

Fic. 6.-When dilute acid is poured upon granulated zinc, a gas is given off and can be collected in bottles.

When this happens you may proceed to fill one or two bottles. When the bottles have been filled, it is better not to remove them from the water until you want to use them.

Collect also a soda-water bottle half full of the gas.

Pour some dilute hydrochloric acid (spirits of salt) upon some pieces of zinc in a test-tube. As before satisfy yourself that hydrogen is given off.

Caution. - be carcful not to bring a light near the thistle funnel, or tube delivering the gets, eacn when the action in the flesk seems to hat'e ceased or a dangerous caplosion may oicur. Be careful also that none of the acid used gets upon your fingers or clothing.

\section{REASONS AND RESULTS.}

Larger quantities of hydrogen are wanted with which to study its properties. - The gas which collects when steam is passed over red-hot iron comes off slowly, and it takes a long time to collect a sufficient amount of it to enable its properties to be easily examined. It would take too long to obtain bottles full of hydrogen by acting upon water with small pieces of sodium. When larger quantities of hydrogen are wanted quickly, 
use is made of a method which has been already learnt. It has been seen in an early lesson in the First Stage of this course of study that when dilute sulphuric acid is poured upon pieces of zinc, the zinc gradually dissolves in the acid; at the same time bubbles of a gas which burns, and is hyclrogen, are given off very rapidly. This method of making the gas is generally made use of when enough hydrogen is required to examine its chief properties.

Granulated zinc.-In this experiment zinc, in the form of little lumps, is used. In this condition it is called granulated zinc. Strips and cuttings of ordinary zinc are first melted over a fire in an iron ladle, and the liquid zinc is slowly poured from a height of two or three feet, into a bucket of cold water. On coming into contact with the water the zinc solidifies in little lumps. Some of the impurities are left in the ladle, and some float on the top of the water.

Plan of the experiment.-A flask, or wide-mouthed bottle, is fitted up as shown in Fig. 6. The india-rubber stopper or cork with two holes through it must fit very closely. The thistle-headed acid funnel and the delivery tube, too, must pass tightly through the holes in the cork, for hydrogen at once finds out any leak, however small. Enough granulated zinc to cover the bottom of the bottle is put into it, and is covered with water. The end of the acid funnel must dip below the water when the cork is put into the neck of the bottle, or the hydrogen may escape by its means.

How to be sure there is no leak. - A good way to be quite sure there is no leak in the apparatus is as follows: When it is arranged as just described, the delivery tube is dipped below the water in the trough, and the bottle or flask clasped with both hands. The warmth of the hands causes the air in the flask to expand, and, if there is no leak, some of the air bubbles through the water in the trough. If, on the other hand, there is a leak, some of the air escapes through that, and there are no bubbles through the water in the trough.

Preparation of hydrogen by means of sulphuric acid and zinc.-Let it be supposed that no leak has been discovered. The apparatus is now quite ready for use. As soon as the sulphuric acid is poured down the acid funnel, hydrogen begins to come off. Before pouring it in, therefore, there must be something ready for collecting the gas. Some bottles are filled with 
water and inverted in the trough of water. A small amount of sulphuric acid is then poured down the funnel and the gas at once starts coming off, but none of it must be collected until the hydrogen is quite pure. You have seen that this can be found out by filling a test-tube, over the water in the trough, with the gas in the usual way. To begin with, a slight explosion occurs when the test-tube of gas is held near a flarne. But after several test-tubes full have been collected and tested in the same way it will be found that the gas burns quietly down the tube. When this happens, one or two bottles may be filled with the hydrogen in the same way.

Use of an acid funnel.-It is sometimes noticed that the bubbles of hydrogen come off very slowly before all the bottles have been filled with the gas. This is often because all the acid has been used up. When this occurs a little more sulphuric acid is poured down the acid funnel, and the hydrogen is again given off briskly. This is the reason for using an acid funnel. It prevents the necessity of taking out the cork from the bottle containing the zinc, and so admitting more air.

Hydrochloric could be substituted for sulphuric acid.- Hydrochloric or muriatic acid is sometimes used instead of sulphuric acid in preparing hydrogen. The same plan as is described in this lesson is adopted. A different substance is left behind in the flask, but this will be described in a later lesson.

\section{To be Rememberen.}

When steam is passed over red-hot iron, the iron becomes rusty, taking oxygen from the steam, and a gas called hydrogen is given off. Larger quantities of hydrogen gas may be prepared by the action of zinc upon dilute sulphuric acid.

When preparing hydrogen by the latter method, note:

(a) Granulated zinc should be used.

(b) The apparatus must be air-tight.

(c) A light must not be brought near the apparatus.

(d) The gas should not be collected for experiment until a test-tube of it burns quietly down the tube.

Hydrogen gas may be also prepared by pouring dilute hydrochloric acid on zinc.

A mixture of hydrogen and air is explosive.

1 II. 


\section{EXERCISE IV.}

I. Describe a method of preparing hydrogen by means of zinc and sulphuric acil.

2. How would you find out whether the hydrogen obtained by the above method was mixed with air?

3. Give reasons why, in preparing hydrogen by means of zinc and sulphuric acid: (a) The bottom of the thistle funnel must be under water; (b) The apparatus must be air-tight.

4. Having fitted up the apparatus for preparing hydrogen from zinc, how would you test whether it was air-tight or not?

\section{LESSON V.}

\section{PROPERTIES OF HYDROGEN.}

\section{PRACTICAL WORK.}

Things required.-Apparatus as in last lesson for preparing hydrogen. Jars or bottles for collecting the gas. Taper on wire. Pneumatic trough. Strong egg-shaped soda-water bottle.

Caution! Never bring a light near an apparatus in which hydrogen is being produced.

\section{What to do.}

Physical properties of hydrogen.-Observe as many properties of hydrogen as you can by examining one of the bottles full of the gas. Notice it is colourless and has no taste.

Pure hydrogen has no smell, but the gas when prepared from ordinary sulphuric acid and zinc has a slightly disagreeable smell. This is due to the presence of small quantities of another gas. This impurity may, however, be removed by passing the gas, before collecting it as described in the last lesson, through a bottle arranged as in $A$, Fig. 7, containing a little Condy's fluid.

[The jars, or bottles, when taken from the trough, must be held mouth downwards as shown in Fig. 9].

Hydrogen burns. - Test one jar of the gas by means of a lighted match or taper as in Fig. 9. Observe that the gas 
burns around the mouth of the jar, but that the flame of the taper is extinguished, but when taken out it again becomes alight on passing through the flame of the burning hydrogen.

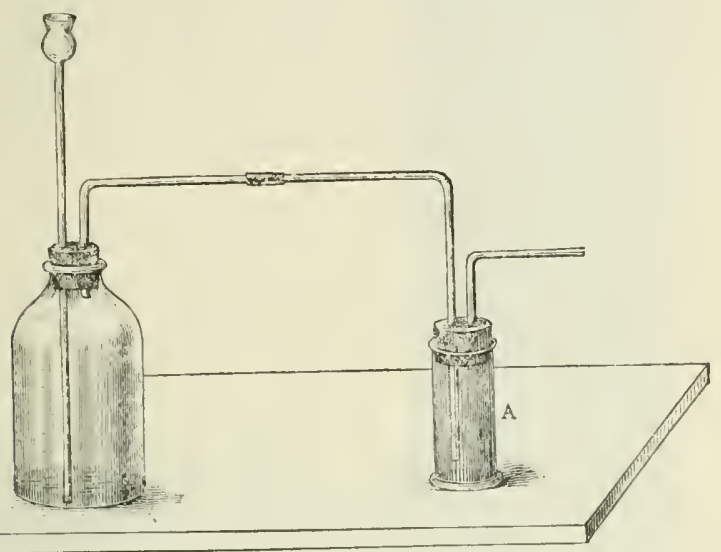

Fig. 7.- How to purify hydrogen before collecting it. The jar $A$ contains a little Condy's fluid.

Hydrogen is lighter than dir.-Take a jar or cylinder $A$ (Fig.8), containing air only, and hold it mouth downwards in one hand. Take another jar or cylinder, filled with hydrogen, in

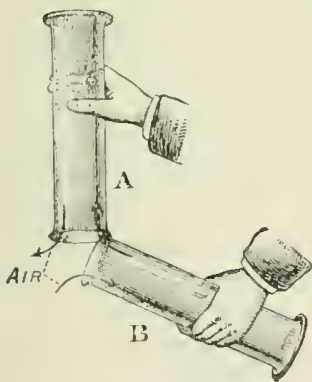

Fig. 8.-Pouring a gas upwards. The hydrogen from $B$ passes up into $A$, and the air from $A$ is driven out.

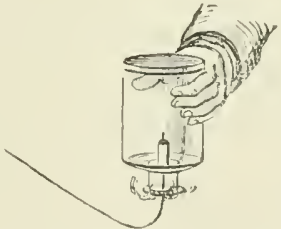

Fig. Q. - The hydrogen burns at the mouth of the bottle, but the flame of the taper is extinguished when inside the buttle of hydrogen.

the other hand, and bring it mouth downwards by the side of the first, then gradually bring it into position $b$. Now put the 
lower cylinder down, and apply a lighted taper to each jar. Show, by applying a light, that the jar which contained air now contains hydrogen, which passed upwards from $B$.

Soap-bubble balloons.-Make some strong soap solution by shredding some good soap into warm water ${ }^{1}$; add a few drops of glycerine. By means of a piece of india-rubber tubing attach a common clay tobacco pipe to the hydrogen apparatus (Fig. IO). When the gas is coming off slowly put the pipe

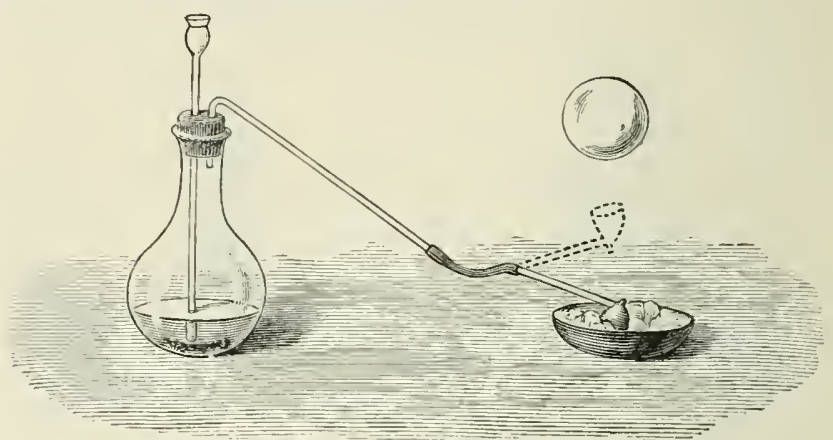

FIG. Io.-Blowing soap-bubbles with hydrogen.

mouth downwards into some of the soap solution. As soon as a bubble forms hold the pipe mouth upwards. As the bubble increases in size a slight jerk will detach it, and it rapidly rises. Why is this?

Explosion of a mixture of hydrogen and air.-Take a strong soda-water bottle (egg-shaped), and half fill it with hydrogen, as described in Lesson IV. Wrap your hand well in a duster and with it hold the bottla firmly. Take the bottle out of the water so that the water in it runs out. The bottle is now filled with a mixture of air and hydrogen. Apply a light and you will not fail to observe that an explosion results.

The flame of burning hydrogen.-Fit a straight-pointed tube drawn out to a point to a hydrogen generator, as shown in Fig. II. After pouring a little sulphuric acid down the thistle funnel, collect a test-tube of the gas issuing from the straight tube, and hold the mouth of the test-tube near a

1 This should be made a day or two before required. 
flame, which must be a few feet away from the generator. The gas will at first go off with a pop, or burn with a squeaking noise, but after two or three trials it will burn quietly, with a blue flame. IVhen you can carry this flume of burning hydrogen to the apparatus from which the gas is being produced, do so, and use it to ignite the gas escaping from the pointed tube. If you remember always to do this, there can be no danger, for when you are able to carry a flame of hydrogen in a testtube of the gas, for a distance of two or three feet to the generating apparatus, you may be sure that the hydrogen issuing from the apparatus is not mixed with air.

Light the hydrogen in this way.

Observe that it burns with a pale blue flame, which after a time becomes yellow. This coloration is due to the glass becoming hot, and some of the substances in it being burnt in the flame of hydrogen.

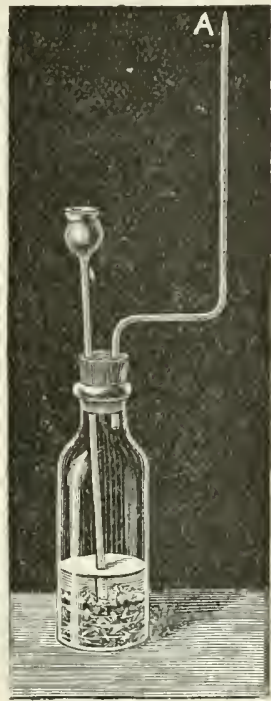

Fig. II.-Arrangement for obtaining a flame of hydrogen.

\section{REASONS AND RESULTS.}

Physical properties of hydrogen.-Hydrogen is a gas which possesses no colour, no taste, and no smell. It is very much lighter than air. For this reason soap-bubbles, or balloons filled with it, rise in the air when free to move. It has been found by many carefully performed experiments that hydrogen is the lightest substance known. The mass of a unit volume, or litre, of hydrogen is consequently taken as the standard with which chemists compare the densities of other gases.

One litre of hydrogen at a temperature of $0^{\circ} \mathrm{C}$., and under the ordinary pressure of the air, which pressure is equal to the weight of a column of mercury 76 centimetres long, has a mass of very nearly nine-hundredths of a gram; more exactly, the number is 0.0896 gram. It would require just over II litres of hydrogen to weigh one gram. A litre of air under the same conditions would weigh I'3 grams 
nearly, and you will remember that a litre of water at $0^{\circ} \mathrm{C}$. weighs a little less than 1000 grams.

You will have no difficulty in understanding that to find the density of any gas compared with hydrogen as a standard, all that it is necessary to do is first to find the mass of a given volume of hydrogen, and then that of an equal volume of the other gas. But, of course, the temperature at which the ex-

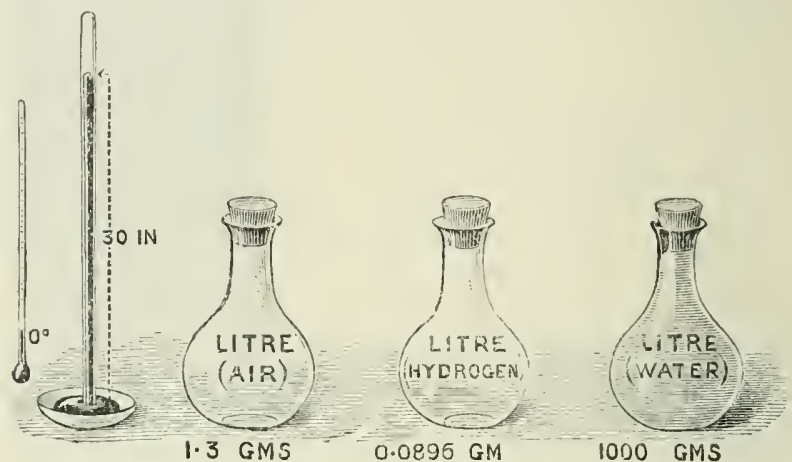

FIG. 12.-Comparative masses of air, hydrogen, and water.

periment is made, and the pressure of the air at the time, should be the same in the two cases; if they are not, allowance has to be made for the difference.

Hydrogen will burn, but it will not allow things to burn in it.When a lighted match is brought to the end of a delivery tube, from which pure hydrogen is issuing, the gas catches on fire and continues to burn with a flame which is at first almost colourless, but very soon changes to a bright golden yellow colour, which is due to the sodium contained in the glass. Hydrogen is therefore said to be combustible.

If a jar of hydrogen is held with its mouth downwards, and a lighted match (or a piece of taper) fised to the end of a wire is pushed up into the jar, the lydrogen, as in other cases, catches on fire and continues to burn at the mouth of the jar; but the flame of the match or taper is put out, showing that things will not burn when surrounded by hychogen gas. If the match or taper is slowly drawn out of the jar it will be again ignited as it passes through the hydrogen flame at the mouth of the jar. 
Thus, though hydrogen is a combustible gas, it will not support combustion in ordinary circumstances.

Hydrogen being lighter than air can be poured upwards. When you wish to pour water from one ressel to another you know very well that the vessel into which water is to be poured is placed below, and the ressel from which the water is to be poured is placed above and tilted. This is because water is hearier, bulk for bulk, than air. Similarly, if it were required to pour a gas considerably heavies than air from one vessel to another, like the gas which is produced when carbon is bumt in oxygen, you would proceed in just the same way as with water. Since, however, lnydrogen is much lighter than air, the order of things must be exactly reversed. The vessel inio which hydrogen is to be poured must be placed above and be inverted, while the ressel from which the gas is to be poured must be below and held with its mouth upwards. This method of pouring hydrogen from one jar to another is shown in Fig. $S$ and is always used when it is required to pour a gas lighter than air froni one ressel to another.

These facts provide another way of collecting the hydrogen prepared as described in the last lesson. A trough of water need not be used at all, but the

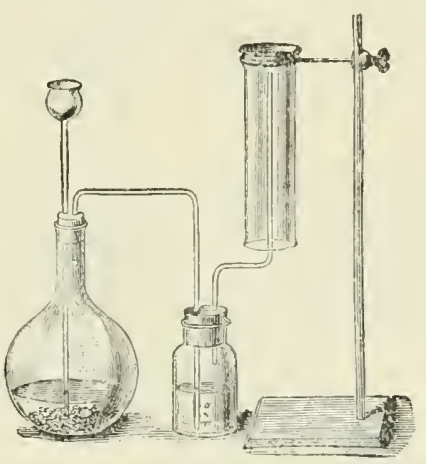

Fig. 13.- Collection of hydrogen by displacement of air. so-called empty jar, that is, the one really full of air, is arranged as shown in Fig. 13 when the hydrogen streams upwards and displaces the air. This plan is called collecting the hydrogen by upward displacement.

Hydrogen is a neutral gas. - Neither blue nor red litmus paper undergoes any change in colour if moistened and plunged into hydrogen gas. Substances which redden blue litmus paper you have learnt to call acid substances. Those which turn a red litmus back to its original blue colour are spoken of as having an alkaline reaction. Gases and other things, which, like hydrogen, cause neither of these changes are always referred to as being neutral, 
Sometimes when hydrogen is prepared by means of zinc and hydrochloric acid, a little of the latter comes over with the hydrogen, so that the gas may appear to be acid. It may be freed from this acid by passing it through water.

\section{TO BE REMEMBERED.}

Hydrogen is a colourless, tasteless, and transparent gas. When pure it has no smell.

It is the lightest gas known and can be poured upwards from one vessel to another.

It burns in the air, but burning substances put into it are extinguished.

If hydrogen be mixed with air, an explosive mixture is formed.

A litre of hydrogen, weighed at a temperature of $0^{\circ} \mathrm{C}$., and when the pressure of the air will support a column of mercury 76 centimetres long, is found to have a mass of 0.0896 gram. The density of all other gases is measured by comparing the mass of a litre of these gases with the mass of a litre of hydrogen.

\section{EXERCISE V.}

I. The density of oxygen gas is 36 ; what do you understand by this? What would a litre of this gas weigh?

2. Describe some experiments which show that hydrogen is lighter than air.

3. How would you show :

(a) That hydrogen will burn.

(b) That hydrogen will not support combustion.

4. Make a list of the physical properties of hydrogen gas.

5. Describe exactly how you would proceed to pour hydrogen gas from one jar into another.

\section{LESSON VI.}

\section{THE BURNING OF HYDROGEN.}

\section{PRACTICAL WORK.}

Things required.-Apparatus for preparing dry hyclrogen as shown in Fig. 14. Stoppered retort, and stand with piece of india-rubber tubing. Calcium chloride. Evaporating basin. 
Laboratory burner. Thermometer. Litmus. 2-oz. flask and cork. Granulated zinc. $500 \mathrm{cc}$. flask. Dilute sulphuric acid.

What to do.

Liquid formed by burning hydrogen.-Arrange a flask or bottle, as before, for the production of hydrogen. Pass the gas through a tube containing chloride of calcium in order to dry it thoroughly. Fill a test-tube with the gas as already described, and when the gas will burn, use the flame to ignite the gas issuing from the tube and allow it to burn under a

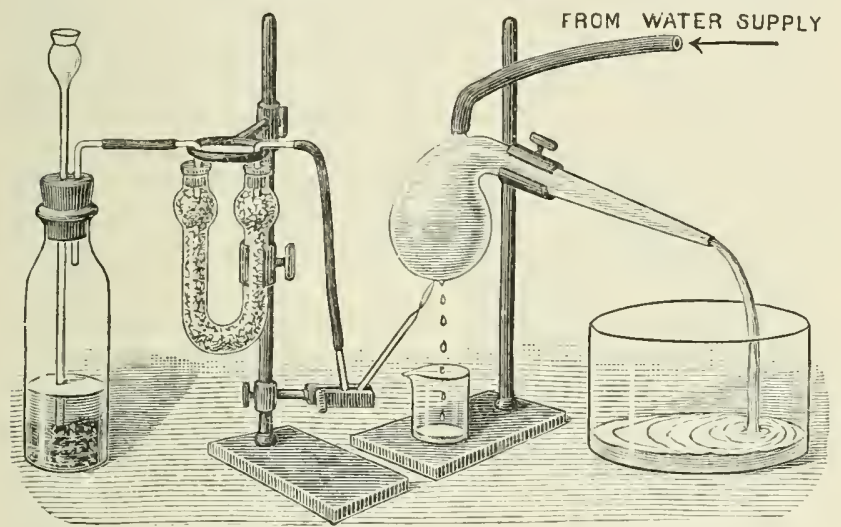

FiG. 14.-Hydrogen is being produced in the bottle, dried in the U.tube, and burnt as shown. The water produced is cooled by the retort and collected in the beaker below.

retort, which is kept cool by a stream of water flowing in where the stopper is generally put, and out at the end of the neck. Observe the formation, on the outside of the retort, of a clear liquid which collects and drops into a clean evaporating basin placed to receive it (Fig. 14).

In this way obtain sufficient of the liquid to enable its properties to be examined. Much time is saved if a number of pupils all work at the same experiment, and the liquid formed by each of the hydrogen flames is added together.

Nature of liquid formed by burning hydrogen.-As already learnt, proceed to find the boiling point, freezing point, and density of the liquid formed when hydrogen burns in the air. The boiling point is found to be $100^{\circ} \mathrm{C}$., the freezing 
point $0^{\circ} \mathrm{C}$., and the density 1. The liquid is consequently pure water.

Evaporate some of the liquid in a basin, and notice that no residue is left.

Test some of the liquid with litmus paper. Observe that it is neutral.

Hydrogen on burning takes oxygen out of the air ${ }^{1}$ - - Select a wide-necked flask $a$ of about 500 c. c capacity (Fig. I 5). Fill the trough or a bucket with war:n water. Place some

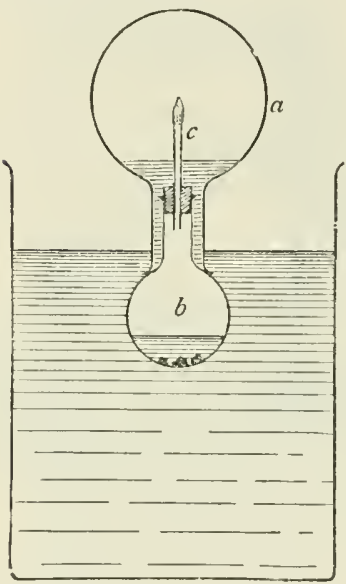

FIG. 15.-Hydrogen is being produced in the flask $b$, and is burning at c. Oxygen is used up from the flask $a$, and water rises to take its place. granulated zinc in the 2 -oz. flask $b$, and add dilute sulphuric acid. Hydrogen is rapidly given off. Close the small flask with a cork provided with a short upright tube $c$, which has been drawn out in the flame of a laboratory burner. When all the air has been driven out of the small flask, which you can find out by collecting a test-tube full by upward displacement, light the hydrogen at the end of the drawn-out tube. Hold the flask $b$ in the water, with the flame just above the surface, and invert the flask a over the flame, so that its mouth is under the water. Release the flask $b$ and it will take the position shown. The flame becomes smaller and smaller. As soon as it goes out, remove flask $b$ by lowering it in the water. Observe the water has risen in the flusk a, showing that some of the air has disappeared. Cool the Hask a by sprinkling water on it and close its nouth by a cork under water. Now remove $a$, and by means of a measuring jar, compare the amount of water in the flask with that which it holds when full. It will be found to be one-fiftl.

1 Aclapted from Perkin \& Leau's Introduction to the Study of Chemistry (Macmillan), p. 218 , 


\section{REASONS AND RESULTS.}

The burning of hydrogen.-You have already learnt that hydrogen burns in the air. Several questions will occur to you, such as, What chemical changes occur when hydrogen burns? Can an experiment be arranged so that the new substance formed may be collected and examined? and others, which may now be answered.

When an apparatus is arranged as in Fig. 14 so that a hydrogen flame burns near a surface which is kept cold, it is found that a liquid is continuously formed which, as the experiment proceeds, collects drop by drop in a basin put to catch it. Since this liquid is formed by the burning of a perfectly dry gas, we know it must be a substance which hydrogen forms with something out of the air. The hydrogen, you know, must be dry as it was first passed through the tube $\epsilon$ containing lumps of calciun chloride, a substance which has the power of quickly absorbing moisture.

The liquid formed as hydrogen burns is water.-When the liquid which collects in the experiment referred to in the last paragraph is examined, it is found to have all the properties of pure water. Thus, its boiling point is $100^{\circ} \mathrm{C}$., its freezing point $0^{\circ} \mathrm{C}$., and its density is 1 ; when evaporated to dryness no residue is left behind, and it cloes not change the colour of a litmus paper used for testing it.

These, as you know, are all characteristics of pure water, and it is therefore quite certain that the liquid which is formed as hydrogen burns is water. Moreover, since in all cases which have been thus far examined, when a substance burns it combines with the oxygen of the air, we are led to suppose that the hydrogen in burning does the same, that is, it combines with the oxygen of the air to form water.

Hydrogen in burning uses up one-fifth of the air.-When hydrogen burns in an enclosed quantity of air over water, it is found that after a time the flame goes out, and the water rises in the vessel in which the air was enclosed to take the place of that part of the air with which the hydrogen combines. If the amount of water which entered the flask in this way is measurcd, it tells the amount of oxygen in the air in the flask. By filling the flask with water and measuring it, the volume of air the whole flask holds can be found. On comparing the amount of 
water which rises into the vessel with the capacity of the vessel, it is found to be one-fifth.

This proves that hydrogen, like other combustible substances, combines with the active part of the air when it burns, and you see that the conclusion arrived at in the last paragraph was quite correct.

Hydrogen and oxygen will not combine at ordinary temperatures.-If no light is near, hydrogen gas may escape into the air without any danger, and with no accompanying chemical change. This shows that the two gases, hydrogen and oxygen, do not combine at ordinary temperatures. If they did so unite, every bubble of hydrogen which came into contact with the air would catch on fire, and form a small quantity of water by combining with the oxygen of the air. The same facts are noticed when hydrogen and air are mixed in a soda-water bottle. The gases do not affect one another, but when a flame is brought near to the mixture, combination at once takes place, and a loud explosion is heard. The heat of the flame raises the temperature high enough to cause the two gases to combine.

The flame of burning hydrogen is intensely hot.-When hydrogen in burning combines with oxygen to form water,

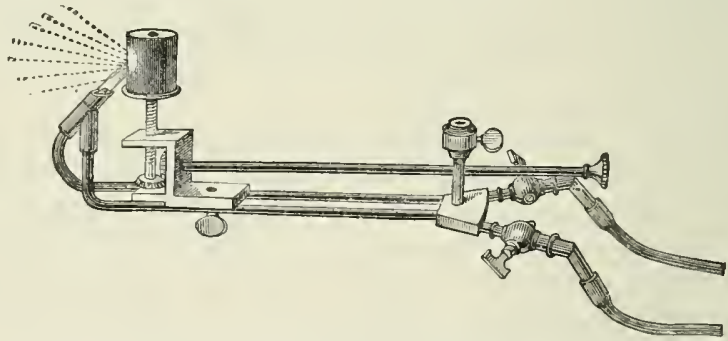

FIG. 16.-Hydrogen passes through one of the tubes, and air or oxygen through the other. The flame of the hydrogen uniting with the oxygen is so hot that the ball of lime is made incandescent.

much heat is produced. The consequence is that the hydrogen flame is intensely hot, very much more so than an ordinary gas flame. When it is required to take full advantage of this heat it is customary to make the hydrogen come into contact and combine with pure oxygen, and not with air, which only contains one-fifth oxygen. The apparatus used for this purpose is called the oxyhydrogen blowpipe, and is an arrangement to allow the 
burning to take place easily, but to prevent the mixing of the two gases to form an explosive mixture. The oxyhydrogen blowpipe is sometimes used to melt platinum, a metal which requires a very high temperature before it will assume the liquid condition.

The lime-light. - When lime is made hot, it becomes intensely bright but does not burn. This fact is made use of in many magic-lanterns. The flame of an oxyhydrogen blowpipe is made to strike against a cylinder of lime as shown in Fig. I6, which, becoming very hot, gives out an intensely bright light called the lime-light, with which most boys and girls are quite familiar.

TO BE REMEMBERED.

When dry hydrogen burns in air it unites with oxygen to form water. - By a suitable arrangement some of the liquid so formed may be collected for examination.

When hydrogen is burnt in a limited quantity of air the volume of the air diminishes by one-fifth, the hydrogen taking the oxygen from the air and combining with it forms water. When the hydrogen flame is burning in the air, it gradually diminishes as the oxygen in the air unites with the hydrogen, and at last goes out when the whole of the oxygen has been removed.

Hydrogen and oxygen will not unite at ordinary temperatures, but the temperature of an ordinary flame will cause them to do so. As the gases unite, an extremely high temperature is produced, the heat being intense enough to melt metals upon which an ordinary furnace would have no effect.

The great heat is made use of in producing the oxyhydrogen limelight, a piece of lime being made so hot as to give out a brilliant light.

\section{EXERCISE VI.}

I. How would you prove that when hydrogen unites with oxygen, water is formed?

2. Describe an experiment with hydrogen to prove that oxygen makes up one-fifth of the air.

3. When hydrogen escapes into the air, why does it not combine with the oxygen in it? What happens when hydrogen unites with oxygen?

4. In what respects is the burning of a flame of hydrogen gas like, or unlike, the burning of a candle?

5. Water can be produced from two gases. What are the gases, and how could you produce water from them?

6. How is the light of the lime-light (frequently used in magiclanterns) obtained? 


\section{LESSON VII.}

\section{THE ACTION OF HYDROGEN ON METAL RUSTS.}

PRACTICAL WORK.

Things required.-Apparatus as shown in Fig. 17. Black oxide of copper. Sulphuric acid. Zinc. U-tube and calcium chloride, Balance. Box of weights. Calcium chloride.

\section{What to do.}

Action of hydrogen on heated copper oxide.-Arrange an apparatus like that shown in Fig. 17 in which a flask $A$ for the making of hydrogen is connected with the bottle $B$ containing strong sulphuric acid. The passage of the hydrogen

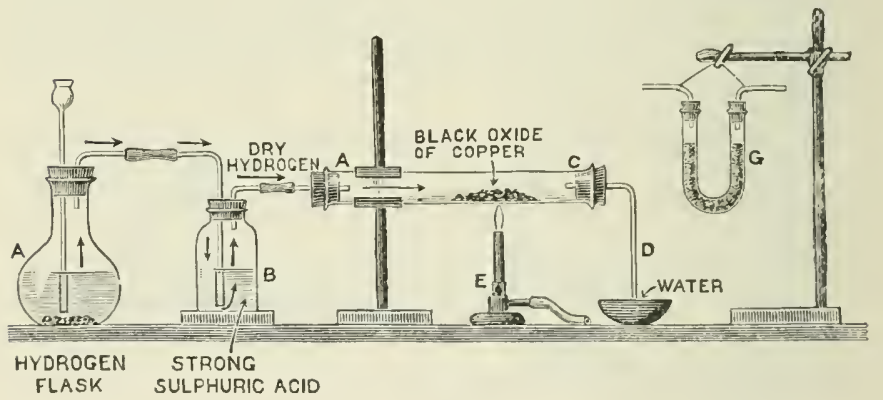

Fir. 17.- When hydrogen is passed over hot oxide of copper, it extracts the oxygen to form water, and leaves copper behind.

through the strong acid completely dries the gas. A small amount of the black oxide of copper is placed in the hard glass tube $A C$ which is about $1{ }^{\circ} 5$ centimetres in diameter, and fitted with the tube $D$ in the manner shown. When you are sure that pure dry hydrogen is escaping from the open end of $D$, heat the oxide of copper in the tube by means of the burner $E$. In a few minutes moisture will be seen to collect in the tube $D$, and presently to drop into the dish put to collect it. 
Examine the residue in the hard glass tube, and note its change to a reddish colour, due to the presence of copper.

Rearrange the apparatus, using the $U$-tube $G$ in the place of the tube $D$. The $U$-tube $G$ containing lumps of calcium chloride is employed to collect the water formed.

Composition of water.- Yut some copper oxide into the tube $A C$ and carefully weigh the tube. Similarly, the mass of the $U$-tube $G$ and its contents must also be determined by weighing. As in the last experiment, when you are sure pure dry hydrogen is escaping from the open end of $G$, heat the copper oxide by means of the laboratory burner. Be sure that all the water formed is collected by the $U$-tube. If any condenses at the end of the hard glass tube $A C$, drive it over by heating the tube at this place.

Allow the tube $A C$ to cool. Discomnect it at $A$ and $C$, and again determine its mass and that of its contents, by weighing. Notice the diminution in mass. Also weigh the $\mathrm{U}$-tube again and observe its increase in mass.

\section{REASONS AND RESULTS.}

Water is formed when hydrogen is passed over heated oxide of copper.-When pure hydrogen, which has been dried by passing it through some substance which very readily absorbs moisture, such as strong sulphuric acid or calcium chloride, is passed over heated black oxide of copper, the oxide is found to lose in mass, giving up something to the hydrogen. With this 'something' it forms water. The oxide of copper is at the same time changed into a reddish powder which on examination is found to be copper.

We cannot be wrong, therefore, in supposing that the something taken out of the oxide is the active constituent of the air which copper unites with when it changes into copper rust or oxide. Another name for this active constituent is, as you know, oxygen. Hence, it may be said that hydrogen in passing over heated copper oxide takes oxygen from it, and combines with it to form water. At the same time the copper oxide is changed back into copper.

This experiment can teach the composition of water.-Since you know that hydrogen takes oxygen out of heated oxide of copper, you will have no difficulty in understanding why hot 
oxide of copper becomes lighter when the gas is passed over it. In fact, it is quite clear that the loss in mass of the oxide of copper in this case tells exactly how much oxygen the hydrogen combines with in forming water. But, as the mass of water formed can be exactly determined, it is possible to calculate easily how much hydrogen and how much oxygen are contained in a given mass of water. Thus, we know the mass of water formed by the combination of an unknown mass of hydrogen with a known mass of oxygen, and we can make a subtraction sum to find the mass of hydrogen.

From: Mass of water formed

Take: Mass of oxygen which is lost by the oxide of copper.

Ans: Mass of hydrogen in the mass of water formed.

An actual experiment.-Using an apparatus like that shown in Fig. 17, the following masses were found by weighing:

Mass of $U$-tube after experiment, - - $\quad 36.473$ grams

Mass of $U$-tube before experiment, - $\quad$ - $35.82 \mathrm{I}$ grams

Mass of water produced, - _ - $\quad$ - $0.652 \mathrm{gram}$

Mass copper oxide before experiment, - 5.562 grams

Mass copper oxide after experiment, - - $\quad 4.982$ grams

Mass of oxygen lost, - $\quad$ - _ $\quad 0.580$ gram

The mass of oxygen is 0.580 gram, and that of the water produced from it is 0.652 gram; therefore the mass of hydrogen must be $0.652-0.580$ gram, that is, 0.072 gram. Or,
Mass of water, - - - - $\quad 0.652 \mathrm{gram}$
Mass of oxygen, - - - $\quad$ - 0.580 gram
Mass of hydrogen, - - - 0.072 gram

How to reason from the results of the experiment.-You know that 0.072 gram hydrogen combines with 0.580 gram of oxygen, or 72 grams of hydrogen combine with 580 grams of oxygen, and it is easy to calculate by proportion how much oxygen one gram of hydrogen combines with, thus :

1 gram of hydrogen combines with $\frac{580}{72}=\begin{gathered}S \text { grams of oxygen } \\ \text { (nearly). }\end{gathered}$ 
Whenever the experiment is carefully performed, the same result is obtained. It may therefore be stated that eight-ninths of a given mass of water consists of oxygen and one-ninth of hydrogen, so that nine pounds of water may be regarded as made up of eight pounds of oxygen and one pound of hydrogen.

\section{To bE ReMeMBERED.}

When hydrogen, which has been freed from moisture, is passed over heated copper oxide, it unites with the oxygen of the oxide to form water.

The water may be collected by passing it through a $\mathrm{U}$-tube containing calcium chloride.

The mass of the water formed is determined by finding the increase in mass of the tube after it has absorbed the water ; and the loss in mass which the oxide undergoes, tells the mass of oxygen in this water. By subtracting the mass of the oxygen from the mass of the water formed, the mass of hydrogen in the water is ascertained.

When the mass of the hydrogen in water is compared with the mass of the oxygen, it is found that the proportions are as $I$ is to $S$. Hence 9 grams of water contains 8 grams of oxygen and $\mathbf{I}$ gram of hydrogen.

\section{ExerCise V'II.}

I. IIow would you show that water is formed when dry hydiogen is passed over heated copper oxide?

2. If to grams of oxide of copper were given you, how would you find out the mass of oxygen it contained?

3. In what proportion, by mass, do hydrogen and oxygen exist in water? How would you go to work to find this out for yourself?

4. Explain the arrangement and use of the bottle containing sulphuric acid, through which hydrogen is passed before passing it over heated copper oxide, in an experiment to form water.

5. In the arrangement in Fig. 17, dry hydrogen is passed over heated copper oxide. and yet water is absorbed by the calcium chloride tube. How is this? 


\section{LESSON VIII.}

\section{NATURAL WATERS.}

\section{PRACTICAL WORK.}

Things required.-Graduated vessel to hold 250 c.c. of water. Samples of rain, tap, and sea water. Eraporating basins. Laboratory burner, sand-bath, tripod or retort stand. Balance and weights. Gallon measure. Carbonate of lime. Common salt.

\section{What to do.}

Evaporation of different natural waters.-Measure out 250 c.c. (that is $\frac{1}{4}$ litre) of clear rain water, tap water, and sea water, into evaporating basins, the masses of which have been determined by weighing. Evaporate to dryness in each case on a sandbath, taking care to lose no liquid by spurting. When the evaporation is complete and the residue (if any) left behind is dry, allow the basins to cool, and again weigh. The increase in mass of each basin represents the amount of dissolved material in equal volumes of each of the kinds of natural water.

Purification of water by distillation.-Distil some tap water and sea water as in Lesson II., Second Stuge. Observe that in both cases pure, or distilled water, is obtained.

Amounts of solids dissolved in natural waters.-Measure out I gallon of tap water (1o lbs.). Weigh out upon separate filter papers 3 grains and $23 \frac{1}{2}$ grains respectively of carbonate of lime or common whiting. These masses will give you some idea as to the amount of solid matter which would be obtained if I gallon of Dee water and I gallon of Thames water respectively were eraporated to dryness. Renember, however, that the residue would not be all carbonate of lime.

Weigh out about $5 \frac{1}{2}$ ozs. of common salt. This represents the mass of solid matter in one gallon of sea water. The solid matter in sea water is, however, not all common salt. 


\section{REASONS AND RESULTS.}

Natural waters.-Pure' water does not occur naturally on the earth. This is because of the great solvent power which you have learnt water possesses. At the moment rain is formed it consists of pure water, being really distilled water which is formed in just the same way as when this liquid is prepared in the laboratory by the condensation of steam. The heat of the sun converts the water from lakes, rivers, seas, and other bodies of water, into vapour, which in the higher or colder parts of the atmosphere is cooled and again forms water. Yet no sooner is the rain formed than it begins to dissolve various substances. In its passage through the air it takes up varying amounts of the gases which make up the atmosphere, such as oxygen and the gas called carbon dioxide, which is formed whenever carbon combines with oxygen, either in burning or breathing. When the surface of the earth is reached, the water dissolves portions of all the soluble ingredients out of the soil and the underlying rocks. The most soluble bodies are, of course, dissolved to the greatest extent. It will be seen later that the solvent power of water is considerably increased by the presence of the carbon dioxile it dissolves, partly from the air and partly from the soil.

Spring or tap water.-Spring and tap water are very often the same liquid. Tap water simply means that which is supplied to our houses from the large iron pipe or water main which is buried in the road. As you know very well, the water from the reservoir, which the main contains, is often spring water which has been brought from a distance. Its dissolved substances have not been removed from it, though its suspended impurities have generally been got rid of by filtering. This filtering, which has to be done on a very large scale, often takes place through beds of sand.

When the properties of, and dissolved substances in, tap water are examined, therefore, a knowledge of spring water is obtained. The amount of residue left in the basin when tap water is evaporated depends upon where the water was brought from. Some tap water, such as that which has been drawn from a chalk country, like parts of Kent, Sussex, and Hampshire, contains a lot of dissolved solids; while that of Manchester, for example, which comes from the Lake district, where the rocks are hard and only dissolved with difficulty, leaves very little residue 
when evaporated. Though, as you will learn more fully in your next lesson, tap water which contains a sinall amount only of dissolved material is the best for washing purposes, the dissolved substances in other specimens of tap water are by no means injurious to health when used to drink. On the contrary they are often beneficial; it is said that water which contains no chalk dissolved in it is not good for children because they require this substance in considerable quantities to build up their bones.

Sea water. - As every boy and girl knows, sea water is often called salt water. The water of the ocean contains sufficient

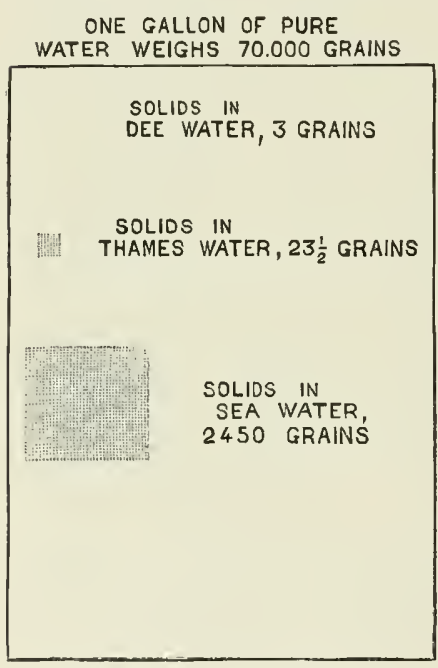

FIG. I8.-Comparative masses of a gallon of pure water, and of the solids found in this quantity of river and sea waters. dissolved matter in it to niake it taste, while in spring, rain, and river water the quantity is so small that the water is tasteless; for this reason the water of springs and rivers is often called fresh water.

Streams and rivers are continually flowing into the sea and carrying into it the substances they have dissolved out of the land. Evaporation is unceasingly going on from the surface of the ocean, robbing it of pure water in the form of water vapour, with the result that there is an accumulation of soluble material in the water which is left. It would consequently seem at first as if the sea must every day become salter. This is certainly not the case. It would be so if it were not for the animals and plants which live in the ocean and extract from the water some of its dissolved material to build up their solid parts.

Amount of dissolved material in different kinds of water.- The mass of a gallon of pure water is 70,000 grains, that is, 10 lbs. avoirdupois. It has been found by careful experiment that a gallon of water from the I)ee, near Aberdeen, which flows 
over a granite country, only contains three grains of dissolved salts.

The amount dissolved in the same quantity of Thames water, at London Bridge, is about twenty-three and a half ( $\left.23 \frac{1}{2}\right)$ grains.

The amount of dissolved material in sea water is very much greater. The actual quantity varies a little, depending upon where the specimen of sea water examined is obtained. A good average result is as follows. A gallon of sea water contains about 2450 grains of soluble matter. Put in another way it can

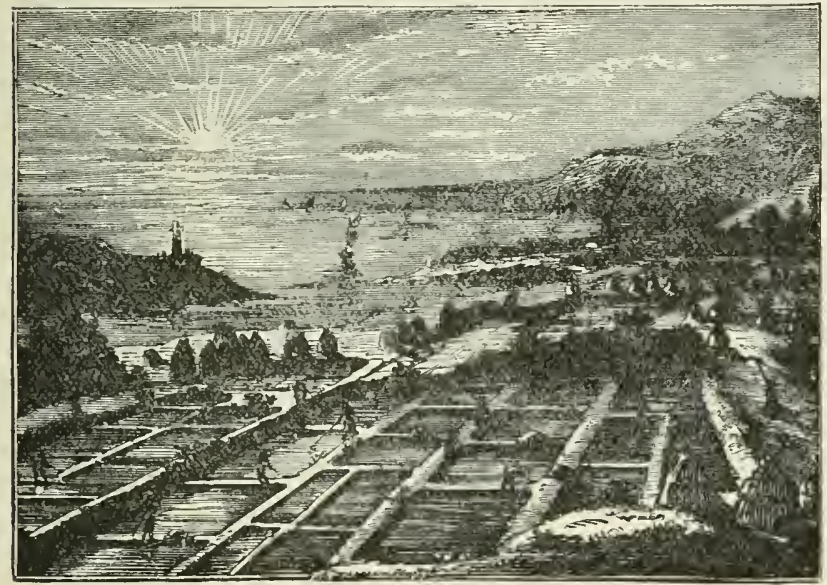

F1G. 19. - Salt is sometimes obtained by evaporating sea water in shallow pits.

be said that one hundred pounds of sea water contain three and a half pounds of dissolved substances. In some places the common salt and other dissolved salts in sea water are obtained by evaporating the water in shallow pits, as shown in Fig. I9.

TO BE REMENBERED.

Rain water is water which has been naturally distilled and is therefore free from dissolved matter.

In its passage through the air rain water takes up carbon dioxide, and this aids it in dissolving solid matter from rocks and soils.

If the rocks through which the water passes contain substances which 
are easily soluble, it will contain much dissolved material ; while water which has passed over harder rocks contains little dissolved matter.

Sea water contains a much larger amount of dissolved matter than river or spring water; for while rivers pour their water into it, this water is evaporated and the dissolved solids remain behind.

Plants and animals are continually removing dissolved matter from sea water.

A gallon of pure water weighs 70,000 grains. A gallon of filtered Dee water coutains only 3 glains of disiolved matter in it. A gallon of filtered Thame's water contains $23^{\frac{1}{2}}$ grains, and a gallon of filtered sea water $2+50$ grains ( $5 \frac{1}{2}$ ozs. nearly).

\section{EXERCISE VIII.}

1. Spring and river waters are not pure. Describe carefully how you would prove this, and say how you would estimate the quantity of dissolved matter in a gallon of each.

2. Sea water has a disagreeable taste, why is this? How do you account for the facts that: $(a)$ All the rivers run into the sea, yet the sea is not full. (b) The amount of dissolved matter in sea water does not increase.

3. How would you proceed to show that: (a) Rain water is free from dissolved solids. (b) Sea water contains very much dissolved matter.

4. A ship which floats up to a certain mark in river-water is found to float more out of water when at sea. How can you account for this?

5. Few rivers enter the Mediterranean, but the water evaporates abundantly. Would you expect the Mediterranean to be more or less salt than sea water generally?

\section{LESSON IX.}

\section{CHALK AND THE ACTION OF IIEAT UPON IT.}

\section{PRACTICAL WORK.}

Things required.-Pieces of chalk, marble, shells, limestone, and calcite. Quicklime. Laboratory burner. Piece of platinum foil. Crucible tongs. Red litmus paper.

What to do.

Physicul churacters of chalk.-Examine a piece of chalk (common whiting will do). Remember that much of the 
prepared material used for writing on the blackboard is not chalk. Notice that chalk is white and soft.

Try to dissolve it in distilled water. Observe that it is insoluble.

Put a little powdered chalk on a damp red litmus paper, and notice there is no change in colour.

Change produced by heating chalk. - Place a little powdered chalk on a piece of platinum foil ${ }^{i}$ and heat it strongly for some minutes in the flame of a laboratory burner. After heating, shake the powder on to a damp red litmus paper. Observe that the red litmus paper is in places changed to a blue colour.

Powder obtained by heating chalk.-Shake up in drinking water some of the powder obtained in the last experiment by heating chalk on platinum foil. Filter, or allow it to settle, then taste; notice the peculiar taste of lime-water.

Perform a similar experiment with chalk in drinking water. Filter and taste the water ; it is almost tasteless.

Action of quicklime on litmus.-Put a little fresh quicklime upon a damp red litmus paper, and again observe the change of colour to blue.

Effect of heating various chalk-like substances.-Try the effect of heating fragments of oyster shell, calcite, limestone, and marble. They appear to undergo a similar change to the chalk, since the residue in every case turns red litmus paper blue.

\section{REASONS AND RESULTS.}

Chalk.-Many valuable facts can be ascertained by a careful study of chalk. This substance occurs naturally in very large quantities in different parts of the earth. It builds up many hills, such as, for example, those in England which are known as the North and South Downs, and is the substance of which many of the pieces of land jutting out into the sea are formed. The Needles in the Isle of Wight, Beachy Head in Sussex and Flamborough Head in Yorkshire are all of them largely built of chalk.

I If platinum foil is not at hand, heat a lump of chalk (not blackboard chalk) on a piece of coarse wire gauze for some time. Or, powdered whiting may be heated on a piece of thin tinplate. The latter is, however, a long process. 
You must be on your guard in examining the properties of chalk not to suppose that all the white solids used for writing on blackboards are composed of chalk. While some of these are certainly made of chalk, many of them contain none of it. Real chalk is a white, soft substance which will not dissolve in distilled water.

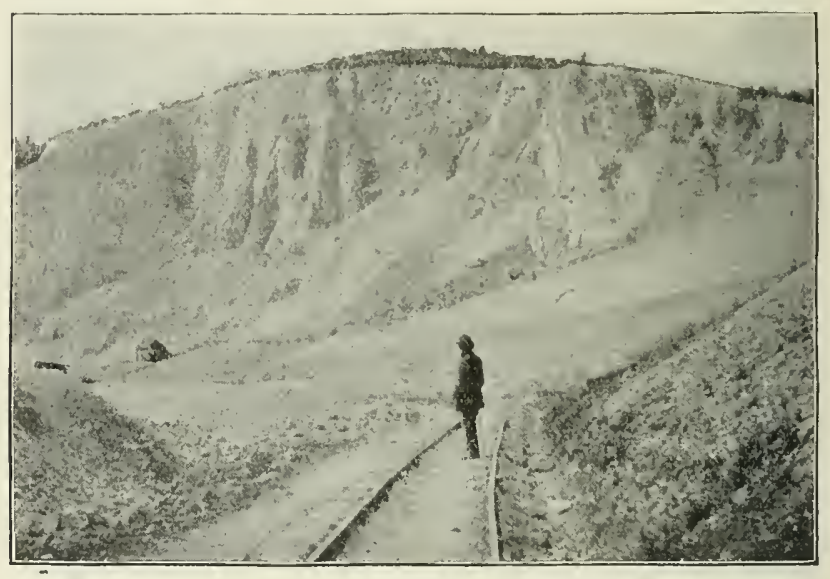

FIG. 20.-A chalk pit near Dorking, Surrey, (From a photograph by Dr. H. R. Mill.)

Chalk undergoes a change when heated. - It is easy to prove by putting some powdered chalk upon a piece of moist red litmus paper that this substance is unable to change the colour of the paper. If, however, some powdered chalk be strongly heated on a piece of platinum foil in a laboratory burner and then placed on a piece of moist red litmus paper, the red colour is changed to blue. The chalk undergoes some change when heated, or it would not acquire this new property. But other substances besides pure chalk are changed in a precisely similar manner when strongly heated. Among these may be mentioned limestone, marble, calcite or calc-spar, and shells.

The burning of limestone.-As most boys and girls know, a substance called quicklime, or more shortly lime, is very largely used by builders in preparing the mortar with which they bind together the bricks, or pieces of stone, used in building. It is 
also a matter of common knowledge that this lime is prepared by strongly heating limestone in what is called a limekiln. The same chemical change takes place on a very large scale in the limekiln, as occurs when a little powdered limestone, or some precipitated chalk, is heated on platinum foil. In other words, when chalk and limestone are strongly heated they are changed into quicklime. The change is brought about by driving a chemical compound, in the form of a gas, out of the limestone.

The limekiln.-Lime is used so largely by builders and also by farmers, who use it to increase the fertility of some kinds of land, that in every part of the country where either limestone or chalk is found, an observant traveller will be sure to recognise limekilns in some place or other. In the best managed limekilns the "burning" is always going on. The limestone or chalk is broken into pieces of a convenient size and together with coal, coke, wood, or some other kind of fuel, is thrown into the top of the kiln.

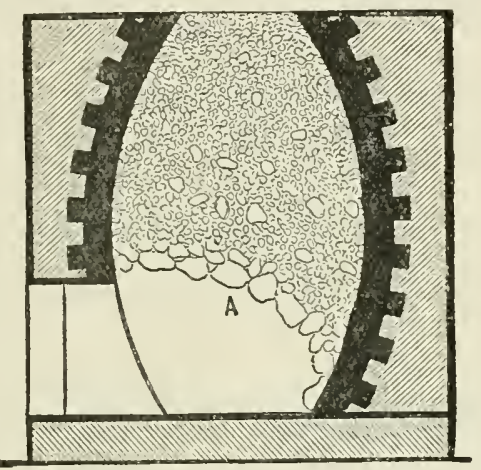

FIG. 21.-Section of a ime-kiln.

The kiln is started by lighting a fire under the arch $A$ (Fig. 2I), which is built of large blocks of limestone. The coke, or other fuel with the limestone, then burns, and the limestone is thus baked. After the rock has been kept red-hot sufficiently long to completely change it into lime, it is raked out from the bottom of the kiln. The plan of putting a mixture of limestone and fuel into the top of the kiln, and raking the quicklime out at the bottom, is continuously kept up, and the kiln is never allowed to get cold.

\section{TO BE REMEMBERED.}

Chalk is a very abundant substance in the earth's crust, forming a large part of many mountains and headlands.

When chalk is strongly heated a gas is driven out of it, and the remaining substance turns moist red litmus paper blue. 
On a large scale chalk is strongly heated with coal in a kiln, when a gas is driven off and lime remains. The process is called lime-burning, but the limestone does not really burn in the ordinary way.

\section{EXercise IX.}

I. A lump of lime and a piece of chalk are given you ; they are much alike in appearance ; how would you determine which was lime?

2. Make a list of sulustances which on heating are changed into lime.

3. Describe the process of lime-burning.

4. How would you obtain lime from a small piece of oyster shell?

5. Chalk is very commonly found in drinking waters. How do you account for this?

\section{LESSON X.}

\section{CHALK AND LIME COMPARED.}

\section{PRACTICAL, WORK.}

Things required.-Pieces of lime and chalk. Saucers. Balance and weights. Sandbath, porcelain dishes, tripod. Laboratory burner. Test-tubes. Stoppered bottle. Platinum foil Vinegar. Distilled water. Hydrochloric acid.

\section{What to do.}

Action of water on chalk and lime.-Place in one dry saucer a lump of chalk, and in a second a lump of freshly-burnt lime. Sprinkle water on both lumps, and observe what happens. There is only a slight effect in the case of the chalk, but the piece of lime swells, eventually crumbles, and during the process gets very hot.

Lime takes up water which cannot be easily driz'en off.Place ten grams of chalk in one evaporating basin - the mass of which is known-and in a second basin of known mass weigh out ten grams of freshly-burnt quicklime. Add water as in the last experiment. After sufficient time for any changes which occur to become complete, place the basins in sandbaths and very carefully heat them till yuite dry. Deter- 
mine the mass of each basin and its contents by weighing, and observe that the chalk has undergone no change in mass, but the mass of the lime has considerably increased.

Chalk does not dissoli'e in water.-Into a stoppered bottle put a little powdered chalk, and half fill the bottle with distilled water. Shake together for ten minutes or so and filter the milky solution. Evaporate a little of the clear liquid on a piece of platinum foil. Notice that there is very little, or no, residue.

Lime dissolves in water.-Repeat the last experiment, but substitute freshly-burnt lime for the chalk. Observe in this case that there is a considerable residue on the piece of platinum foil.

Action of acids on chalk.--Place a little powdered chalk in a saucer, or evaporating basin, and add a clrop or two of vinegar (hydrochloric acid is better) to it. Notice the fizzing which occurs.

Acids cause no fizzing with lime.-Repeat the last experiment with freshly-burnt lime. There is no such fizzing. If the lime is not freshly burnt there will be a slight effervescence.

Gas produced by the action of acids on chalk.--Put some pieces of chalk or whiting into a test-tube or test-glass ; pour acid upon it. When the fizzing has continued for a short time, dip a burning match into the mouth of the tube. The flame will be extinguished.

\section{REASONS AND RESULTS.}

Chalk and lime.-When chalk or limestone is kept at a red - heat for some time in a kiln, as described in the last lesson, a very great change takes place in the properties of the solid after being so treated. If the solid is carefully examined before and after heating, and the behaviour of lime and chalk with water and acids observed, much can be discovered about their difference in properties.

Action of water upon lime.-When water is poured upon a little chalk a slight bubbling occurs, which is due to the escape of air bubbles. But when poured on a lump of freshly-burnt lime some remarkable changes occur. The lime begins to swell, getting larger and larger, until, by and by, it crumbles 
to pieces. During these changes the lime becomes very hot. It can often be seen to give off a quantity of steam. Whenever a change is accompanied by this heating of the materials concerned there is good reason to believe that the action is a chemical one, that is, the chemical nature of the substance used undergoes some change. You will soon decide, for other

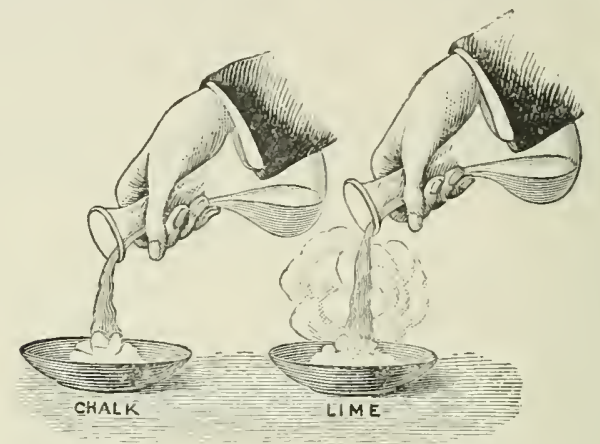

FiG. 22.-Different effects produced by pouring water upon chalk and lime.

reasons, that a chemical change occurs when water is poured upon lime. If you remember this experiment, and, the next time you get the opportunity, you watch bricklayers getting lime ready for making mortar, you will see that when large quantities of lime are acted upon by water, enough heat is developed to boil the water (Fig. 23).

Lime increases in mass when acted upon by water.-A better indication that a chemical change really takes place when water is poured upon lime is the increase in mass which it experiences. If quantities of chalk and lime, the masses of which are known, are acted upon with water as just described, and, after sufficient time has been allowed for any chemical changes which may occur to be completed, the solids are thoroughly dried, it is found, after again weighing, that though the mass of the chalk has undergone no cliange that of the lime is very much greater. The fact is, the lime has formed a new chemical substance by uniting with the water. This new compound is called slaked lime. The process of adding water to the lime, in the manner the bricklayers do, is called slaking it. 
Lime-water.-By shaking up some powdered chalk with distilled water in a stoppered bottle, filtering the solution, and evaporating some of the clear liquid on a platinum foil, it is easily proved that chalk will not dissolve in pure water. When, however, a similar experiment is performed with some freshlyburnt lime, a considerable residue is left on the platinum foil when some of the clear liquid is evaporated. Hence, you can be sure that lime is soluble to a certain extent in water. The solution formed is the lime-water, which is useful for many experiments.

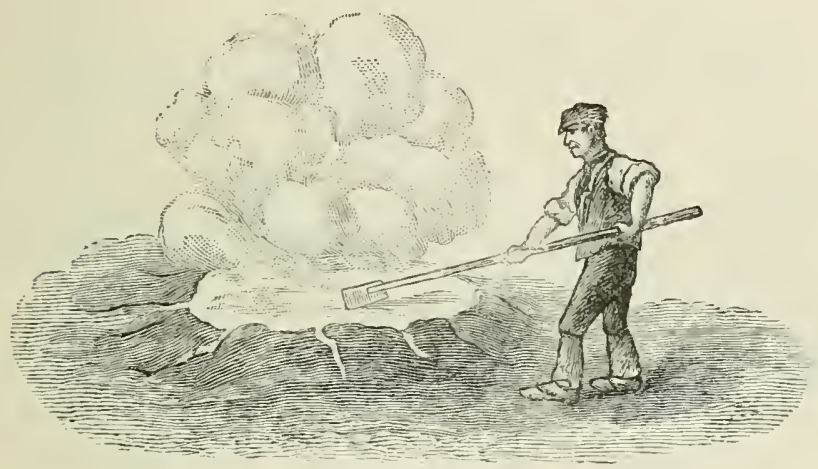

FIG. 23. -Slaking lime.

Action of acids on chalk and lime.-In studying the solubility of substances in acids (in one of the earlier lessons), you learnt that when marble is acted upon by an acid it fizzes very much or effervesces, as it is better called. At the same time it gradually disappears. What is true of marble is also true of chalk. When vinegar, which is an acid used for pickling things, is poured upon a piece of chalk, the chalk effervesces, and during the fizzing is dissolved. If hydrochloric acid is used instead of vinegar the bubbling is even brisker.

When, however, freshly-burnt lime is treated in the same way as the chalk, no bubbling is to be seen, though the lime gradually dissolves-especially if the acid is warmed.

What causes the fizzing? --If a piece of chalk is put into a test-tube and there acted upon by an acid, the flame of a lighted match put into the tube while the chalk is fizzing is extinguished. 
There is in the tube a gas which puts out the flame, and it is the escape of this gas which gives rise to the effervescence. So far you have learnt to recognise two gases which extinguish a flame, and one of these you know by the name of nitrogen. You may think, therefore, that nitrogen is given off when chalk and acid are brought together, but this is not true. The gas is another gas altogether, and you will learn later how to distinguish it from nitrogen.

TO BE REMEMBERED.

When chalk is strongly heated in a kiln it is changed into quicklime, the properties of which are unlike those of chalk, thus:

LIME.
Dissolves in water forming " lime-
water."

Absorbs water with great increase in temperature, and this water is not driven off by heating, but combines with the lime and produces an increase in mass.

When an acid is poured upon it fizzing does not take place.
CHALK.

Will not dissolve in pure water.

Is only wetted by water, and on heating, the water is again driven off.

When an acid is poured upon it fizzing takes place, a gas escaping from the chalk.

\section{ExERCISE X.}

I. Describe carefully what takes place when water is poured upon a piece of quicklime.

2. How would you prove that lime is soluble and chalk insoluble in pure water?

3. When water is poured upon quicklime we believe that they unite together. What are the reasons for this belief?

4. Describe what happens when an acid is poured on limestone; and give reasons for the occurrence.

5. If a piece of white stony-looking material were given to you, how would you discover whether it was chalk or lime? 
STUDY OF THE ACTION OF HEAT ON CHALK. 63

\section{LESSON XI.}

\section{FURTHER STUDY OF THE ACTION OF HEAT ON CHALK.}

PRACTICAL, WORK.

Things required.-.-Platinum foil. Chalk. Laboratory burner. Foot blowpipe, or muffle furnace if possible. Balance and weights. Crucibles and crucible tongs.

\section{What to do.}

Effect of heating chalk.--Repeat the experiment of heating a small amount of powdered chalk upon a piece of platinum foil. Recall to mind what has been learnt about the change into quicklime.

Loss of mass when chain is heated.-Very small amounts of chalk can be completely converted into quicklime by heating them in a porcelain crucible over a good laboratory burner. If this is the only apparatus available, a rough quantitative experiment is all that you will be able to accomplish.

Under these conditions find the mass of the porcelain crucible by weighing, and then add about half a gram of precipitated chalk. Determine the mass of the added chalk by weighing. Heat the porcelain crucible in the flame of the largest laboratory burner you have for about half an hour. Allow the crucible to cool, and again determine the mass. Heat again for another ten minutes, allow to cool, and again weigh.

Proceed to make the following simple calculation by proportion : If the mass of chalk taken, when continuously heated for some time, loses in mass to the extent noticed, what would 100 grams lose in the same circumstances?

Conversion of chalk into lime.-But, if possible, the heating of chalk should be done either in the flame of a foot blowpipe or better still in a muffle furnace (Fig. 24). Find the mass of your crucible by weighing: add about 2 grams of powdered chalk and again weigh. Heat in the muffle furnace 
at a bright red heat for an hour or so, allow it to cool, and again weigh. As before explained, calculate the loss of mass which Ioo grams of chalk would experience if treated in the same way.

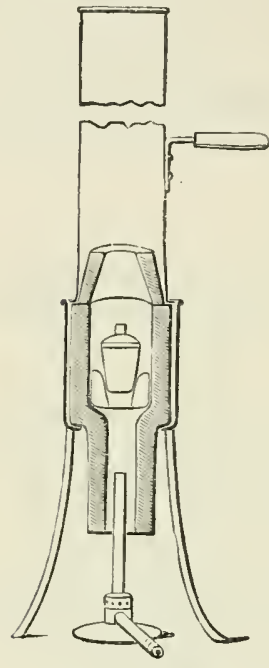

Fig. 24.-Muffle furnace suitable for converting chalk intolime. (Made by Mliessrs. J. J. Griffin \& Sons, Ltd.)

If a foot blowpipe or furnace is not available, the crucible after being heated for some time over a laboratory burner, may be put upon a very clear hot fire. It must be carefully transferred with crucible tongs, and before the second weighing, carefully wiped on the outside.

\section{REASONS AND RESULTS.}

Changes in mass when chalk is heated. That chalk does undergo a cha jo when heated you have already learnt in a previous lesson. But by studying the changes in mass which take place when chalk is strongly heated several important conclusions are arrived at. To obtain satisfactory numerical results it is desirable to heat a fair amount of powdered chalk in a muffie furnace, though a very small quantity of chalk can be completely converted into quicklime when heated in a good laboratory burner. After heating the chalk in a crucible in a muffle furnace for about an hour the crucible is taken out, allowed to cool again, and then reweighed. This plan is continued until there is no further loss of mass on reheating. A simple proportion sum will now show how much 100 grams of chalk would lose if heated strongly, seeing that a given mass of chalk loses the amount noticed.

An actual experiment.-Here is the result of an experiment carried-out in the way described.

Mass of crucible and chalk,

Mass of crucible alone, .

$17{ }^{\circ} 8_{3}$ grams.

Therefore mass of chalk $15^{\circ} 243$ " 
STUDY OF THE ACTION OF HEAT ON CHALK. 65

Mass of crucible and quicklime, . $16+50$ grams.

Mass of crucible alone, . . . $15 \cdot 243$,

Therefore mass of quicklime, . 1'207 ",

Loss of mass of chalk, . $=2 \cdot 140-1^{* 207}=0^{\circ} 933$ gram.

From the result thus obtained, the loss of mass of 100 grams of chalk when heated can be calculated by proportion as follows :

$2^{*} 1$ to grams of chalk lose in mass when heated $0 * 933$ gram.

Therefore I gram loses in mass when heated $=\frac{0^{*} 933}{2^{*} 140}$ gram.

And 100 grams lose in mass when heated $=\frac{0^{\circ} 933}{2.140} \times 100$

$$
=\frac{93^{\circ} 3}{2^{\circ} 14}=43^{\circ} 6 \text { grams. }
$$

Percentage loss of mass of chalk when strongly heated.Whenever chalk or limestone-no matter from what locality-

BEFORE BURNING

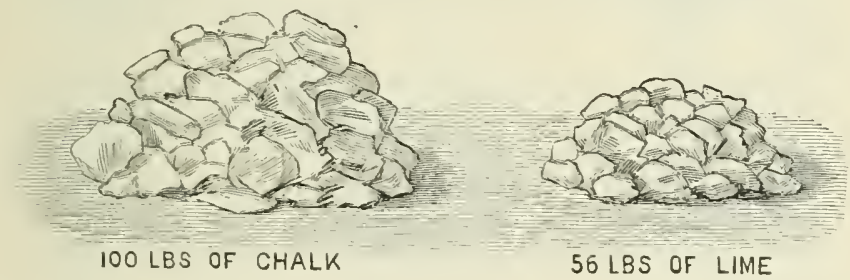

FiG. 25. - When roo lbs. of chalk are heated, $56 \mathrm{lbs}$, of lime are produced.

is strongly heated in a kiln or in a laboratory furnace, it loses about 44 per cent. of its mass, as shown in the above experiment. That is to say, 100 grams, or pounds, or tons, of chalk lose 44 grams, or pounds, or tons, in mass when strongly heated. But as you have learnt before, this loss in mass is due to the escape of a gas which puts out flames and which is called carbon dioxide, so that we may say that, when 100 grams of chalk are strongly heated, 44 grams of the gas, carbon dioxide, are driven out and 56 grams of quicklime are left behind. 
TO BE REMEMBERED.

When chalk is heated in a crucible over a foot blowpipe, or in a muffle furnace, it undergoes a decrease in mass.

The exact decrease may be ascertained by first finding the mass of the crucible, putting in some powdered chalk, and by weighing again. The second result minus the first gives the mass of the chalk. Heat the crucible strongly until there is no further decrease in mass. The decrease in mass after the heating tells the loss which the chalk suffers.

100 grams of chalk on heating are found to yield 56 grams of lime and 44 grams of a gas known as carbon dioxide.

\section{EXERCISE XI.}

1. Knowing that chalk consists of lime and a gas which puts out flames, how would you set to work to find out the amount of the former in a lump of chalk given you?

2. A sample of chalk yielded 132 grams of quick-lime when strongly heated ; what was the mass of the sample taken?

3. Calculate the mass of lime and carbon dioxide respectively in a cwt. of chalk.

4. Of what substances does chalk consist? Give full reason for your answer. Give the names of substances having a similar composition to chalk.

5. Limestone is carted from a quarry to a limekiln, where it is converted into lime. The limestone used, and lime produced, are weighed. What is the result, and why?

6. How many cwts. of lime could be obtained from roo cwts. of limestone if heated sufficiently in a limekiln?

7. When limestone is strongly heated it becomes lighter. How do you account for this? 


\section{LESSON XII. \\ ACTION OF ACIDS ON CHALK.}

PRACTICAL WORK.

Things required.-Vinegar, suiphuric acid, hydrochloric acid. Pieces of chalk, marble, limestone, oyster shells. Powdered calcite or percipitated chalk. Balance and weights. Testtubes. Apparatus as in Fig. 26.

\section{What to do.}

The gas produced by the action of acid on chalk.-Place in different test-tubes pieces of chalk, limestone, marble, and oyster shell. Upon each of the solids pour a little vinegar. Observe the bubbling. After a minute or two test the gas in each tube with a lighted match. In every case the flame is extinguished.

Substitute, in turn, for the vinegar in the last experiment (I) hydrochloric acid, (2) dilute sulphuric acid. Notice the same results as before.

Loss of mass when an acid acts on chalk.-Into a flask $A$ (Fig. 26) fitted with india-rubber stopper and tubes, as shown, pour some dilute hydrochloric acid, and weigh the flask with the contained acid. Weigh a small test-tube $B$ (i) empty (ii) with some chalk in it. Place this in the flask, taking care not to allow the acid to reach the inside of the tube. Re.place the cork and shake the flask so as to allow the acid and chalk to

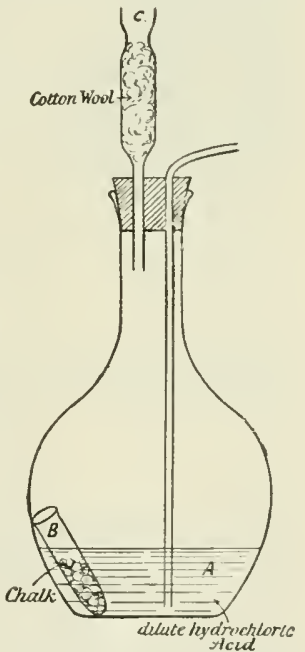

FIc. 26.-When the chalk in $B$ is acted upon by the acid in $A$ it loses 44 per cent. of its mass. come in contact with one another. The gas (carbon dioxide) formed escapes through the tube $C$, in which cotton-wool is packed to prevent the escape of moisture. When the action 
is at an end draw a current of air through the flask by sucking the tube $C$, in order to displace the gas still left inside. Weigh the flask again, and subtract the mass so obtained from that of the flask + mass of tube and chalk. The resulting number is evidently the mass of the gas evolved. Calculate the loss of mass for 100 grams of chalk

If the experiment is repeated several times, or done independently by different students, the results obtained may be added together and

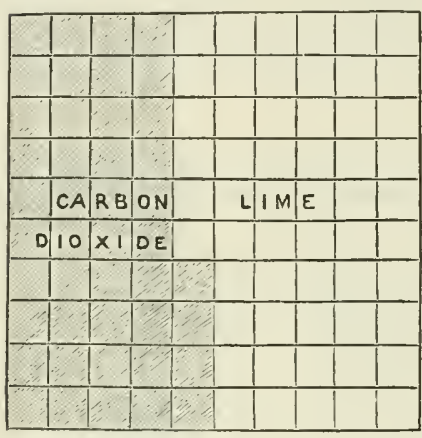

Fig. 27.-Chalk consists of 56 per cent. of lime and 44 per cent. carbon dioxirle. divided by the number of experiments, in order to obtain an average result. It will be found that 100 grams of chalk lose about 44 grams of gas when acted upon by an acid.

Graphic representation of the proportion of gas and lime in chalk.--Construct on paper a square, each side of which is one decimetre long Divide the whole into 100 square centimetres. Shade 44 of these. The shaded portion represents graphically the percentage of carbon dioxide in chalk, the unshaded portion the percentage of quicklime.

\section{REASONS AND RESULTS.}

Action of acids on chalk. - Whenever vinegar, or one of the common acids, such as hydrochloric or sulphuric acids, is poured upon chalk, a brisk effervescence takes place and the chalk is gradually dissolved. The same results are obtained if substances having the same chemical composition as chalk, viz. limestone, marble, oyster shells, or calcite, are treated with acids. The fizzing is, as you have before learnt, due to the escape of a gas which cxtinguishes flames.

A test for chalk and limestone.The geologist, or man of science who examines and studies rocks, makes use of this experiment to discover whether rocks are limestones or not. 
Some limestones are black and not easily recognised by the eye. But if, when a little acid is dropped upon them they fizz like the chalk in a test-tube does when acid is poured on it, the geologist can be finirly sure, even if they are black, that they are limestones all the same.

Changes in mass when acids act upon chalk. - If a certain mass of chalk or limestone is weighed, and an acid is then allowed to act upon it until no more gas is given off, it is found that the chalk always loses mass in a given proportion. When Ioo grams of chalk are treated with enough acid to expel all the gas which puts out a flame, the loss in mass is always 44 grams. Now, as none of this gas is given off when acids come into contact with quicklime (the substance which is left when chalk is strongly heated), the conclusion which must be come to is that quicklime contains none of it, and that strong heat acts in the same way as the acid in expelling the gas. The loss of 44 grams in mass therefore tells you that 100 grams of chalk contain 44 grams of the gis which puts out flames, and called carbon dioxide ; and the experiment of strongly heating chalk leads you to believe the remaining 56 grams are quicklime, or that

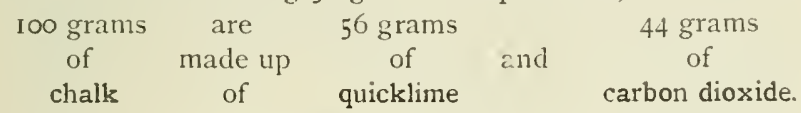

Action of acids and of heat on chalk compared. - These results are of such great importance that it is worth while to look at them in another way to try to thoroughly understand them. You have learnt that 100 grams of chalk when strongly heated lose in mass and give $; 6$ grams of quicklime. Also, when 100 grams of chalk are acted upon by acids there is a loss of mass too, and 44 grams of an invisible gas, which puts out flames, are given off, and this gas turns blue litıus red.

To prevent repetition this gas will in future be referred to by the name chemists have given it, namely carbon dioxide.

But by adding 56 and $4+$ together the result is exactly Ioo, and it looks as if the quickline and carbon dioxide together make up chalk. Since you will sce in a later lesson that chalk can actually be made from the combination of these two compounds, there need be no room for doubt, and it may be written as a fact, that 
TO BE REMEMBERED.

Chalk, limestone, marble, calcite, and oyster shells have the same composition; and when a dilute acid is pouled upon them they gradually dissolve, giving off a gas which extinguishes a flame.

When chalk is treated with acid, it is found by weighing that every IOO grams lose 44 grams of carbon dioxide, but if strongly heated the same mass yields $5^{6}$ grams of quicklime. These numbers suggest that chalk consists of 44 per cent. of carbon dioxide and $5^{6}$ per cent. of quicklime.

\section{ExERCISE XII.}

I. If a pebble were given to you, how could you discover whether it was limestone or not?

2. Powdered marble is slowly sprinkled into a beaker, the bottom of which is covered with dilute hydrochloric acid. State carefully what happens, proving what you say by experiment where possible.

3. Into a beaker containing dilute acid, 5 grams of whiting are placed. Before adding the whiting the mass of the beaker and acid is ascertained. What will be the increase in mass after the whiting has been added and the fizzing has ceased? Give reasons fully.

4. What happens when chalk is exposed to great heat? Describe a different method of obtaining one of the products.

5. How could you show that oyster shells are similar in composition to the "fur" from a tea kettle?

\section{LESSON XIII.}

\section{STUDY OF THE GAS OBTAINED FRON CHALK.}

\section{PRACTICAL WORK.}

Things required.-Apparatus as in Fig. 28 for the preparation of carbon dioxide. Several cylinders or jars with wide necks for collecting the gas. Candle on a wire. Lime-water. Marble in small pieces, or chalk. Blue litmus. Hydrochloric acid. Apparatus shown in Fig. 3I.

\section{What to do.}

Preparation of carbon dioxide.-Into a flask or bottle fitted like that in Fig. 28, place some chalk, or better, small pieces, 
of marble. Place the delivery tube in a glass cylinder, or a jar with a wide mouth. A disc of cardboard through which the delivery tube passes rests on the top of the jar. Pour dilute hydrochloric acid down the fumnel. During the effervescence gas is given off and collects in the jar. When a burning taper is extinguished immediately it enters the jar, take out the delivery tube and put it into another jar. Cover the first jar of gas with a disc of card. In the same way collect several jars of the gas.

Properties of carbon dioxide. -Notice that the gas is (1)

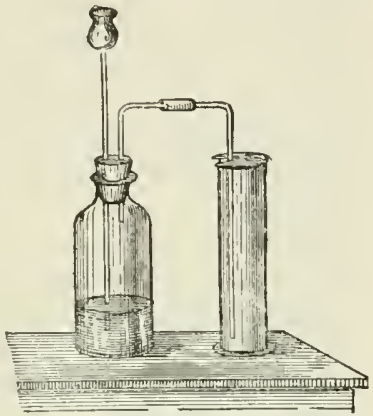

Fic. 28. - Apparatus for producing and collecting carbon dioxide gas. invisible, without taste or smell; (2) that it extinguishes a. lighted taper ; (3) that it must be heavier than air or it could not be collected in the way described.

Carbon dioxide is heavier than air.-Take a jar of carbon dioxide and a jar containing air. Hold the mouth of the

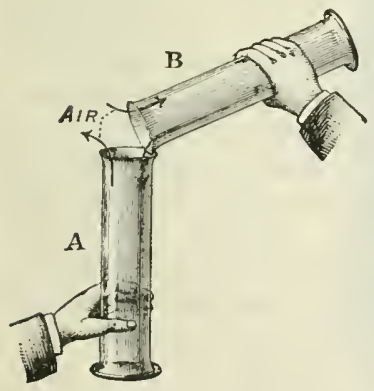

F1G. 29. - Carbon dioxide gas is heavier than air, and can therefore be poured from $B$ into $A$, like a liquid.

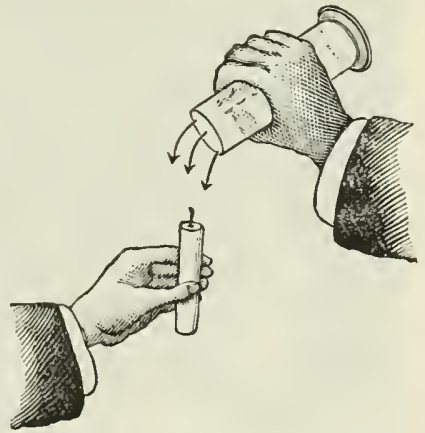

FIG. 30.- The flame of a taper is ex. tinguished when carbon dioxide is poured upon it.

former over the mouth of the latter as shown in Fig. 29, so as to pour the carbon dioxide from $B$ into the jar $A$. Afterwards test the gases in the jars by means of a lighted taper. The 
lower jar $A$ will be found to contain the gas which put out the flame.

Hoid a small lighted candle in one hand and a jar of carbon dioxide gas in the other. Pour the gas over the flame, and notice that the light is extinguished.

Acid solution formed by carbon dioxide.... Pour a little water made blue with litmus into a jar of the gas and shake it up. Some of the gas dissolves, and the colour of the solution turns red.

Action on lime-water.-Pass the gas from the delivery tube through some lime-water. Observe that a milkiness is produced, owing to the production of a white powder or precipitate, which disappears after a short time.

Boil the solution thus obtained, and notice that the milkiness again appears.

Filter the milky solution, and so obtain the white powder on a filter paper. Add a few drops of dilute hydrochloric acid to the powder. Notice the effervescence. Test the gas which is given off; it puts out a flame.

Carbon dioxide produced by fermentation.--Fit up a large flask with a well-fitting cork through which passes a piece of

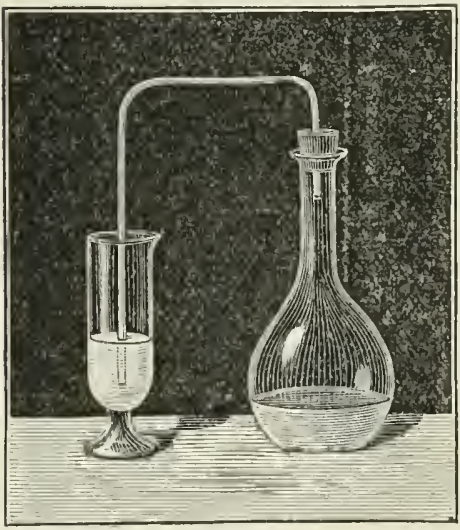

FIG 31.-Carbon dioxide is produced when sugar ferinents in the flask. glass tubing bent twice at right angles, Fig. 31 . Dissolve a handful of sugar in some tepid water, and put it into the flask with some yeast. Arrange the tube so that one end of it dips into lime-water contained in a test-glass as shown in Fig. 31 . Allow the whole to stand some time. The lime-water turns milky. Fermentation takes place in the flask, and carbon dioxide is given off. To keep the carbonic acid gas in the air from the lime-water it will be best to cover the top of the 
test-glass with a piece of cardboard, the delivery tube passing through a hole in its centre.

\section{REASONS AND RESULTS.}

Preparation of bottles of carbon dioxide. - The best way to prepare bottles or jars of the gas which puts out flanes is to make use of the fact that the gas is given off when acids act upon chalk, limestone, or marble. All that is wanted is a convenient means to collect the gas produced. A good way to do this is to place pieces of marble about the size of peas into a bottle fitted like that in Fig. 28. Dilute hydrochloric acid is poured down the thistle funnel, and when it comes into contact with the marble, the gas is given off. Enough acid is poured in to cover the bottom of the funnel, so the gas cannot escape up the funnel; and it passes through the other tube in the cork. The gas collected is heavier than air, and can therefore be collected as shown in Fig. 28. As the gas accumulates in the jar, the air is pushed out at the top. After several bottles or jars have been filled, the properties of the gas can easily be examined.

Properties of carbon dioxide.-An examination of the gas shows that it is colourless and has no smell. As it is heavier than air it can be poured downwards just like a liquid ( $s e c$ Fig. 29.)

Carbon dioxide is slightly soluble in water, and the solution which is thus formed turns a blue litmus paper red, just as you have learnt acids do. For this reason the solution of carbon dioxide in water is often called carbonic acid, and the carbon dioxide itself is sometimes spoken of as carbonic acid gas. In naming the properties of this gas you must not forget that one which has been so frequently mentioned, namely; that it puts out the flame of a taper or match, and is consequently called a non-supporter of combustion. The action of carbon dioxide on lime-water is so important a property that it deserves a separate paragraph.

Action on lime-water.-If carbon dioxide is passed from the delivery tube of an apparatus generating it into lime-water a milkiness is seen, but if the experiment is continued the milkiness by and by disappears. If the clear solution which results after the disappearance of the white powder or precipitate is 
boiled, the milkiness again makes its appearance. The reason of this is that the white substance of which the precipitate is formed dissolves in water which has become saturated with carbon dioxide. When the clear solution, which appears after the solution of the powder, is boiled, the carbon dioxide is driven out of it, and the liquid again becomes pure water. The precipitate reappears because it will not dissolve in water. This explanation should be kept in mind, because it explains many facts about natural waters which will be dealt with in later lessons.

The chemical change when carbon dioxide is passed into limewater.-What are the facts taught by the experiments described? When an acid is added to the white powder which is formed when carbon dioxide is passed into lime-water, a brisk efferrescence is noticed, and the gas which is given off is found to put out a flame. But this is just what happens when the acid is dropped on to chalk. You are consequently led to believe that carbon dioxide gas combines with the lime in the lime-water to form chalk. In other words, the cliange which takes place when carbon dioxide is passed into lime-water is just the opposite to that which occurs in a limekiln where chalk is split up, by heat, into lime and carbon dioxide.

In this case you have seen that

$$
\text { Chalk splits lime and carbon dioxide ; }
$$

and in the experiment with lime-water you have seen that

Carbon unites lime to
dioxide with form chalk.

Uses of carbon dioxide. - The fact that carbon dioxide is a non-supporter of combustion is made use of in many forms of chemical fire extinguishers, which are generally solutions which on heating evolve carbon dioxide. As burning cannot take place in this gas, the flames are therefore extinguished when the gas reaches them.

The solubility of carbon dioxide in water is increased by pressure, and the sparkling nature of the various aerated waters, like soda-water, is due to the carbon dioxide with which they have been charged at high pressures, and which escapes when the pressure is reduced to that of the atmosphere by the opening of the bottle (Fig. 32). As the pressure is very great, the bottles have to be very thick. 
Carbon dioxide is also produced during fermentation, and in the "rising" of bread. The rising is due to the escape of carbon dioxide generated by the fermentation of the sugar formed from the starch in the flour under the influence of the yeast.

By cold and pressure carbon dioxide gas may be changed to a liquid, and also solidified, forming a soft white substance something like snow, which when mixed with ether forms a powerful freezing mixture, the temperature sinking to about $-100^{\circ} \mathrm{C}$.

\section{To be Remenbered.}

Carbon dioxide, also called carbonic acid gas, may be obtained in large quantities by acting upon chalk or marble with hydrochloric acid.

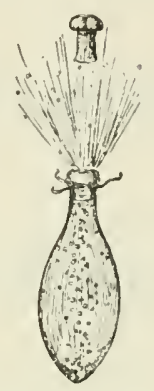

Fig. 32.
escaping The gas dioxide.

Properties of carbon dioxide. - It is a gas which

is colourless, odourless, transparent, much denser than the air, and therefore can be poured downwards. It will not burn, and a lighted taper will not burn in it. It turns blue litmus red, and when passed through lime-water, the latter becomes milky.

When carbon dioxide is passed into lime-water, the liquid at first becomes milky, particles of chalk being formed in it; but as the water becomes saturated with the gas this chalk is again dissolved. On boiling, the chalk reappears as the carbon dioxide is driven out of the water.

\section{Chalk consists of lime and carbon dioxicie.}

By intense cold and great pressure carbon dioxide gas may be converted into a liquid, or into a snow-like solid.

\section{EXERCISE XIII.}

I. Describe the apparatus you would use for the preparation of carbon dioxide.

2. How would you collect some of the gas without a pneumatic trough? Could hydrogen be collected in this way?

3. If hydrogen is being collected without a trough, why do you not collect it in the same way as carbon dioxide?

4. Write all you know about the properties of carbon dioxide.

5. How would you show that chalk consists of lime and carbon dioxide?

6. Describe, with sketch, experiments which prove that carbon dioxide is denser than air. 


\title{
LESSON XIV.
}

\author{
FURTHER STUDY OF THE ACTION OF ACIDS ON \\ METALS AND CARBONATES.
}

\section{PRACTICAL WORK.}

Things required.--Test-tubes, wide-mouthed bottles or deep cylinders. Iron filings or iron tacks. Hydrochloric acid. Taper. Sulphuric acid. Washing soda. Apparatus for carbon dioxide as shown in Fig. 28. Seidlitz powder. Baking powder. Oyster shells. Lime-water.

\section{What to do.}

The action of hydrochloric and sulphuric acids on iron.Into a test-tube put some iron filings, iron tacks, or small nails. Pour on dilute hydrochloric acid. When effervescence has taken place for a short time apply a lighted taper to the mouth of the tube. The gas given off burns. What is it?

Perform a similar experiment, using sulphuric instead of hydrochloric acid.

The action of acids upon washing sodu.-Set up apparatus as shown in Fig. 28. Put into the bottle some washing soda,

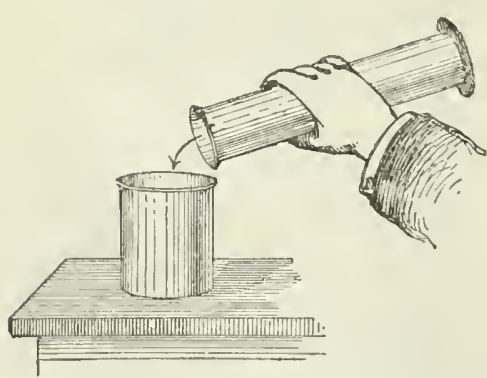

FIG. 33.-If carbon dioxide is poured into clear lime-water the lime-water turns milky. cover with water, and after corking pour a little acid down the thistle funnel. Examnine the gas which fills the jar. Apply a lighted taper to it. Plunge the taper into the gas. Pour lime-water into the jar. What gas is it?

The action of acids upon oyster shalls.Clean out the bottle, and into it put some

broken oyster shells, and repeat the last experiment. What gas do jou obtain? 
The action of water upon baking powder.-Obtain some baking powder; put a small quantity into the bottom of a deep beaker or cylinder and cover with water. Plunge a lighted taper into the jar. What gas is given off?

The gas from a Seidlits powider.-.Perform a similar experiment with a seidlitz powder if you can obtain one, or with the substance sometimes sold as "Kali" and examine the gas which comes off. What is it?

Put some lime-water into the bottom of a beaker, and incline towards it the cylinder which contained the powder, so that some of the gas will pass from the cylinder into the beaker (Fig. 33). Shake the lime-water. What happens?

\section{REASONS AND RESULTS.}

Hydrogen gas obtained from iron and acid.-When iron filings or small iron nails are put into a test-tube, and dilute hydrochloric acid or sulphuric acid is poured upon them, the result is much the same as when zinc is treated in a similar way. A gas is given ofe which at first ignites with a slight explosion, but soon burns quietly at the mouth of the tube. The iron acts upon the acid used in just the same way as zinc does, causing hydrogen to be liberated, and this is the gas which burns at the mouth of the tube. The unpleasant smell which accompanies the production of the gas is due to the presence of another gas formed by the action of the acid upon impurities in the iron.

Action of acids upon carbonates.--By substituting common washing soda for marble in the apparatus used for preparing carbon dioxide a supply of this gas can be obtained. As soon as a little acid is poured down the thistle funnel the gas comes off very briskly, and if collected either by displacement of air in a jar, or over water, it is found to have the same properties as the gas obtained from limestone.

But though washing soda and limestone both yield carbon dioxide, they are not made of exactly the same materials. It has several times been stated that limestone, marble, and similar substances, consist of calcium carbonate, or, as you have seen, of lime and carbon dioxide. Washing soda is called by the chemist carbonate of soda or sodium carbonate; it consists of carbon and oxygen conbined with sodium, and not with calcium as in limestone, but just as an acid liberates carbon dioxide from carbonate of lime, so the acid liberates the gas from carbonate 
of sodium or washing soda. When an acid and a carbonate are brought together this gas is almost always produced.

Other ways of producing carbon dioxide. - If you mix together the two substances forming a Seidlitz powder, and pour water upon them, fizzing rapidly takes place. If the experiment is carried on at the bottom of a deep cylinder, a lighted taper plunged into it is extinguished, and the escaping gas does not burn. If some lime-ivater be put into a beaker, and the cylinder be inclined over it, some of the gas will pass into the beaker, and on shaking the lime-water becomes milky.

Baking powder generally contains the same substances as a Seidlitz powder, and the gas coming from it may be tested in the saine way.

Everyone has noticed the holes in bread, to which its spongy character is due. These holes are produced by carbon dioxide gas. Sometimes yeast is mixed with the flour, and acts upon it, setting free carbon dioxide which is held by the dough, much as soap suds hold your breath when you blow a soap bubble. Very many bubbles are produced close together, and this accounts for the large number of holes in bread.

Baking powder is often used instead of yeast. This is mixed with the flour and gives off carbon dioxide which forms the bubbles in the bread, and makes the bread porous and light.

You will perhaps wonder how it is that in the case of baking powder and Seidlitz powders, effervescence is produced when water only is added. In this case an acid is used which exists in the solid state, and is mixed with another substance very much like washing soda, containing carbon dioxide. Adding water causes the acid to come into close contact with the substance containing the carbon dioxide, and to set the gas free.

To be Remembered.

When dilute sulphuric or hydrochloric acid acts upon iron, hydro gen is given off, but not so briskly as when these acids act upon zinc.

Carbon dioxide may be obtained from washing soda by the action of dilute acid upon it.

Carbon dioxide is given off from many substances which effervesce on the addition of water, as in the case of Seidlitz powder, baking powder, "kali," etc. In these substances an acid is present which acts only when water is added.

Aerated waters are generally highly charged with carbon dioxide. 


\section{EXERCISE XIV.}

I. If you wish to prepare hydrogen gas, what substances might be used? State which substances you consider best, and give reasons why they are best.

2. What is the use of baking powder? Describe an experiment which shows the nature of the gas given off from it.

3. From what substance other than limestone or marble can carbon dioxide be prepared?

4. How would you show that the gas given off when an acid acts upon marble, is the same as that given off when an acid acts, upon washing soda?

5. Washing soda is called "carbonate of soda" by chemists. Do you know why?

6. By what experiment would you show that aerated waters are charged with carbon dioxide?

\section{LESSON XV.}

\section{BURNING AND BREATHING.}

\section{PRACTICAL WORK.}

Things required.-Several glass cylinders or bottles. Piece of glass tubing with lower end bent like letter $J$ for burning coal gas in cylinder. Candle on wire. Lime-water. Tube to blow through. Laboratory burner. Apparatus as shown in Fig. 37.

\section{What to do.}

Carbon dioxide is produced by a burning candle.- Repeat the experiment of burning a candle or taper in a clean dry white bottle (Fig. 34). After the flame has been extinguished, withdraw the taper. Pour a little freshly made lime-water into the bottle and shake it up. Notice the milkiness of the lime-water.

Carbon dioxide is produced when oil, gas, or wood burns.Do similar experiments with a small oil lamp and a gas jet (Fig. 35). Test the gas which is left in each case with limewater. Observe the milkiness produced.

Cut a long thin chip of wood, hold it in the flame of a laboratory burner until it burns brightly, then thrust it into a 
cylinder or bottle, the bottom of which is covered with limewater to the depth of about an inch. When the stick ceases to burn, withdraw it and shake the lime-water.

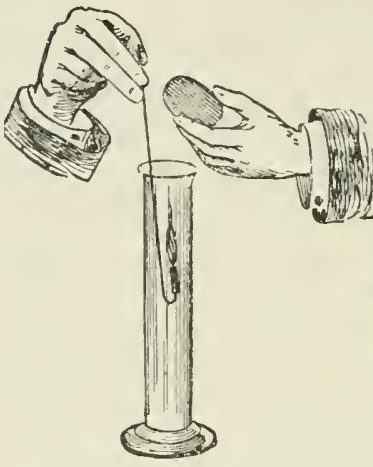

FIG. 34.-Carbon dioxide is produced when a taper burns.

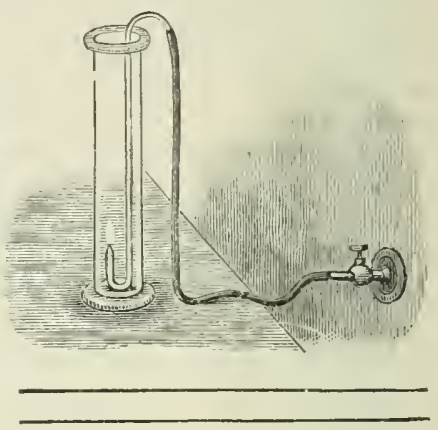

FIG. 35.-Carbon dioxide is produced when ordinary gas burns.

Air after being breathed contains carbon dioxide.-Blow through a piece of glass tube into some clear, freshly-made lime-water contained in a wineglass or tumbler. Milkiness

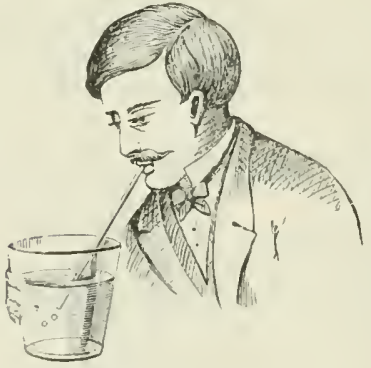

Fig. 36.-Carbon dioxide brea.hed ont from the lungs will turn clear limewater milky: is at first produced, but if the blowing is continued long enough it by and by disappears.

Fill a jar with water and invert it in a basin of water. Blow air from your lungs into the jar by means of a tube. When the jar is full of air place a disc under it and lift it out of the water. Show that the air will extinguish a lighted taper.

Repeat the two preceding experiments by blowing air from a bellows instead of from the lungs. Notice that this unbreathed air has not the same effects upon a lighted taper or lime-water as breathed air. 
The air contains carbon dioxide.--Pour some clear limewater into a blue dinner plate, or some other shallow vessel of a dark colour. Leave it exposed to the atmosphere for a little while. Notice the thin white scum formed on the top. The carbon dioxide in the air has turned the top layer of liquid milky.

Breathing changes the character of air.-Fit two bottles with corks and tubes as shown in Fig. 37. See that the corks are air-tight. Put some clear lime-water into each bottle. Place the tube $C$, or an india-rubber tube leading from it, in your mouth. When you suck at the tube air is drawn in through the glass tube which dips into the limewater in the bottle $A$. When, however, you blow instead of sucking, your breath passes out through the tube which dips into

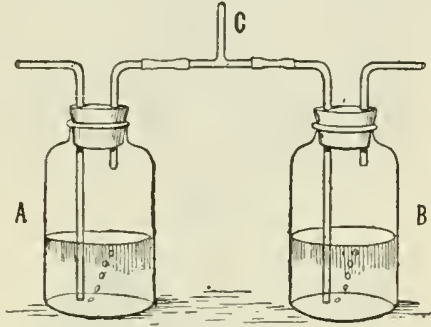

FIG. 37.- Air drawn into $A$ does not turn lime-water milky, but when blown through $B$ from the lungs the lime-water in $B$ is turned milky.

the lime-water in the bottle $B$. Notice that the lime-water in $A$ remains clear, but that in $B$ is rendered milky by the air you breathe out. You thus see that fresh air has little or no effect upon lime-water, but breathed air quickly turns clear limewater milky.

\section{REASONS AND RESULTS.}

Burning.-When things such as candles, oil, gas, and wood are burnt either in the air or in pure oxygen, a gas is produced which has the power of turning lime-water milky. All these substances contain, in one form or another, a substance called carbon. As you have seen in previous lessons the gas, produced when these substances burn, is carbon dioxide. In fact, whenever a substance rich in carbon burns in a plentiful supply of air or oxygen, this carbon dioxide is produced. Knowing how many fires there are, in all civilised countries, in houses, furnaces, engines, and so on, it is not difficult to understand that at every hour of the day very large quantities of this carbon 
dioxide are formed. A moment's thought will tell you this gas always escapes, sooner or later, into the air.

Carbon dioxide is given off in breathing.-If a person blows with the mouth into clear lime-water the lime-water is turned milky. This is another important fact. It is clear that carbon dioxide escapes from our mouths in breathing. And so it does from every animal. Not only, then, do all cases of ordinary burning result in the addition of carbon dioxide to the air, but also every act of breathing. It does not matter how small the animal is, all the time it is alive it is continually adding to the atmosphere a certain amount of the gas which puts out flames.

Chemical combustion in the body.-As carbon dioxide is produced in breathing, you may already have arrived at the conclu-

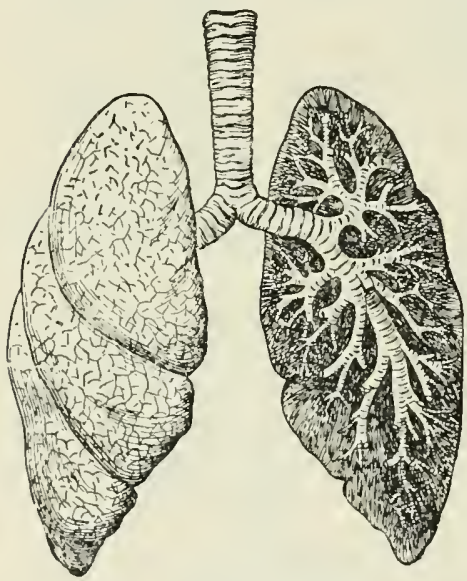

FIG. $3^{8}$ - Wind-pipe and lungs. The right-han 1 lung has been cut to show the branching tubes. sion that carbon and oxygen unite together in some way in the body to produce this gas. What really happens is something like this. When you draw air into your mouths, the mixture of oxygen and nitrogen of which the air is composed, passes down the wind-pipe into the lungs inside your chests. The lungs, which are like the "lights" or lungs of animals to be seen at the butcher's, are two spongy masses which take up a large part of the chest (Fig. 38). They contain throughout a very large number of little air spaces with very thin walls ( $F$ ig. 39). All over these thin walls tiny blood-vessels are spread, and the walls of these are also very thin. The oxygen of the air passes through these thin walls into the blood. The blood carries the oxygen to every part of the body.

Whenever you lift an arm, move a leg, or use any muscle, part of the substance of the muscle is used up or burnt. It joins with the oxygen in the blood. The muscle contains, 
with other things, hydrogen and carbon. The hydrogen of the muscle unites with the oxygen brought by the blood to form water; and the carbon of the muscle combines with some more of this oxygen to form carbon dioxide. These waste products, water and carbon dioxide, are taken away from the muscles by the blood, which is always in motion, to the lungs. Here the carbon dioxide is given up and passes, with nitrogen and air which you breathe out, back into the atmosphere.

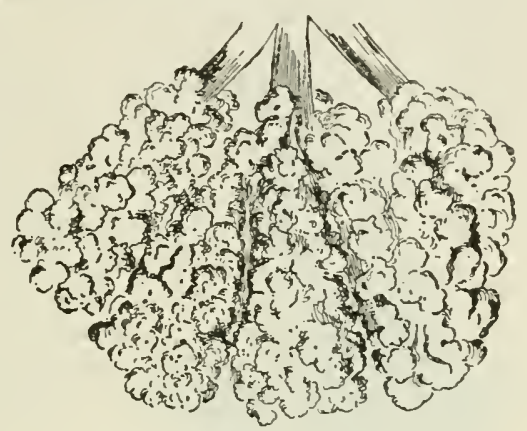

FIG. 39.-Air cells in a piece of lung.

Similar changes take place when you use your brain. You cannot think without using up part of your brain. 1t, too, combines with the oxygen brought to it by the blood.

These facts explain why we require our meals. After your muscles or your brain have been used for a certain time you begin to feel hungry. That means something is required to rebuild the used-up muscle and brain. You take food, and this, after undergoing wonderful changes of which you will some day learn, supplies the blood with material which it carries oft to the muscle or brain to repair them. But besides repairing waste the food is also the source of ihe body's warmth. As you know, when chemical action takes place heat is dereloped, and it is the heat formed in this way which warms the body.

Breathing of other animals. - What is true of boys and girls, and men and women, is equally true of every animal which possesses lungs. They all breathe in air containing oxygen, and breathe out air containing carbon dioxide.

Carbon dioxide in the air.-You will now understand how it is that the air always contains some carbon dioxide. Every case of ordinary burning and the breathing of every animal adds a certain amount of this gas to the atmosphere. But there is never very much of this carbon dioxide to be found in the air out of doors. The reason for this will be the subject of the next lesson. You will learn that carbon dioxide not only extinguishes 
flames, but also prevents the continued life of animals, for these die in the gas. Unless, therefore, some process was constantly at work getting rid of the carbon dioxide all animals would eventually be unable to live.

Dangers of carbon dioxide. - The proportion of carbon dioxide in pure air is three or four parts in ten thousand; that is to say,

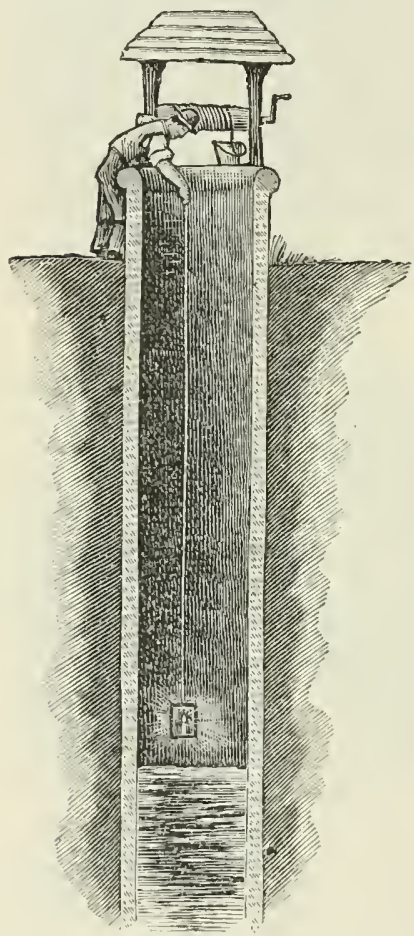

Fir. 40.--Workmen often lower a lighted candle into an old well before descending, in order to test if carbon dioxide is present in too large a proportion for safety. in ten thousand cubic feet of air there are three or four cubic feet of carbon dioxide. If the air of a room contains as much as six parts in ten thousand of carbon dioxide, it appears "stuffy" or " close" to a person coming into it from the outside, and if it contains a greater proportion it is unfit to breathe. This shows you the importance of a good supply of fresh air to a room in which there are a number of persons and of gas-lights, using up the oxygen and producing carbon dioxide.

A dreadful instance of the effect of impure air upon life occurred many years ago in India, when I 46 Englishmen were shut up for a night in a closed room about twenty feet square, having only one or two small windows. In the norning, 123 were found dead in this "Black Hole of Calcutta," as the room was afterwards called, and the survivors were so changed by the awful night of struggle for air and water that they did not know one another.

Old wells and cellars frequently contain too large a proportion of carbon dioxide to permit any one to descend into them with safety. In breweries, also, carbon dioxide accumulates at the 
bottom of the large tubs or "vats" in which fermentation has taken place. Many workmen have lost their lives by descending into vats containing carbon dioxide. To test whether the air in such places is fit to breathe, a lighted candle is usually lowered into them. If the candle burns just as brightly as in the open air, it may be concluded that the place is safe to enter, but if it becomes dim in the slightest degree the air is not fit to breathe. A candle will burn in air containing ten or twelve per cent. of carbon dioxide, but four or five per cent. of carbon dioxide in air is sufficient to cause death. The candle test of purity of air is, therefore, not entirely to be depended on.

In some parts of the earth, a large quantity of carbon dioxide issues from the ground and often causes death to animals which breathe it. Death's Gulch, Yellowstone Park, California, is a place of this kind. Grizzly bears are frequently found suffocated to death in this valley.

\section{To be Remembered.}

Carbon dioxide. - When candles, gas, wood, or any substance which contains carbon burns in the air or oxygen, carbon dioxide is formed. This gas is also given off in the breath of animals. From these sources large quantities are continually passing into the atmosphere.

Breathing is really a kind of burning; for the oxygen taken into the body by the lungs unites with the carbon in the body to form carbon dioxide, and with the hydrogen to form water, these products being expelled from the body partly in breathing.

Carbon and hydrogen form a large portion of our food, which, after becoming a part of the substance of the body, are burned up and carried away by the blood to be again removed from the body.

Air containing more than six parts of carbon dioxide in ten thousand is unfit to breathe.

\section{EXERCISE XV.}

1. How would you show that the air you breathe out contains more carbonic acid than pure air?

2. What are the various ways in which carloon dioxide gets into the atmosphere?

3. How would you show that, when coal gas burns, the same substance passes into the air as when you breathe?

4. Describe as fully as you can what becomes of the oxygen taken into the lungs. 
5. When would you expect a man to breathe out most carbonic acid gas, when sitting still or when working hard, and why?

6. Clear lime-water is left in an unstoppered bottle, what happens and why?

7. Why is it dangerous to descend into an old well or mine which has not beeen rentilated?

\section{LESSON XVI.}

\section{CARBON DIOXIDE IN THE AIR.}

\section{PRACTICAL WORK.}

Things required.-Spring water or water saturated with carbonic acid gas. Fresh watercress. Test-tubes. Basin of water. Splinters. Glass jar. Large funnel. Green leaves. Piece of sheet iron or tin plate.

\section{What to do.}

Carbon dioxide in water.-Frocure some fresh spring water, which generally contains carbon dioxide dissolved in it. You

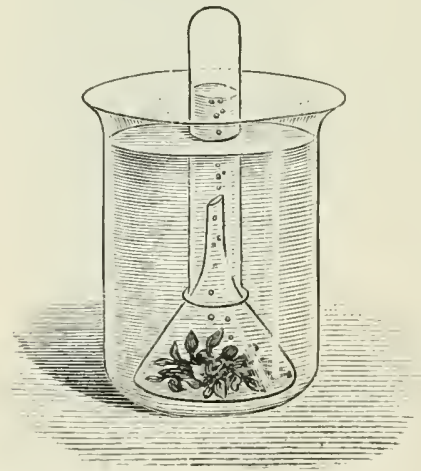

FIG. 4I.-Oxygen is given off from fresh watercress in bright sunlight. can see whether the water you think of using contains carbon dioxide by adding lime-water. If there is no milkiness the water is unsuitable for the experiment. In that case you must pass carbon dioxide into some water for a little while from the delivery tube of an apparatus like that in Lesson XIII.

Oxygen from plants.Take a bunch of fresh watercress, or water weeds, and put it into a beaker or glass jar and completely fill it with the water saturated with carbon dioxide. Cover the plants with a funnel nearly as wide as the jar, 
as shown in Fig. 4I. Fill a test-tube with water and invert over the funnel. If properly managed there should at first be no gas in the test-tube. Place the jar in bright sunlight for an hour or two and then examine it. You will notice bubbles of a gas have collected at the top of the tube. Test the gas with a glowing splinter of wood. It is found to be oxygen.

Plants in sunlight and in darkness.-Repeat the whole experiment, but instead of putting the bottle in bright sunlight place it in the dark. Observe that in such circumstances no bubbles of oxygen are formed.

Carbon in plants.-Take some green portions of a plant (leaves will do) and heat them on a piece of tin plate over a laboratory burner. Note that they become charred, showing the presence of carbon.

\section{REASONS AND RESULTS.}

How to recognise carbon dioxide in the air. - That there is always a certain amount of carbon dioxide in the air can be proved by exposing fresh lime-water in a shallow vessel. V'ery soon the lime-water becomes covered with a thin white layer of chalk, which is formed by the combination of the carbon dioxide in the air with the lime in the lime-water. One reason why there is never very much carbon dioxide in the air out of doors is because there is an agency continuously at work getting rid of this gas. This agency is the green parts of plants which occur everywhere. You must now try to understand the work which is done by these green parts of plants.

How plants get rid of carbon dioxide in the air.-When fiesh watercress is put into a bottle completely full of water containing carbon dioxide in solution, and the bottle is inverted in a basin of water without allowing air to get into the bottle, it is found that, when the bottle and its contents are exposed to bright sunlight, bubbles of gas collect at the top of the bottle. These bubbles, when tested, are found to be pure oxygen. If, however, the bottle with the cress in it is kept in the dark no bubbles of oxygen collect. Or, if a bottle of water in which carbon dioxide is dissolved be put in the sun, without any watercress, no oxygen collects in the top of the bottle.

In other words, two things are necessary for the formation 
of bubbles of oxygen. They are (1) the vegetation, (2) the sunlight. The same conditions have been found to always hold true. You may say that green plants in the presence of bright sunlight have the power of turning oxygen out of carbon dioxide. They keep the carbon for themselves, and it helps them to grow. If the experiment were carefully performed it would be found that the watercress has increased in mass after being exposed in these circumstances to bright sunlight for some time.

The balance of nature.-The wonderful relation between animals and plants in regard to their action upon the air, is a beautiful example of the way in which nature provides for one class of its creatures even out of the refuse of another. Animals by their breathing are continually using up the oxygen and returning to the atmosphere the compound carbon dioxide, a gas which is fatal to animal life. On the other hand, plants take in the carbon dioxide, and, in the presence of sunlight, the green material in their leaves can split up the gas into the two simpler substances of which you have learnt it is built, namely, carbon and oxygen. The carbon the plants keep for themselves, the oxygen they do not want, and return to the atmosphere again. In this way plants help to keep the atmosphere in a suitable condition for the healthy life of animals.

Wherever vegetation flourishes it is actively at work purifying the air by using up carbon dioxide and giving out oxygen. You will understand from this that open spaces and parks are of great value in towns, for they prevent the accumulation of carbon dioxide in the air as well as provide places for recreation.

You will not, however, suppose that green plants do nothing but take in carbon dioxide and give out oxygen, for they take in a little oxygen, and in darkness they give out an appreciable quantity of carbon dioxide. But even when this is taken into account we know that vegetation is of very great use in keeping down the proportion of carbon dioxide in air.

Another way of regarding plants. - Think for a moment about the kinds of food which animals eat. What do you eat? At breakfast you have bread and butter, or porridge, or bacon, or eggs. At dinner you have meat and vegetables and perhaps pudding. At tea you take bread and butter again, and so on. Now all these things can be divided into two classes. They either come from plants or animals. Which food come from 
plants? You know the bread, the porriclge, the vegetables all do. And which come from animals? The bacon, the meat for dinner, the milk, the eggs, and many other things. In fact nearly all the food of yourselves and all animals come from either some plant or some other animal.

But if you consider what the food of plants is, you are led to quite another conclusion. Plants get all their food either by means of their roots from the soil, or by means of their leaves from the air. You know very well that if you only had the soil and the air to get your food from you could not live. Nor could any animal live. This is another great use of plants; they manufacture food for animals from the chemical substances in the soil and in the air. You may almost look upon a wheat or potato plant as a small manufactory, in which material from the soil and air is turned into substances suitable for the food of man or other animals.

Always remember that without plants all animal life must cease. Not only do they help to keep the air in a condition for animals to breathe, but they are also always silently at work making food for animals. They are the manufacturers of natural food, and animals are the consumers.

\section{To be Remembered.}

The presence of carbon dioxide in the air may be shown by exposing lime-water in a shallow ressel. The lime-water soon becomes coated with a thin layer of chalk.

The green parts of plants have the power in bright sunlight of breaking up carbon dioxide, the carbon they keep to build up their solid parts, and oxygen is given off into the air.

Animals give off carbon dioxide (which passes into the air) and take oxygen from the air. Plants give out oxygen and take carbon dioxide from the air; in this way both are supplied from the air with the substances they need.

Plants take substances from the soil and fiom these together with the material from the air the vegetable matter they consist of is prepared.

Vegetables form a large part of the food of animals, which thus indirectly feed upon substances obtained from the soil.

\section{EXercise XVI.}

I. How would you show that the air contains other substances besides nitrogen and oxygen? What are these substances? 
2. How would you show by experiment that plants give off oxygen gas?

3. What are the most favourable conditions for the production of oxygen by plants?

4. Give reasons for the fact that the air of large cities contains a little more carbon dioxide than that of the country.

5. Write a short account of the uses of plants.

\section{LESSON XVII.}

\section{HARD AND SOFT WATERS.}

PRACTICAL WORK.

Things required.-Test-tubes. Apparatus for preparing carbon dioxide. Lime-water. Laboratory burner or spirit lamp. Soap solution prepared from Castile soap and methylated spirit. Spring and rain water. Flasks. Calcium chloride. Sea water.

What to do.

Chalk dissolves in water containing carbon dioxide.-Pass carbon dioxide into clear lime-water until the solution is clear again, after first becoming milky.

Effect of boiling water in which chalk is dissolved.-Boil a part of the clear solution in a test-tube. Observe the return of the milkiness. What is the cause?

Boil in a flask a little natural water which is hard because of the presence of chalk; observe that the water becomes milky.

Soap solution to test the hardness of water.-Dissolve some Castile soap in spirits of wine and label the solution as "soap solution."

Add a few drops of soap solution to distilled water. Shake the mixture. Notice a lather is easily formed.

Temporary and permanent hardness of water.-Add soap solution to some of the clear solution obtained by passing carbon dioxide for some time through lime-water. Shake the mixture and observe that a lather is formed only after a considerable quantity of soap solution has been added. 
Similarly observe that it is difficult to make a lather with a solution of calcium chloride.

Boil portions of the'solution in the last two experiments before adding the soap solution. Soap lathers in the first solution quite easily after it has been boiled; boiling makes no difference to the second solution.

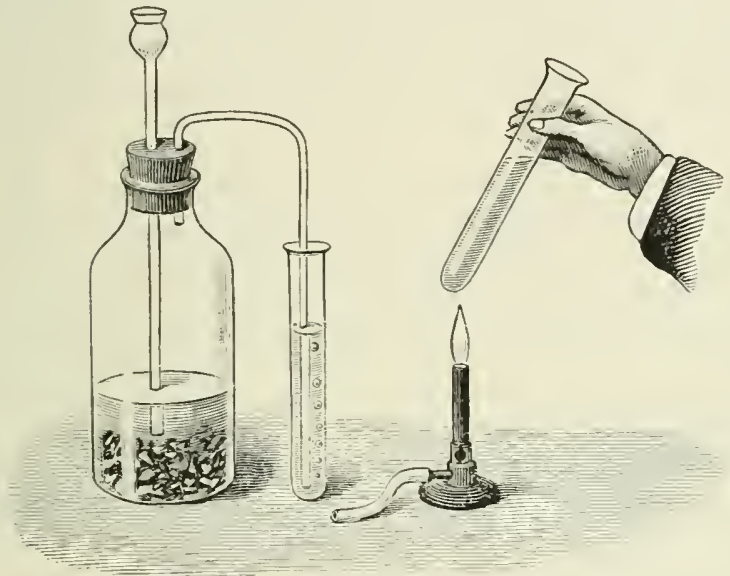

FIG. 42.- When carbon dioxide is passed into clear lime-water, the water turns nilky, and afterwards clear. The milkiness is again obtained by boiling the lime-water.

Hardness of sea-water.-Try whether the soap solution forms a lather when shaken up with sea-water. Does boiling make any difference?

The measurement of the hardness of water with soap solution.-On a narrow test tube gum narrow strips of paper, about $\frac{1}{2} \mathrm{~cm}$. apart, so as to form a measure for the soap solution. From this add soap solution (a drop or two at a time) to about a wineglass full of rain-water; cover this with your hand and shake vigorously after each addition. When a lather forms which remains for five minutes, cease to add soap solution, and note the volume of it used.

Treat an equal quantity of spring water in the same way and note the amount of soap solution required.

By taking various samples of water, equal in quantity, and treating them as described, you may roughly compare the 
facility with which tiney form a lather. The harder the wates the more is the anount of soap solution required.

Hard water may be softened by the addition of lime.- Into some water which contains dissolved carbonate of lime pour some clear lime-water until the water becomes quite milky. Then filter. Find how much soap solution is required to produce a lather which remains for five minutes in 50 c.c. of the clear water. Test an equal volume of the water which has not been treated with lime-water in the same way.

\section{REASONS AND RESULTS.}

Hard and soft waters.-It is a fact familiar to everyone that soap lathers very easily in some waters and not at all in others. If rain-water be used, the lathering takes place with great ease, while with the water supplied to some towns a lather can only be made with difficulty ; and if we attempt the same process in sea-water there is no lathering at all. Those waters in which soap lathers easily are said to be soft. When this is not the case the water is spoken of as nard.

Soft waters.-Water containing no dissolved mineral matter, or water which is pure, dissolves soap easily, and when the solution is shaken up a lather is at once formed.

Hard waters. - Hard waters always contain dissolved mineral substances. These substances may either be soluble in pure water itself, or in water which has first dissolved carbon dioxide. When water is boiled it is hotter than when it is taken from a spring or tap, and as hot water usually dissolves more of a substance than cold, you would hardly expect mineral substances in water to be given up when the water containing them boils. But this does happen, and the reason is that boiling drives out the carbon dioxide from solution in the water.

Many solids which are soluble in water owing to the presence of carbon dioxide, are not dissolved by pure water; hence when the water is boiled and the gas is given off, these substances are deposited upon the sides of the vessel in which the boiling is done.

These facts enable us to divide hardness in waters into two classes-(1) Hardness which is not removed by boiling, called permanent; (2) Hardness which is removed by boiling, called temporary. 
How natural waters become hard.-No sooner is the water vapour in the air condensed into rain than its work of solution begins. First, the rain in its passage to the earth dissolves samples of the gases in the air. The most soluble of these gases are oxygen and carbon dioxide, and evidently there will be most of these dissolved. When the surface of the earth is reached the solution of many more substances begins. The amount of each material dissolved, of course, depends upon the extent to which it dissolves. All the time the water is percolating through the soil and underlying rocks, it is dissolving some of their constituents.

Of these substances dissolved some are soluble in pure water, others dissolve only in water containing carbon dioxide. The hardness to which the first class gives rise is permunent, that caused by the second class temporary.

Ways of getting rid of temporary hardness.-First, there is the plan of boiling which has been already mentioned. But it is quite clear that when engineers wish to soften the supply of water to a town they cannot boil the whole amount. It would not only be very inconvenient, but also very expensive. Another process is adopted.

You must bear in mind that the object in view is to get rid of the carbon dioxide in the water. If this can be done, the substances at first in solution in the water become insoluble, and are given up.

What the engineer often does is to have lime put into the water. The lime combines with the carbon dioxide, in the way you have learnt, to form chalk. The carbon dioxide being removed from the water, it can no longer dissolve the carbonate of lime, and this, together with the chalk formed, is thrown down.

Ways of getting rid of permanent hardness.-You already know that boiling is of no use in remoring hardness when the water is permanently hard. But there are two other ways of softening permanently hard water.

The first plan you have perhaps seen the washerwoman employ. She puts soda into the water. The chemist's name for soda, you learnt in a previous lesson, is sodium carbonate. When the sodium carbonate comes in contact with the substance which causes permanent hardness a chemical change takes place, and the originally soluble substance causing the 
hardness is changed into a compound insoluble in water which is consequently thrown down. The water is thus softened. The substance in solution in water which usually causes permanent hardness is calcium sulphate, one form of which is plaster of Paris. When washing-soda comes into contact with this compound the calcium sulphate is changed into calcium carbonate, the chemist's name for chalk, which, being insoluble in pure water, is thrown down as a precipitate, and so got rid of.

The second plan is called distillation, and is equally useful in both kinds of hardness.

Reason for getting rid of hardness.-One object in view in getting rid of every kind of hardness is to diminish the amount of soap necessary in using water for cleansing processes. When soft water is used the soap immediately dissolves in it causing a lather at once. When hard water is employed a considerable quantity of soap is first used up in combining with the chalk and other substances, which render the water hard, to form the curdy material seen at the top of hard water after soap has been used in it. This curdy matter is insoluble in water, and represents so much wasted soap.

\section{To BE REMEMBERED.}

Soft waters are those in which soap lathers easily.

Hard waters are those containing dissolved solids which use up soap without making a lather.

Hardness is of two kinds.

(a) Permanent, caused by the presence of calcium sulphate, and can only be got rid of by adding washing soda or by distillation.

(b) Temporary, caused chiefly by carbonate of lime, and got rid of by boiling or by adding lime.

Water becomes hard as it passes over rocks in the earth, dissolving mineral matter from them. In this solvent action it is assisted by the carbon dioxide which it dissolves in passing through the air.

Hard water requires much more soap to form a lather than soft water; the mineral substances unite with the first portion of the soap taken to form a useless curd.

\section{EXERCise XVII.}

1. Describe an experiment which shows that hard water requires more soap to form a lather than soft water.

2. What is the cause of hardness in water, and how may it be removed? 
3. What is the reason for adding soda to water? How does it act?

4. Briefly describe the reasons for the hardness of most spring-waters. Why is rain-water not hard?

5. Why are hard waters divided into two classes, and in what ways does their hardness differ?

6. After washing my hands in spring-water, with soap, I noticed a curd or scum on the water; account for this. What would have happened had I used rain-water, and why?

\section{LESSON XVIII.}

\section{LIMESTONES.}

\section{PRACTICAL WORK.}

Things required.-Fur from tea-kettle. Chalk from a chalk pit. Tumbler. Hydrochloric acid. Lime-water. Flasks. Wide test-tube. Wood splinters. Filter paper. Funnel. Strip of clear glass about 3 ins. by $\mathrm{I}$ in. Compound microscope. $^{1}$

\section{What to do.}

"Fur" from a kettle compared with chalk.-Collect some crust or "fur" from the inside of a tea-kettle; compare its appearance with that of chalk.

Put a small quantity of clear lime-water into the bottom of a tumbler or test-glass. Put some of the "fur" into a small flask, and pour on it a little dilute hydrochloric acid. Note the effervescence which takes place. Tilt the flask over the tumbler so that the escaping gas will - flow from the flask to the tumbler, taking care that no liquid runs out of the flask. Shake the tumbler containing the lime-water. Note that the latter turns milky (Fig. 43).

Put a little of the fur into a wide test-tube and pour upon it dilute acid. Plunge a lighted taper into the tube, or a burning wood splinter. Note that it is extinguished.

1 This is not essential, but will be an adventage. 
Perform similar experiments with chalk, and notice similar results.

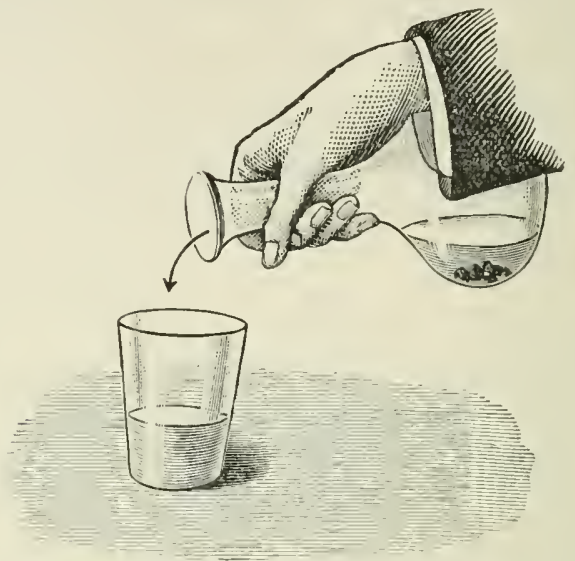

Fig. 43-- Carbon dioxide obtained from the "fur" of a kettle will turn the lime-water in the tumbler milky.

Chalk from spring-zeater:-Boil spring-water in a clean flask for some time. Observe the appearance of chalk in the water. Filter the water; then pour dilute acid upon the filter. Observe the effervescence. Also notice that the tlask is no longer clean, fur has commenced to form on the inside.

What chalk is made of.-If a microscope is obtainable, get a piece of chalk from a chalk pit, powder it and shake up a small quantity in water. Pour off the water containing the fine particles, and examine a small quantity of the sediment under the microscope by placing a few particles on a piece of clear glass.

How" to obtain a deposit of "fur" from spring-auter.-Put a short piece of dean glass tubing into a kettle which is in constant use. At the end of a week or two examine it. Break it, and notice that fur is only deposited on the outside.

\section{REASONS AND RESULTS.}

Furring of kettles. - An cxamination of the inside of a kettle which has been in use for some time generalty reveals the presence of a white chalk-like deposit. If a little of this white 
incrustation be removed and examined it is found to be brittle, and when treated with an acid it effervesces and gives off a gas which puts out flames. But this is just what takes place when an acid is poured upon chalk. The fur inside the kettle is chalk. It was present in the form of hardness in the water which has been from time to time boiled in the kettle. The solubility of the chalk depended, as you know, upon the carbon dioxide dissolved in the water. When the water was boiled the carbon dioxide was driven out, and the water was therefore unable to dissolve the chalk, which

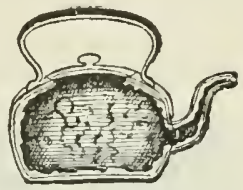

FIG. 44. - The "fur" inside a kettle is of the same composition as chalk. was consequently thrown down on the inside of the kettle to make the white deposit.

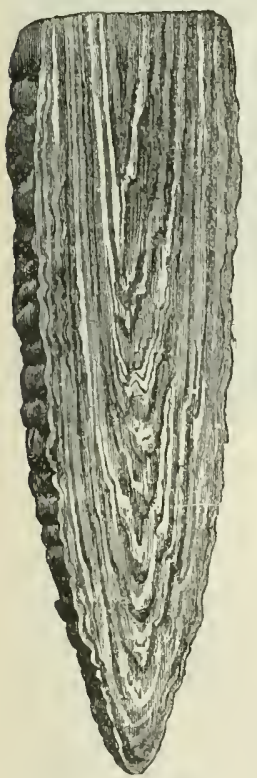

FIG. 45.-Section of a stalactite showing the layers produced by the gradual deposit of calcium carbonate.

Some limestones are formed in the same way as the fur in the kettle.-The water of many springs contains as much carbon dioxide as it can hold. For this reason these springs are able to dissolve a large quantity of chalk. When such water comes to the surface of the earth the pressure upon it is much decreased, and a great deal of the carbon dioxide escapes. You already know that it is the carbon dioxide in the water which enables it to dissolve chalk, and therefore when some of this gas escapes, the water can wo longer hold so much of that substance, and chalk is deposited by the water, in some cases to such an extent as to form a thick layer of rocky material which is called calcareous tufa or travertine.

So abundant is this rock in Italy that it is used as a building stone, many of the finest buildings in ancient and modern Rome being built of it.

Stalactites and stalagmites. - The streams which flow over limestone countries become saturated with calcium carbonate, which, as you will remember, is the chemical name

III. 
for chalk. In their course they often trickle through crevices in the roofs of caverns (which have themselves been formed in the limestone by the same solvent power of water containing carbon dioxide). The drop of water, which is in this manner exposed on the roof of the cavern, slowly evaporates, and the escape of the carbon dioxide and loss of water causes a small amount of the chalky deposit to be formed on the roof (Fig. 46).

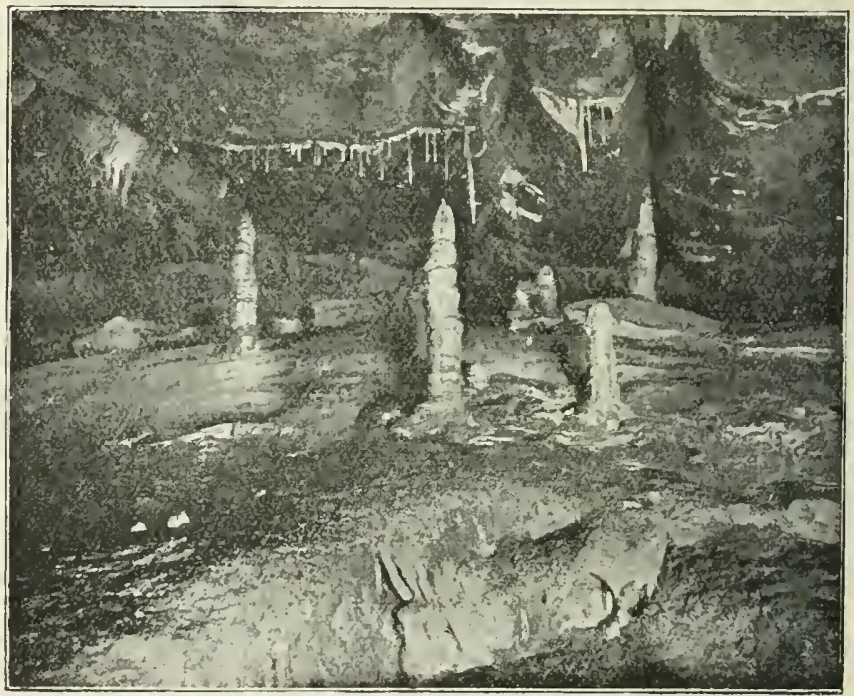

Fig. 46.-Stalactites and stalagmites are formed from calcium carbonate dissolved in water and given up on account of the loss by the water of carbon dioxide.

This is continuously added to by a constant succession of drops, until eventually beautiful pendants of calcium carbonate are formed, called stalactites, sometimes coloured by the pres. ence of iron rust, and often having a wild profusion of forms, as in the Clapham Cave in Yorkshire, shown in Fig. 46. Further evaporation of the water takes place on the floor of the cavern, giving rise to layers of the same compound. These layers are called stalagmites.

How other limestones are formed.-But it must be pointed out here that by far the greatest quantities of limestone have been 
formed in quite another way. It is a well-known fact that many animals which live in the sea have the power of extracting the calcium carbonate in solution in sea-water, and which has got there from the rivers and streams containing it. This calcium carbonate eventually builds up the shell generally possessed by the animals mentioned.

You must not suppose the animals know anything about what they do. They are no more concerned in the process than you are in the building up of your bones from the substances in solution in your blood.

When the animal dies its shell remains on the sea bottom. The shells of the multitudes of similar animals, accumulating on

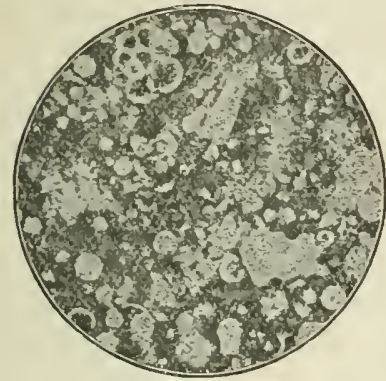

Fig. 47.-Chalk seen under a microscope.

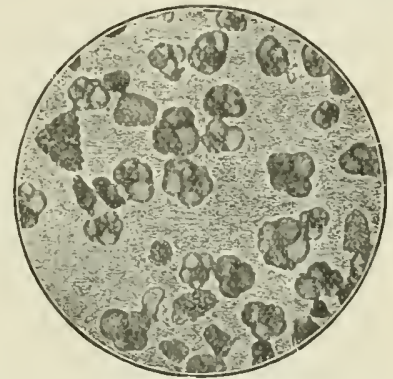

FIG. 48.-Deposit obtained from the bottom of the Atlantic, and viewed under a microscope.

(From photographs by Mr. J. E. Barnard.)

the ocean floor in the course of many ages, build up a new deposit of limestone. The animals most active in this work of limestone building are extremely small. The greater part of a lump of chalk, which like limestone is made of the shells of aniinals, is composed of tiny shells of minute creatures known as globigerinae (Fig. 48). These shells can be detected in the chalk by powdering a piece of chalk from a chalk-pit and shaking up the powder in water. This causes the finest particles to become suspended, and these can be poured off. The sediment which remains behind, when examined under a microscope, looks like Fig. 47. 


\section{TO BE REMEMBERED.}

The fur on the inside of a tea-kettle consists of chalk deposited from the water. Boiling expels carbonic acid gas (carbon dioxide), and leaves the water unable to hold dissolved chalk.

Some limestones, as well as stalactites and stalagmites, are formed in much the same way as the fur inside a kettle. Water running through crevices in the earth dissolves carbon dioxide, and then dissolves chalk from the rocks over which it passes.

On reaching the surface again some of the gas escapes and the water, no longer able to hold the chalk, deposits it. Sometimes thick sheets of limestone are gradually formed; they are known as travertine, or if the deposit takes place from the roof of a cavern, it is known as a stalactite.

The microscope shows that some limestones and chalk are made up of the shells or skeletons of tiny animals.

\section{EXERCISE XVIII.}

1. How would you show that the fur of a kettle is similar in composition to chalk?

2. Explain clearly why "fur" appears on the inside of tea-kettles.

3. What are the various ways in which limestones are formed?

4. What is a stalactite, and how is it formed?

5. Describe what is seen when chalk is examined under a microscope.

6. What is the condition of water after it has been well boiled? Give reasons for your answer.

7. Which water is the harder, that from springs rising out of chalk, or from springs rising out of hard rocks such as slate?

\section{LESSON XIX.}

\section{NATURAL CHANGES IN WHICH CHALK AND CARBON DIOXIDE TAKE PART.}

\section{PRACTICAL WORK.}

Things required.-Whiting. Small quantities of oyster, mussel, cockle, and egg shells; bath-brick, sand, pipe-clay, freestone, stone from road, blackboard chalk. Samples of limestone. Test-tubes. Hydrochloric acid. Distilled water. Apparatus 
for preparing carbon dioxide. Carbonate of lime. Flask. Tripod. Laboratory burner.

What to do.

Whater in which carbonate of lime dissolves. - Put a small quantity of whiting or carbonate of lime into distilled water and stir it up. Note that it is not dissolved. Pass carbon dioxide through this water for some time, and observe that some or all of the carbonate of lime dissolves. By adding more water and again passing the gas through the whole will dissolve.

[If distilled water is not obtainable, water which has been boiled in a clean saucepan for ten minutes and then filtered will answer the purpose.]

Chalk from water.-Take some of the water, which must be quite clear, from the last experiment, and boil it. Note the formation of chalk.

Put a piece of clean glass tubing into a kettle used for boiling hard water. Examine the piece at the end of a fortnight; it is covered with a whitish coating of carbonate of lime. Put the tube into weak acid. Notice the effervescence, and that the glass again becomes perfectly clean.

Different kinds of carbonate of lime.-Procure as many samples of limestone as possible, and put a drop of acid on each. Notice the effect.

Take pieces of shells (oyster, mussel, cockle, etc.), freestone, blackboard "chalk," egg shells, bath-brick, sand, pipe-clay, and stone from the road. In each case put a small piece or quantity into a test-tube, and pour on dilute acid. State the result in each case and say which you consider contains calcium carbonate.

\section{REASONS AND RESULTS.}

How caves are formed. - The solvent action of water containing carbon dioxide is most strikingly seen in those districts where the rocks consist of limestone or chalk. In our own country such rocks occur largely in Derbyshire, Gloucestershire, Somerset, and Yorkshire. In these districts are to be found many immense hollows, known as caverns, in the rocks. One of these, the Peak cavern at Castleton in Derbyshire, is believed to be $2300 \mathrm{ft}$. long, and is in some places $120 \mathrm{ft}$. high. Many 
of these caverns have been hollowed out by water, and large or small streams still run through many of them.

An examination of the rocks in these districts shows them to be everywhere full of joints and cracks, and if tested with a little vinegar or hydrochloric acid, the effervescence or fizzing which takes place shows the presence of carbonate of lime in them.

Rain, which has already taken carbon dioxide from the air, obtains more from the earth, and rapidly finds its way into every crevice, trickling from one to another. Joining with other similar streams it meets, it forms a larger stream, all the time dissolving carbonate of lime from the rocks over which it flows. In this way in the course of years, underground passages are hollowed out, which in places may be so enlarged as to make huge underground chambers.

In limestone districts rivers often disappear partially or entirely into the earth, coming to the surface again at long distances from the place where they disappeared.

The water in these districts is usually bright and spark-

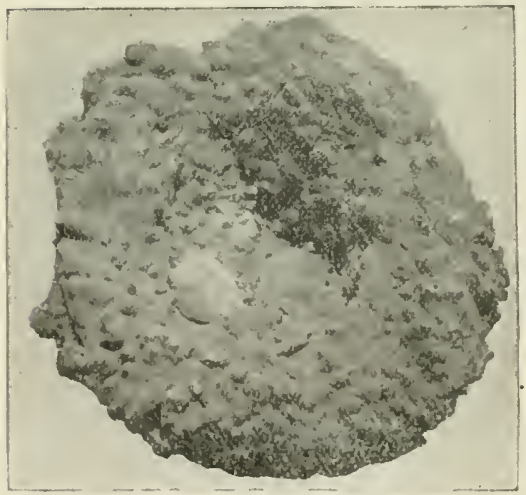

FIG. 49.-A petrified bird's nest and eggs. Photographed by Mr. R. Nightingale. ling ; if boiled, carbon dioxide is obtained from it, and the water becomes milky or turbid on account of the chalk which it contains becoming visible. Kettles used in such neighbourhoods rapidly become coated with a crust or fur on the inside.

\section{Petrifying springs,} -Visitors to these districts are often interested by what are wrongly called petri-

fying springs or wells. Articles such 'is pieces of wood, birds' nests, egg shells, etc., left in these springs for a few days are said to be turned into stone, but what really happens is, that the water of these springs being saturated with carbon dioxide, can 
therefore dissolve much chalk, but on coming to the surface some of the gas escapes and part of the chalk is deposited on the article, thus hiding the material of which the thing is made.

It is quite incorrect to say that articles so coated are petrified or turned into stone, for on breaking them the original substances will be discovered underneath the chalky coating. You may study this for yourself by putting a piece of glass tubing about three inches long into a kettle used for boiling hard water. At the end of a week or two the coating formed will hide the glass underneath.

What becomes of this dissolyed carbonate of lime?-The water of limestone districts finds its way into rivers and finally carries its burden of carbonate of lime to the sea. What becomes of it there?

In a previous lesson it was explained that the remains of tiny creatures were even now accumulating on the ocean floor to form what may be, in the future, a bed of chalk or limestone. These creatures exist in myriads in some parts of the ocean, and it is easy to understand that they must take from it an immense amount of calcium carbonate. In some varie-

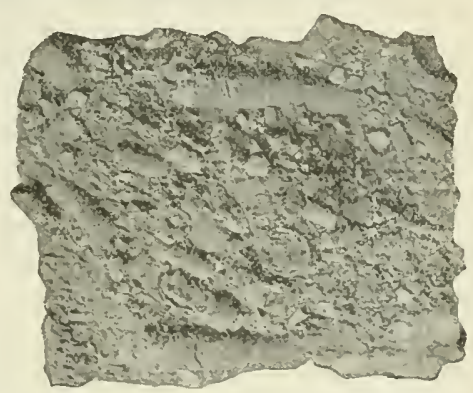

F1G. 50.-Limestone with fragments of shells upon it. From a photograph by Prof. WV. IV. Watts. ties of limestone, fragments of shells of animals which have lived in the sea are easily seen, as in Fig. 50.

Oyster shells, mussel shells, and in fact the bones and shells of most of the inhabitants of the sea, consist largely of carbonate of lime, the whole of which is obtained from the sea-water.

If dilute acid is poured upon a piece of coral, effervescence takes place, and you will readily come to the conclusion that the coral is of the same character as chalk. Hundreds of islands in the Atlantic and Pacific Oceans are made up mostly of this substance, while a coral reef 1000 miles long extends along the North East coast of Australia. This coral consists of the hard parts of countless animals, which obtained the 
carbonate of lime of which the coral is formed from the waters of the ocean.

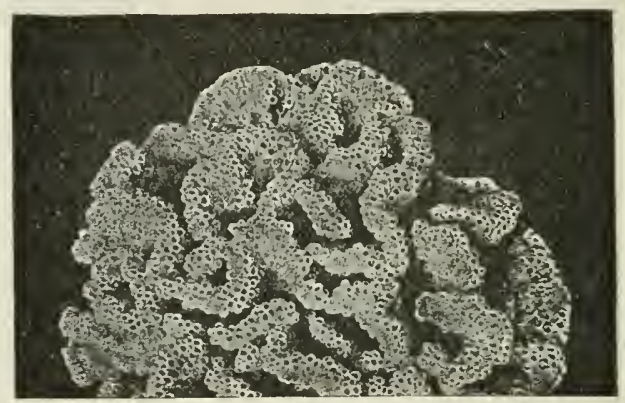

FIG. 51.-Coral consists of calcium carbonate.

Action of carbon dioxide in towns and cities.-Living in towns we may not be able to observe some of the effects of water upon the rocks, but even in cities water and carbon dioxide perform their work of solution.

Statues and monuments are often made of marble, a crystalline form of calcium carbonate, while some of our finest buildings are of limestone. Into the air of cities the large number of fires, and the people and animals who live there, pour carbon dioxide, which is readily taken up by every shower of rain, so forming a solution of the gas in water, and it is easy to understand that the marble monuments or buildings of limestone are gradually worn away by the rain carrying away portions of them.

In future it will be interesting for you to observe this action, especially on any marble monuments you may know of which have been exposed to the weather for several years.

TO BE REMEMBERED.

In districts where limestone rocks occur, the effects of water containing carbon dioxide are very evident.

Such water passing into the earth dissolves parts of the rocks over which it flows, in some cases forming large hollows or caverns, or making passages underground into which it disappears.

Rocks which are acted upon by such water, also cause an effervescence when treated with an acid. 
When underground water is highly charged with carbonic acid, it often loses some of this gas on coming into the air, and some of the carbonate of lime it contains is deposited upon objects in it, these objects are not petrified but only coated with the calcium carbonate.

Carbonate of lime dissolved from the rocks is carried by rivers to the sea, it is taken from the sea-water by the animals living in it to form their skeletons or shells.

The air of towns, with the aid of the water falling as rain, wears away buildings or monuments of limestone.

\section{Exercise XIX.}

I. Water flowing over some rocks has little action upon them; how is this?

2. Explain how caverns are formed.

3. How is it that in a few years the lettering on some tombstones becomes indistinct?

4. What does petrified mean? A kettle used for several months becomes coated with a hard stony substance inside. Has it become petrified? Give reasons for your answer.

5. Carbonate of lime is very abundant in some river waters, but there is not so much in sea-water. Account for this.

\section{LESSON XX.}

\section{MORTAR.}

\section{PRACTICAL IVORK.}

Things required.-Slaked lime. Angular sand. Plates. Mortar from an old building. Hydrochloric acid. Plaster of Paris. Hydraulic cements. Piece of glass tubing. Wineglass.

What to do.

Slaked lime and sand.-Mix some powdered slaked lime and water into a thick paste ; let it stand on a dinner plate or piece of slate for several days. Perform a similar experiment with sand only.

How to make mortar.-Mix together some slaked lime in fine powder with three times as much angular, or sharp, sand. 
Mix this into a stiff paste with water, and allow to stand for several days.

Presence of lime in new mortar.-Put a little of the mortar you have made into a wide test-tube or wineglass; pour dilute acid upon it.

Crush another sample and shake it up in distilled water. Filter the liquid. Blow air from the lungs through the water by means of a glass tube. Notice that it turns milky, showing that the water contains lime from the mortar.

Absence of lime in old mortar - Repeat the last experiment with mortar from the outside of an old building. Note that the effervescence is brisker. Why? The solution does not turn milky, because it does not contain lime.

Plaster of Paris is not a carbonate.-Repeat the last experiment with plaster of Paris. There is no effervescence on treating with acid. This solution is not turned milky when blown through. Why?

\section{REASONS AND RESULTS.}

The manufacture of mortar.--Mortar, which, as every schoolboy knows, is used to bind together bricks and stones in

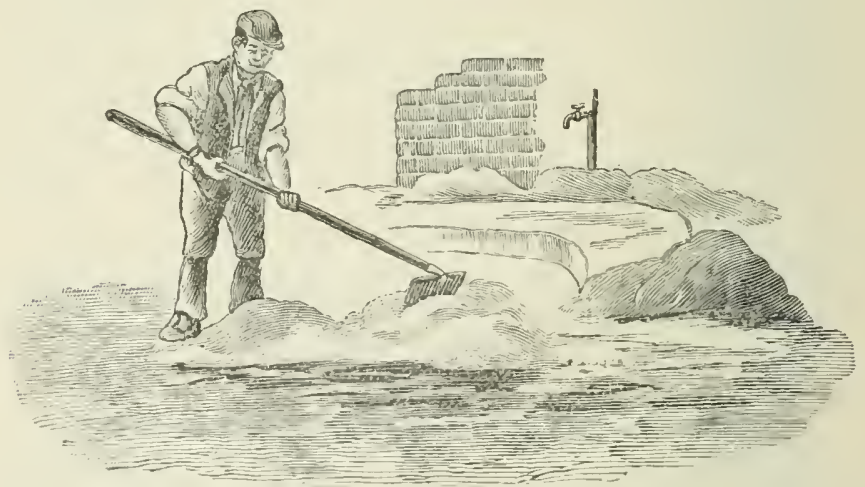

FIG. 52. - Mortar is made by mixing slaked lime and sand.

building houses, is made by thoroughly mixing together slaked lime and sand. 
Sands composed of sharp angular fragments are best. About three times as much sand as there is slaked lime is used, and after mixing the two constituents the mortar which is thus made is ready for use.

How the mortar is used.-A thin layer of mortar is spread evenly over the surface to which the brick or stone is to be fixed, and the brick or stone is pressed down upon it so as to press out some of the water which may be in the mortar. As the remaining water in the mortar evaporates, the layer of inortar becomes harder and harder. But the setting of mortar is quite different from the mere drying. A chemical change also takes place.

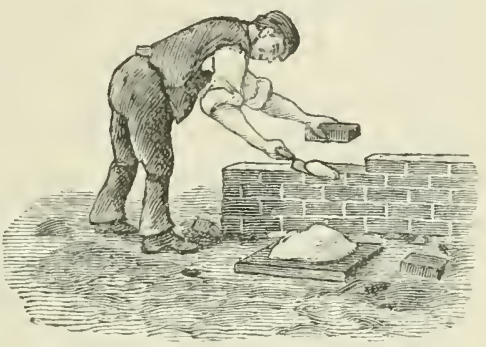

Frg. 53.-Mortar is used wet.

The setting of mortar.-You have already learnt that the atmosphere always contains a certain amount of carbon dioxide gas. You also know from the experiment of shaking together carbon dioxide and lime-water, that the lime in the lime-water and the carbon dioxide in the vessel unite together to form a white precipitate of chalk. It is to these facts that the setting of mortar is due. The lime in the mortar, and the carbon dioxide in the air continuously, though slowly, unite together to form chalk or calcium carbonate, and this combination eventually converts the outside of the layer of mortar into a hard stony mass.

But it takes a very long time for this change to penetrate far into the mortar. Even after twenty or thirty years an examination of the mortar in the middle of a wall shows that the lime in it has not undergone any change. Still, the more the lime of the mortar combines with the carbon dioxide of the air the harder the mortar becomes, and the stronger the joint it makes.

In short, you may say, the setting of mortar is due to the combination of the lime in it, with the carbon dioxide in the air, to form calcium carbonate.

How this change in mortar may be recognised.-To convince 
yourself that the change described in the last paragraph really does take place, you must make use of another fact you have learnt from an experiment in a previous lesson. When an acid is dropped upon chalk or any other form of calcium carbonate a brisk effervescence at once takes place, and, as you have also seen, this is the test made use of by the geologist to recognise limestones.

Consequently, then, if you take some mortar from an old building and pour acid upon it, you ought, if there really has been such a change as described in the last paragraph, to get plenty of fizzing. If you perform the experiment you will find that this does happen.

Why freshly plastered rooms remain wet for a long time.-The plaster with which the walls of rooms are covered to make them ready to receive the wall-paper is very similar in its composition to mortar. You know very well that if the wall-paper is put on before the plaster is thoroughly dry, the paper is soon spoilt. You have noticed, too, most likely, that in new houses, rooms are often not papered until they have been lived in for some time. This is because the plaster takes so long to dry. The reason of this is a chemical one. It will be necessary to recall several things you have learnt before. The slaked lime contains quicklime and water, or,

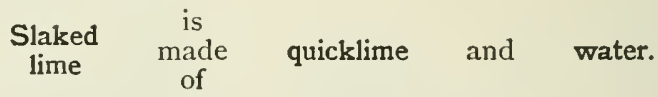

Secondly, carbon dioxide unites with quicklime to form calcium carbonate, or,

Calcium
carbonate made
of carbon ande anicklime.

Now, there is slaked lime in the plaster on the walls, and the carbon dioxide in the air comes into contact with it. The gas unites with quicklime to form chalk or calcium carbonate, but it does not want the water which the slaked lime contains. The water is consequently turned out and this is why the plaster remains wet so long, or,

Slaked lime $\begin{gathered}\text { unites } \\ \text { with }\end{gathered}$ carbon dioxide form calcium carbonate 
How to hasten the drying of plaster.-Since the drying depends upon the chemical action of the carbon dioxide, it is a common plan to burn charcoal, coke, and other substances containing carbon in the room where the damp walls are. The carbon dioxide which is formed by the burning of the fuel is not allowed to pass up the chimney, but to escape into the room. The large amount of carbon dioxide which the air is thus made to contain hastens the necessary chemical changes, though if the hardening goes on too quickly cracks are often produced.

Plaster of Paris.-Plaster of Paris and cements must not be confused with mortar which is made of sand and lime; they are quite different in composition and do not contain carbonate of lime.

Plaster of Paris made into a stiff paste with water soon sets quite hard, and is used for giving a smooth, white surface to ceilings and walls of houses.

For constructing the walls of docks and the foundations of bridges, hydraulic cement $-\mathrm{a}$ kind of mortar which sets under water-is used.

\section{TO BE ReMembered.}

Mortar, used for holding bricks and stone together, is made by mixing about one part slaked lime with three parts of angular sand into a thick paste.

The setting of mortar is due to the combination of the lime in it with the carbon dioxide in the air to form calcium carbonate.

When the carbon dioxide of the air unites with the lime in the mortar, water is set free. Thus

Slaked unites carbon to calcium
lime with
dioxide form carbonate and water.

But the carbon dioxide only requires the quicklime with which to form chalk, and the water is set free.

By producing a quantity of carbon dioxide in a room which has been freshly plastered, the combination of this substance with lime in the plaster goes on more quickly, and the walls dry more rapidly.

\section{EXERCISE XX.}

I. How is mortar made?

2. Which constituent of the air is most essential to the proper setting of mortar? How does it act? 


\section{IO ELEMENTARY PHYSICS AND CHEMISTRY.}

3. What method is often adopted to hasten the drying of the walls of a new house? State clearly the reason for adopting the method you suggest?

4. How would you account for the "damp" often seen in the walls of a new house?

5. How may it be demonstrated that the mortar from the walls of an old building is different in composition from that of a new building?

6. How would you show that plaster of Paris has not the same composition as mortar? 


\section{INDEX.}

Acids, action on carbonates, 77 ; action on shells, 76 ; action on washing soda, 76 ; further study of action of, on metals and carbonates, 76-79.

Air, active part of, If, I5; and water, I9; breathed out, contains carbon dioxide, 80 ; contains carbon dioxide, $81,83,86-89$; inflammable, 24 ; search for active part of, $\mathbf{I}_{5}$.

Area, measurement of, 3 .

Baking-powder, action of water on, 77.

Balance, 4 ; of nature, 88.

Balloons, soap-bubble, 36 .

Barometer, 6.

Blowpipe, oxyhydrogen, 45 .

Bread, holes in, 78 .

Breathing and burning, 79-85; change character of air, $8 \mathrm{I}$.

Breathing, is really a kind of burning, 82.

Burning, $8 \mathrm{I}$; and breathing, 79-85; and rusting, 14 ; of a candle, 15 ; of coal-gas, I5; of hydrogen, $40-$ 45,43 ; of oil, 15 ; of phosphorus, I5; of limestone, 56 .

Calcium carbonate, 77 ; different kincls of, ror.

Carbon, in plants, 87 .
Carbonates, action of acids on, 77 .

Carbon dioxide, 69; action of, on line-water, 72, 73; action on monuments, rof; dangers of, 84 ; in breathed out air, 80,82 ; in the arr, 86-89; in water, 86 ; is an acid, 72 ; is heavier than air, $7 \mathbf{1}$; preparation of, 70,$73 ;$ produced by fermentation, 73 i produced in burning of candle, oil, gas, and wood, 79; properties of, 7I, 73; uses of, 74 .

Caves, how formed, ror.

Chalk, action of acids on, 59, 6r, $67-69$; action of acids and heat on, compared, 69; action of heat upon it, $5+58,63$; action of water on, $58 ;$ and lime compared, 58-62; change produced by heating. 55 . 56 ; conversion into lime, 63 ; does not dissolve in water, 59; from spring water, 96 ; gas produced by action of acids on, 59, 67, 70-75; loses in mass when heated, $6_{3}, 6_{4}$; loss of mass when acted upon by acid, 67, 69; physical characters of, 54 , 55; seen under microscope, 99; substances like, 55; test for, 68 ; what it is made of, 96.

Classes, of things, $\mathbf{I}$.

Condelisation, 9. 
Convection, 13; currents, 13.

Coral, I04.

Crystals, 8; deliquescent, 9; efflorescent, 9; soda, 9; sulphur, 9; rock-salt, 9 ; waterless, 9 .

Density, 4 ; of solids, 5 .

Deposit, of chalk at bottom of ocean, 99.

Displacement, upward, 39.

Distillation, 9.

Explosion, of mixture of air and hydrogen, 36 .

Evaporation, 9, 17.

Flame, of hydrogen, $3^{6}$; is intensely hot, 41 .

Foot, 3 .

Funnel, use of acid, 33 .

Fur, inside a kettle, 97.

Gases, 2 ; soluble in water, 7.

Globigerina, 99.

Gram, 4; multiples of, 4; parts of, 4 .

Hardness, how got rid of when permanent, 93 ; how got rid of when temporary, 93; measurement of with soap solution, $9 \mathrm{I}$; of seawater, $9 \mathrm{I}$; of water, 90 , 91 ; permanent, 92; temporary, 92 ; reason for getting rid of, 94 .

Heat, and temperature, $I \mathbf{I}$; capacity for, I2; effects of, 6; latent, 13; quantity of, 12; specific, I2.

Hunger, 83.

Hydrochloric acid, 33.

Hydrogen, 24; action of, on metal rusts, 46.49; action on heated copper oxide, 47 ; burning of, $40^{-}$ 45 ; flame of, $3^{6}$; is lighter than air, 35 ; is neutral, 39; may be dangerous, $3 \mathbf{I}$; obtained from iron and acid, 77 ; on burning takes oxygen out of the air, 42 , 43; physical properties of, 37; preparation of large quantities, 3I, 32 ; properties of, 34-40; turned out of water by sodium sometimes burns, 27; will not support combustion, 39 .

Hygrometer, 10.

Ice, density of, II.

Inch, 3 .

Iron, action between water and, 2I ; action of hydrochloric acid on, $7 \bullet$; action of sulphuric acid on, 76.

Joints, in limestone, Io2.

Kali, 77 .

Leaks, how to test for, 32 .

Length, measurement of, 2 ; standard, 2.

Lime, absence of, in old mortar, I06; acids cause no fizzing with, 59 ; action of water on, 58, 59; and chalk compared, 58-62 ; dissolves in water, 59 ; increases in mass when water acts on it, 60 ; presence in new mortar, I06; slaked, 6o; takes up water which cannot be easily driven off, 58.

Limekiln, 57.

Lime-light, 45 .

Limestones, 95; burning of, 56 ; how formed, 98 ; made of shells, 103; some formed in the same way as the fur in the kettle, 97 ; test for, 68.

Lime-water, 6i. 
Liquid, formed by burning hydrogen, 4r. 43 .

Liquids, 2 ; soluble, 7 ; which do not mix, 7 .

Litre, 3 .

Mass, 4 ; measurement of, 4 .

Matter, I.

Metre, 3 ; divisions of, 3 .

Mortar, I05-ro9; how change in, may be recognised, ro7; how to make, 105; how used, ro7; manufacture of, 106; the setting of, 107.

Natural waters, how they become hard, 93.

Nature, balance of, 88.

Oxygen, I5; from plants, 86 ; preparation of, 15 ; properties of, 16 ; mixture, I6.

Percentage, loss of mass when chalk is heated, 65 .

Plants, another way of regarding, 88 ; contain carbon, 87 ; get rid of carbon dioxide in air, 87 ; give out oxygen, $86 ;$ in sunlight and darkness, 87.

Plaster, how to hasten drying of, I09; of Paris, I06, ro9; on walls remains wet for a long time, I08,

Potassium chlorate, $\mathbf{I}_{5}$.

Pound, standard, 4.

Quicklime, 56.

Rusting, and burning, I4; of iron, I4.

Salt, obtained by evaporating seawater, 53 .

III.
Science, the study of, I.

Seidlitz powder, the gas from, 77.

Senses, I.

Soap, solution, 90; as a measure. ment of hardness in water, 91 .

Sodium, 25, 26, 27; action on water, 26, 28 ; drives hydrogen out of water, 26, 28; how to collect the gas it turns out of water, 28.

Sodium carbonate, 77 .

Solids, 2; soluble and insoluble, 7.

Solution, 7,17 ; no loss of mass in simple, 8 ; of things in acids, 8 ; saturated, 8.

Springs, petrifying, I02.

Stalactites, 97.

Stalagmites, 97 .

Steam, latent heat of, I3; what happens when it passes over redhot iron, 24.

Stuffs, common, 2 .

Temperature, and heat, II ; compared with water-level, II.

Thermometer, 6; fixed points of, 7 ; liquid in, 6; two common kinds of, 7 ; wet and dry-bulb, Io.

Travertine, 97.

Tufa, calcareous, 97.

Volume, 3 ; measurement of, 3 .

Water, action of cold iron upon, 23; action of heated iron upon, 23; always in air, to ; amount of dissolved material in natural, 52 ; and air, I9; as a solvent, 20; boiling point of, 17 ; changes in volume of, Io; characteristic properties of, $\mathrm{x} 7$; chemical pro. 
perties of, 20 ; composition of, $25,47-49$; density of, 18 ; distilled, Io; freezing point of, I7 hard and soft, 90-94; into which sodium is put undergoes a change, 29 ; is formed as hydrogen burns, 43 ; is not combustible, I8; maximum density of, II ; natural, 50-53; physical properties of, I9; rain, 1o; sea, 52; spring or tap, 5 I.

Wax, melting point of, 17 .

Yard, 3.

Yeast, 78 .

Zinc, action upon acids, 30 ; granulated, 32. 


\section{MACMILLAN \& CO.'S \\ Science Class Books \\ Adapted to the South Kensington Syllabuses.}

\section{I.-PRACTICAL PLANE AND SOLID GEOMETRY.}

Practical Plane and Solid Geometry for Elementary Students. By J. HARRISON, M.I.M.E. 2s. 6d.

Practical Plane and Solid Geometry for Advanced Students. By $\mathrm{J}$. HARRISON, M.I.M.E., and G. A. BAXANDAlL. 4s.6d.

Geometrical Drawing and Design. By J. H. SPANTon, H.M.S. Britannia. 2s. 6 d.

\section{II.-MACHINE CONSTRUCTION AND DRAWING.}

Machine Construction and Drawing. By F. Castle, M.I.M.E. 4s. 6d.

\section{III.-BUILDING CONSTRUCTION.}

Building Construction for Beginners. By J. W. RrLey, Rochdale Technical School. 2s. $6 \mathrm{~d}$.

Building Construction for Advanced Students. By J. W. RiLey.

IIn preparation.

\section{V.-MATHEMATICS.}

An Elementary Course of Mathematics. Comprising Arithmetic, Algebra, and Euclid. By H. S. Hall, M.A., and F. H. Stevens, M.A. 2s. 6 d.

An Elementary Course of Mathematics. Comprising Arithmetic, Algebra, and Geometry. By H. S. Hall, M.A., and F. H. Stevens, M.A. 2s. 6d.

Graduated Test Papers in Elementary Mathematics. By the Rev. WALTER J. Wood, M.A. is.

Elementary Practical Mathematics. By F. Castze, M.I.M.E. 3s. 6d.

Practical Mathematics for Beginners. By F. Castle, M.I.M.E. 2s. 6d Key, 5s, net.

Manual of Practical Mathematics. By F. Castle, M.I.M.E. 6s.

Mathematical Tables. By F. Castle, M.I.M.E. 2d.

Logarithmic and other Tables for Schools. By F. CAstle, M.I.M.E. 6 d.

\section{VI.-THEORETICAL MECHANICS.}

Elementary Mechanics of Solids. By W. T. A. EMTAGe, M.A., Director of Public Instruction in Mauritius. 2S. 6d.

Mechanics for Beginners. By W. Gallatly, B.A. 2s. 6d.

Mechanics for Beginners. Part 1. Mechanics of Solids. By Rev. J. B. Lock, M.A. 2s. 6d.

Hydrostatics for Beginners. By F. W. SANDERSON, M.A. 2s. 6d.

$$
\text { MACMILLAN AND CO., LTD., LONDON. }
$$




\section{SCIENCE CLASS BOOKS.}

Adapted to the South Kensington Syllabuses.

\section{VII.-APPLIED MECHANICS.}

Appled Mechanics for Beginners. By J. Duncan, Wh.Ex., A.M.I.M.E. 2s. $6 \mathrm{~d}$.

Lessons in Applied Mechanics. By Professor J. H. Cotterill, F.R.S., and J. H. SLADE. 5s. 6 d.

\section{VIII.-SOUND, LIGHT, AND HEAT.}

Elementary Lessons in Heat, Light, and Sound. By D. E. Jones, B.Sc, Inspector of Science Schools under the Science and Art Department. 2S. 6d.

General Physics and Sound. By E. D. Edser, A.R.C.Sc. [In the Press. Lessons in Heat and Light. By D. E. Jones, B.Sc. 3s. 6d.

Practical Exercises in Heat. A Laboratory Course for Schools of Science and Colleges. By E.S. A. Robson, M.Sc. (Vict.). 2s. 6d.

Practical Exercises in Iight. By R. S. ClAy, D.Sc. 2s. 6 d.

Heat for Advanced Students, By E. EDSER, A.R.C.Sc. 4s. 6d.

Light for Students. By E. Edser, A.R.C.Sc. 6s.

Elementary Physics. By Balfour Sterwart, F.R.S. 4s. 6d. Questions, 2 .

\section{IX.-MAGNETISM AND ELECTRICITY.}

Electricity and Magnetism for Beginners. By F. W. SANDERSon, M.A. 2s. $6 \mathrm{~d}$.

Magnetism and Electricity for Beginners, By H. E. HADLzY, B.Sc. (Lond.). 2s, $6 \mathrm{~d}$.

Practical Exercises in Magnetism and Electrlcity. Being a Laboratory Course for Schools of Science. By H. E. HADLEY, B.Sc. 25. 6d.

Magnetism and Electricity for Students. By H. E. HadieY, B.Sc. 6s.

Elementary Lessons in Electricity and Magnetism. By Prof. Silyanus P. Thом Ron, F.R.S. 4s. 6 d.

\section{$X$. and XI.-CHEMISTRY.}

\section{INORGANIC CHEMISTRY-THEORETICAL.}

Chemistry for Beginners. By Sir HeNRY Roscoz, F.R.S., assisted by J. LUNT, B.Sc. 2s, $6 \mathrm{~d}$.

The Elements of Chemistry. By Prof. Ira Remsen. 2s. 6d.

Inorganic Chemistry for Advanced Students. By Sir H. E. Roscoe, F.R.S., and Dr. A. HARDEN. 45. 6d.

$$
\text { MACMILLAN AND CO., LTD., LONDON. }
$$




\section{SCIENCE CLASS BOOKS. \\ Adapted to the South Kensington Syllabuses.}

INORGANIC CHEMISTRY-THEORETICAL (continued).

Chemical Problems. By Prof. T. E. ThORPR, F.R.S. With Key. 2s.

Chemical Arithmetic. By S. Lurton, M.A. With r2oo Problems. 4S. 6d.

\section{INORGANIC CHEMISTRY-PRACTICAL.}

Introductory Chomistry for Intermediate Schools. By LıNeL M. Jones, B.Sc. 2s.

Chemistry for Organised Schools of Science. By S. Parrish, B.Sc., A.R.C.Sc. (Lond.), with Introduction by Dr. Forsyth. 2s. $6 \mathrm{~d}$.

Practical Inorganic Chemistry. By G. S. Turpis, M.A., D.Sc. 2s. 6d.

Practical Inorganic Chemistry for Advanced Students. By Chapman JoNES, F.I.C., F.C.S. 2s. 6 d.

The Junior Course of Practical Chemistry. By F. Jones, F.C.S. 2s. 6d. Practical Exercises in Chemistry. By G. C. Donrngton, M.A. 2s. 6d.

Tables for Qualitative Chemical Analysis arranged for the use or Students, By Prof. A. Liversidge, M.A., LL.D., F.R.S. 4s. 6d. net.

Elements of Quantitative Analysis. By G. H. Bailey, D.Sc., Ph.D. 4s. 6d.

\section{ORGANIC CHEMISTRY.}

Lessons in Organic Chemistry. By G. S. Turpin, M.A., D.Sc. 2s. $6 \mathrm{~d}$.

Organic Chemistry. By Prof. IRA Remsen. 6s. 6d.

Practical Organic Chemistry for Advanced Students. By J. B. СонвN, Ph.D. 3s. 6d.

Theoretical Organic Chemistry. By J. B. Cohen, Ph.D. 6s.

\section{XII.-GEOLOGY.}

Geology for Beginners. By W. W. WAtTs, M.A., F.G.S. 2s. 6d.

\section{XIV.-HUMAN PHYSIOLOGY.}

Physiology for Beginners. By Sir Michael Foster and Dr. L. E. Shore. 2s. $6 \mathrm{~d}$.

Lessons in Elementary Physiology. By the Right Hon. T. H. HuxLzy, F.R.S. 4s. 6d. QUESTIONS, Is. 6d.

\section{XV.-GENERAL BIOLOGY.}

An Introduction to Nature-Study. By ERnest Stenhouse, B.Sc. 3s. 6d.

\section{XVI.-ZOOLOGY.}

A Manual of Zoology. By the late T. JEFFREY PARKER, D.Sc., F.R.S., and W. A. HASWELl, M.A., D.Sc., F.R.S. Illustrated. Ios. $6 \mathrm{~d}$.

$$
\text { MACMILLAN AND CO,, LTD., LONDON. }
$$




\section{SCIENCE CLASS BOOKS.}

Adapted to the South Kensington Syllabuses.

XVII.-BOTANY.

Botany for Beginners. By ERnest Evans, Burnley Technical School. 2s. 6d.

\section{XVIII.-PRINCIPLES OF MINING.}

The Principles and Practice of Coal Mining. By J. Tonge. 5s. net.

$$
\text { XIX.-METALLURGY. }
$$

A Text-Book of Elementary Metallurgy. By A. H. Hrorns, Principal of the School of Metallurgy, Birmingham and Midland Institute. 3s. QuesTIONS, IS.

$$
\text { XXII.-STEAM. }
$$

Steam Engine and Gas and Oil Engines. By Prof. J. PerRY, F.R.S. 7s. 6d. net. Steam and other Engines. By J. Duncan, Wh.Ex., A.M.I.M.E. 5s.

\section{XXIII.-PHYSIOGRAPHY.}

Experimental Science (Section I. Physiography). By Prof. R. A. Gregory and A. T. Simmons, B.Sc. 2s. 6 d.

Physiography for Beginners. By A. T. Simmons, B.Sc. 2s. 6d.

Physiography for Advanced Students. By A. T. Srmmons, B.Sc. 4s. 6d.

Elementary Lessons in Astronomy. By Sir Norman Lockyer. 5s. 6d.

\section{XXIV.-AGRICULTURAL SCIENCE AND RURAL ECONOMY.}

Elementary Lessons in the Science of Agricultural Practice. By $\mathrm{H}$. TANNER, F.C.S. 3s. 6 d.

\section{XXV.-HYGIENE.}

Hygiene for Beginners. By E. S. Reynolds, M.D. 2s. 6d.

Hygiene for students. By E. F. Willoughi, M.B. 4s. 6c.

Science of Common Life (Experimental Hygiene). By A. T. Simmons, B.Sc. and E. Stenhouse, B.Sc. 2s, 6 d.

\section{XXVI.--ELEMENTARY SCIENCE OF COMMON LIFE.}

Science of Common Life (Experimental Hygiene). By A. T. Simmons, B.Sc., and E. Stenhouse, B.Sc. 2s, $6 \mathrm{~d}$. 


\section{PROF. R. A. GREGORY, AND A. T. SIMMONS, B.Sc.}

EXERCISES IN PRACTICAL PHYSICS. Adapted to First and Second Year's Work of Schools of Science. In two vols. Globe 8 vo. 2s. each.

BDUCATIONAL NBWS. "This book is neither of too advancer a type for the scholars in a higher grade school nor too elementary for students begiuning their course in a Technical Institute or College. The experiments are sufficiently detailed, and sufficiently illustrated by diagrams to allow of correct working. Its bulk is not needlessly increased by theoretical explanations; it professes to be not a scientific treatise, but a practical text-book, and as such we can recom. mend it. The diagrams are good; we would particularly call our readers attention to those on the use of the vernier."

EDUCATIONAL TIMES.- "The opening words of this volume- "You are provided with a foot-rule '-are typical of its thoroughly practical character."

PHYSICS FOR IRISH INTERMEDIATE SCHOOLS. Being a First Year's Course of Exercises in Practical Physics. Globe 8vo. 2s.

A MANUAL OF ELEMENTARY SCIENCE. A Course of Work in Physics, Chemistry, and Astronomy for Scholarship Candidates (Sections I. aud II.). Globe 8vo. 3s. 6d.

EXPERIMENTAL SCIENCE-PHYSIOGRAPHY. (SECTion I.) An Elementary Course of Physics and Chemistry Adapted to the Syllabus of the Science and Art Department. Globe 8vo. 2s. $6 \mathrm{~d}$.

ELEMENTARY PHYSICS AND CHEMISTRY. In Three Stages. Adapted to the Syllabuses of (1) Alteruative Class Subject-Course H; (2) Specific subject XIII.; (3) Practical Science in Evening Continuation Schools. Globe 8 vo. 1s. 6d. each.

\section{STAGE I.}

GUARDIAN. - "The educational value of this first course, if the experiments are really performed, thought out, and written about, as herein indicated, is dis. tinctly great-far greater, in fact, than Paul Bert's book. . . The book merits very extensive use in schools: it is a good stepping-stone to higher things."

\section{STAGES II. AND III.}

SCHOOLMASTER,- "These books are well worth the attention of those who are interested in the teaching of the elements of science in our elementary schools. They are useful because they contain a large amount of instruction respecting many of the chemical and physical changes which almost daily come under our notice. They are educational because the course of instruction is so arranged as to cultivate the powers of observation and reasoning."

LESSONS IN SCIENCE. A Preliminary Course of Physics and Chemistry. Globe 8vo. 3s. 6d.

SCHOOLMASTER. - "The book is capable of rendering excellent service to those who use it."

MACMILI,AN AND CO., LTD. LONDON. 
AN EXERCISE BOOK OF ELEMENTARY PRACTICAL

PHYSICS. Fcap. 4to. 2s. 6d.

BDUCATIONAL TIMBS.- "Mr. Gregory is no mere intelligent dispenser of other men's prescriptions. His book is essentially original. He has one of the most valuable qualities in a teacher-a ready iuvention."

THE PLANET EAR'TH. Globe 8vo. 2s.

\section{WORKS BY A. T. SIMMONS, B.Sc.}

PHYSIOGRAPHY FOR BEGINNERS. Globe 8vo. 28. $6 \mathrm{~d}$. ROYAL COLLEGB OF SCIBNCE MAGAZINE._-"Mr. Simmono' book sbould have a large circulation, and we recommend it both to those who will use it as a text-book, or as ground-work for lecturcs and demonstrations."

PHYSIOGRAPHY FOR ADVANCED STUDENTS. Globe 8 vo. 4s. $6 \mathrm{~d}$.

EDUCATIONAL NEWS. - "No better book on the subject has hitherto come under our notice, and we recommend it with full confidence."

\section{BY A. T. SIMMONS, B.Sc., AND L. M. JONES, B.Sc.} ELEMENTARY GENERAL SCIENCE. Globe 8vo. 3s.6d

NATURE.- "It contains an admirable course of practical work covering all the principles of mechanics, phyaics, and chemistry included in the new subject for the London Matriculation. . The volume contains an instructive course of work which will be of real assistance to both teachers and pupils in schools where elementary science is taught."

$A C A D E M Y$. - "We have given the little work a very careful examination, and are convinced that no better introduction to physics and chemistry is at present available."

By A. T. SIMMONS, B.Sc., and H. RICHARDSON, M.A. INTRODUCTION TO PRACTICAL GEOGRAPHY. Globe 8vo. Sections I-IV. 3s. 6d. Also Section I., Maps. Section II., The Globe. Section III., Climate. Globe 8vo. Limp Cloth. 1s. each. Key, 3s. 6d. net.

GEOGR APHICAL TBACHER. - " We realise the great value of the book. . . . For ourselves we must gratefully acknowledge indebtedness to the authore, and therefore most cordially recommend the book to other teachers."

EDUCATION.- "A perfect treasury of useful information for teachers."

SCHOOLMASTRR.- "It is an admirable accompsnying text-book to ordinary school geography for the older pupils in schools."

SCHOOL WOKLD.- "This excellent book comes at a psychological moment."

$A T H B N A B U M$. - "We recommend thle excellent book to the attention of sohool authorities."

BY A. T. SIMMONS, B.Sc., AND E. STENHOUSE, B.Sc. SCIENCE OF COMMON LIFE (Experimental Hygiene). An Introductory Course of Work in the Principles of Domestic Science. Globe 8vo. 2s. 6d.

A work in elementary science designed for girl students. Its object is to explain the broad principles of physical and chemical science, and to illustrate them by application to the ordinary facts of household life. Thus the student learns something of the composition of the air and the principles of rentilation, the composition of water and its properties, with their practical effects; the chlef constituents of ordinary food, and the chemistry of cooking; with some rudimentary account of the human frame. Expcriments are fully illuetrated by diagrams.

MACMILLAN AND CO., LTD LONDON. 


